CENTRO UNIVERSITÁRIO FEI

DOUGLAS ARAUJO ROMÃO

ANÁLISE EXPERIMENTAL DOS EFEITOS DOS VAZAMENTOS INTERNOS NO DESEMPENHO DE UM EXPANSOR TIPO SCROLL

São Bernardo do Campo 
DOUGLAS ARAUJO ROMÃO

\section{ANÁLISE EXPERIMENTAL DOS EFEITOS DOS VAZAMENTOS INTERNOS NO DESEMPENHO DE UM EXPANSOR TIPO SCROLL}

Dissertação apresentada ao Centro Universitário FEI, como parte dos requisitos necessários para obtenção do título de Mestre em Engenharia Mecânica. Orientado pelo Prof. Dr. Paulo Eduardo Batista de Mello.

São Bernardo do Campo 
Araujo Romão, Douglas.

Análise experimental dos efeitos dos vazamentos internos no desempenho de um expansor tipo scroll / Douglas Araujo Romão. São Bernardo do Campo, 2017.

90 f. : il.

Dissertação - Centro Universitário FEI.

Orientador: Prof. Dr. Paulo Eduardo Batista de Mello.

1. expansor tipo scroll. 2. ORC. 3. CAES. I. Eduardo Batista de Mello, Paulo, orient. II. Título.

Elaborada pelo sistema de geração automática de ficha catalográfica da FEI com os dados fornecidos pelo(a) autor(a). 
Aluno: Douglas Araujo Romão

Título do Trabalho: Análise experimental dos efeitos dos vazamentos internos no desempenho de um expansor tipo scroll.

Área de Concentração: Sistemas da Mobilidade

Orientador: Prof. Dr. Paulo Eduardo Batista de Mello

Data da realização da defesa: 23/02/2017

São Bernardo do Campo, 23 / 02 / 2017.

\section{MEMBROS DA BANCA EXAMINADORA}

Prof. Dr. Paulo Eduardo Batista de Mello

Ass.:

Prof. Dr. Antonio Luiz Pacífico

Ass.:

Prof. Dr. Cyro Albuquerque Neto

Ass.:

A Banca Julgadora acima-assinada atribuiu ao aluno o seguinte resultado:

APROVADO $\triangle \quad$ REPROVADO

\section{VERSÃO FINAL DA DISSERTACÃO}

APROVO A VERSÃO FINAL DA DISSERTAÇÃO EM QUE FORAM INCLUÍDAS AS RECOMENDAÇÕES DA BANCA EXAMINADORA
Aprovação do Coordenador do Programa de Pós-graduação

Prof. Dr. Rodrigo Magnabosco 


\section{AGRADECIMENTOS}

Ao meu orientador, Prof. Dr. Paulo Eduardo Batista de Mello, pelo grande suporte, ensinamentos e ajuda necessária para o desenvolvimento deste trabalho.

À minha esposa e filho, que motivam involuntariamente a evolução pessoal e profissional continuamente.

Ao Centro universitário FEI, pela infraestrutura e disponibilidade de recursos necessários para o desenvolvimento deste trabalho. 


\section{RESUMO}

Com o aumento da demanda global por energia, aumentar o rendimento de sistemas consumidores e conversores de energia se faz fundamental já que existe um limite entre demanda e disponibilidade dos recursos do planeta. A recuperação de calor em fontes de baixa temperatura e o armazenamento de energia proveniente de fontes renováveis intermitentes é uma opção para o atendimento desta situação. Dentro deste contexto, o rendimento das máquinas que fazem a conversão de energia térmica é fundamental para garantir um bom desempenho dos ciclos de potência. Em caso de máquinas rotativas, para baixas potências envolvidas, o expansor tipo scroll (ETS) se mostra o de melhor desempenho. O presente trabalho apresenta o estudo da influência das folgas internas sobre o desempenho de um ETS. As análises foram feitas comparando os resultados de um modelo analítico encontrado na literatura e utilizado em diversos estudos científicos com os resultados experimentais obtidos com um protótipo, com diferentes folgas internas. Para a alteração das folgas, foram utilizados três conjuntos de eixos excêntricos com diferentes geometrias, sendo cada conjunto projetado para folgas de flanco de $200 \mu \mathrm{m}, 100 \mu \mathrm{m}$ e $50 \mu \mathrm{m}$. O fluido utilizado foi ar comprimido com pressões de até 4 bar absoluto e rotações do equipamento entre 1800 e $3000 \mathrm{rpm}$. Obteu-se uma eficiência isentrópica máxima de 40\% para a folga tangencial de 165 $\mu \mathrm{m}$, com uma rotação de $2600 \mathrm{rpm}$, os resultados experimentais e analíticos ficaram próximos para a faixa de operação.

Palavras-chave: expansor tipo scroll, ORC, CAES 


\begin{abstract}
The global increasing demand for energy, increase the income consumers systems and power converters becomes essential as there is a limit in availability of resources of the planet. The heat recovery in low temperature sources and energy storage from intermittent renewable sources are options that contribute for the solution of this issue. Within this context, the performance of a machine that makes the conversion of energy is essential to ensure a good cycle performance. In case of rotating machines, for low power range, the scroll type expander (STE) shows the best performance. This work presents one study of the influence of internal leakages over the performance of an STE. The analysis was made comparing the results of an analitycal model available in literature with a prototype with different internal clearances in the expander. Three sets of eccentric shafts with different geometries were used to change the clearances. Each set was designed for the flank clearance of $200 \mu \mathrm{m}, 100 \mu \mathrm{m}$ and $50 \mu \mathrm{m}$. The fluid used was compressed air with pressure lower than 4 bar absolute and rotations of the machine between 1800 and $3000 \mathrm{rpm}$. A maximum isentropic efficiency of $40 \%$ was obtained for the tangential clearance of $165 \mu \mathrm{m}$ with a rotation of $2600 \mathrm{rpm}$, the experimental and analytical results were close to the operating range.
\end{abstract}

Key-words: scroll type expander, ORC, CAES 


\section{LISTA DE ILUSTRAÇÕES}

Figura 1 - Representação do processo de uma máquina térmica.

Figura 2 - Representação dos rotores scroll em corte longitudinal e transversal e a indicação $\begin{array}{ll}\text { de suas folgas. } & 18\end{array}$

Figura 3 - Modelo de instalação estudada por Quoilin et al. 21

Figura 4 - Diagrama Temperatura x Entropia comprando fluidos orgânicos e água. 22

Figura 5 - Faixa de operação para 3 tipos de expansor em função de sua aplicação em ORC.23

Figura 6 - Representação de um sistema CAES. 24

Figura 7 - Vista esquemática de um conjunto compressor Scroll, com definição. 25

Figura 8 - Ilustração das etapas de expansão de um fluido em um ETS. 25

Figura 9 - Representação gráfica da sub (9.a) e sobre (9.b) expansão. 26

Figura 10 - Relação entre o filling factor e o aumento na pressão de alimentação. 27

Figura 11 - Filling factor e eficiência global em função da rotação do expansor, com e sem injeção de água. $\quad 28$

Figura 12 - Obstrução parcial da câmara de admissão pelo rotor móvel. 29

Figura 13 - Desempenho de um expansor em função da pressão de alimentação do fluido. 31

Figura 14 - Eficiência isentrópica x Relação de pressão para uma pressão de entrada de 12 bar.

Figura 15 - Eficiência isentrópica x Relação de pressão para uma pressão de entrada de 9 bar.

Figura 16 - Influência da lubrificação na potência mecânica, eficiência volumétrica e potência especifica para testes com ar (a) e amônia (b).

Figura 17 - Representação gráfica da eficiência isentrópica pela relação de pressão entre sucção e descarga em um ETS.

Figura 18 - Representação gráfica das curvas e linhas de construção da geometria scroll.

Figura 19 - (a) Eixos excêntricos, sua excentricidade define a folga tangencial, (b) Scroll fixo e (c) Scroll móvel, indicando a posição de montagem dos eixos excêntricos.

Figura 20 - Fluxograma do ar comprimido na bancada experimental.

Figura 21 - Freio de Foucault e encoder ligados ao eixo do expansor.

Figura 22 - Freio de Foucault, encoder e a distância "b" entre o eixo do expansor e a posição da célula de carga.

Figura 23 - Esquema do modelo analítico do expansor

Figura 24 - Esquema do modelo analítico do expansor 
Figura 25 - Comparação entre a potência mecânica medida pela prevista (a), vazão em massa medida pela prevista (b) e a temperatura de exaustão medida pela prevista (c), sendo amônia o fluido utilizado.

Figura 26 - Representação das folgas entre os scrolls. Dimensões em milímetros. 53

Figura 27 - Representação dos dados obtidos durante o ensaio com eixo projetado para folga tangencial de $468 \mu \mathrm{m}$ e set point para a rotação de $3000 \mathrm{rpm}$.

Figura 28 - Comparação de desempenho do expansor em função de diferentes rotações para uma mesma folga tangencial - $468 \mu \mathrm{m}$

Figura 29 - Comparação de desempenho do expansor em função de diferentes rotações para uma mesma folga tangencial - $489 \mu \mathrm{m}$

Figura 30 - Comparação de desempenho do expansor em função de diferentes rotações para uma mesma folga tangencial - $165 \mu \mathrm{m}$

Figura 31 - Comparação de desempenho do expansor para uma rotação de 2600rpm, mas com folgas tangenciais distintas.

Figura 32 - Comparação de desempenho do expansor para uma rotação de 2200rpm, mas com folgas tangenciais distintas.

Figura 33 - Comparação de desempenho do expansor para uma rotação de 1800rpm, mas com folgas tangenciais distintas.

Figura 34 - Comparação de desempenho do expansor para uma rotação de 2600rpm, mas com folgas tangenciais distintas, incluindo as incertezas.

Figura 35 - Comparação entre o modelo analítico e o experimental para folga de $165 \mu \mathrm{m}$ e rotação de $2600 \mathrm{rpm}$.

Figura 36 - Comparação entre o modelo analítico e o experimental para folga de $165 \mu \mathrm{m}$ e rotação de $2200 \mathrm{rpm}$.

Figura 37 - Comparação entre o modelo analítico e o experimental para folga de $165 \mu \mathrm{m}$ e rotação de $1800 \mathrm{rpm}$.

Figura 38 - Avaliação do filling factor pela rotação, para o eixo de $165 \mu \mathrm{m}$. 


\section{LISTA DE QUADROS}

Quadro 1 - Medida dos eixos excêntricos

Quadro 2 - Parâmetros utilizados para a construção dos scrolls fixo e móvel

Quadro 3 - Dados operacionais do expansor para $2000 \mathrm{rpm}$ e $1 \mathrm{~kW}$

Quadro 4 - Dados dos instrumentos 46

Quadro 5 - Dados coletados durante o ensaio 57

Quadro 6 - Incertezas dos parâmetros medidos 


\section{LISTA DE SÍMBOLOS}

Todas as unidades estão no Sistema Internacional de Unidades (S.I.), a menos das exceções informadas no próprio texto.

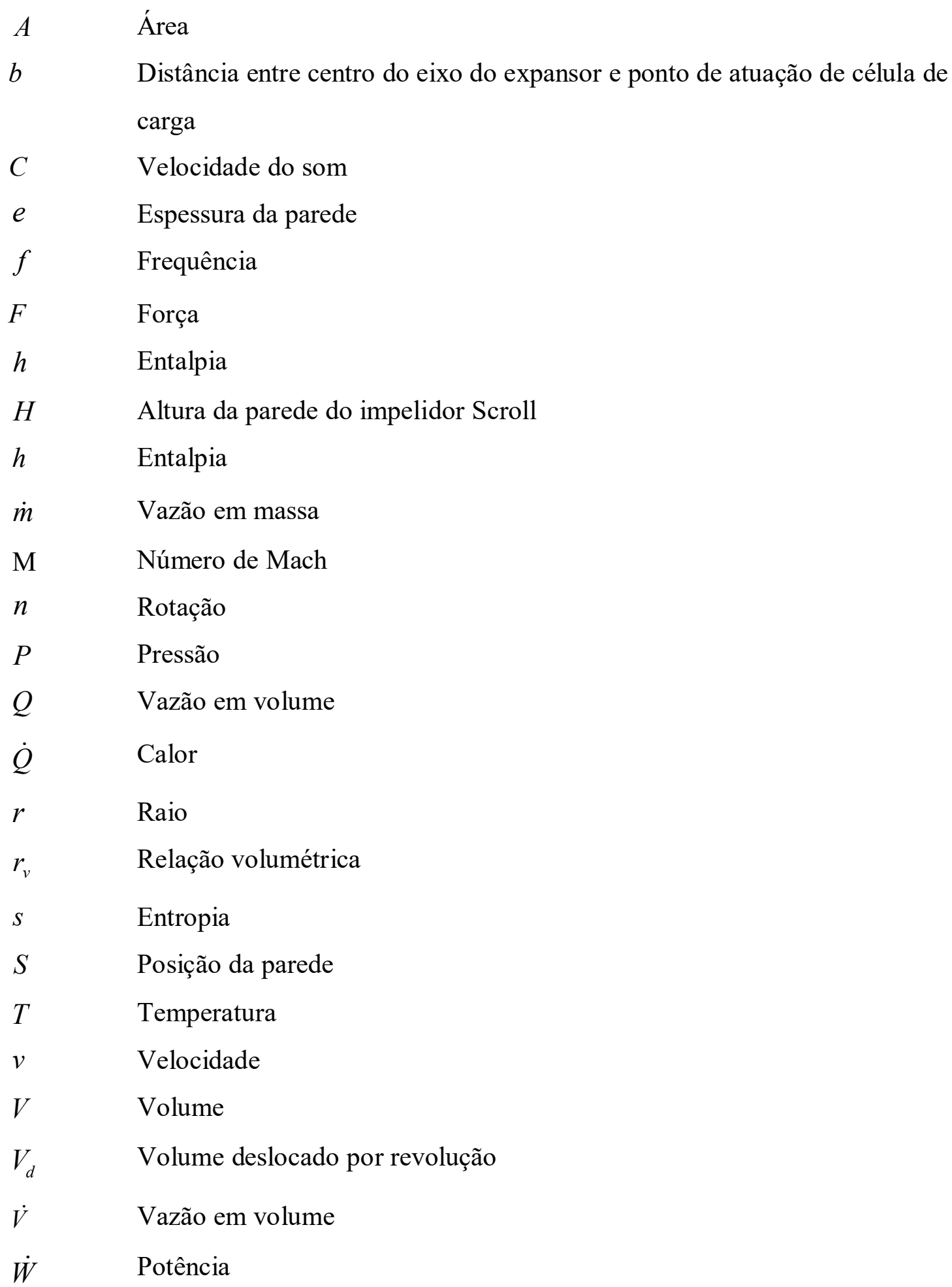




\section{SÍMBOLOS EXPRESSOS POR LETRAS GREGAS}

$\begin{array}{ll}\gamma & \text { Razão entre calores específicos } \\ \delta & \text { Folga } \\ \eta & \text { Eficiência } \\ v & \text { Volume especifico } \\ \rho & \text { Densidade } \\ \varphi & \text { Filling fator } \\ \varphi^{\prime} & \text { Ângulo } \\ \theta & \text { Ângulo de orbitação }\end{array}$




\section{LISTA DE SUBSCRITOS}

\begin{tabular}{|c|c|}
\hline$b$ & círculo básico da involuta \\
\hline$c p$ & Compressor \\
\hline crit & Crítica \\
\hline eo & inicial da involuta externa \\
\hline es & externo inicial \\
\hline$e x$ & exaustão do expansor \\
\hline $\exp$ & Expansor \\
\hline$f e$ & parede externa do scroll fixo \\
\hline$f i$ & parede interna do scroll fixo \\
\hline$h$ & reservatório de alta temperatura \\
\hline in & entrada do bocal divergente \\
\hline io & inicial da involuta interna \\
\hline is & interno inicial \\
\hline$l$ & reservatório baixa temperatura \\
\hline leak & Vazamento \\
\hline loss & Atrito \\
\hline $\max$ & Final da involuta \\
\hline$m e$ & parede externa do scroll móvel \\
\hline$m i$ & parede interna do scroll móvel \\
\hline net & Liquida \\
\hline$o$ & orbitação nominal \\
\hline pred & Produzida \\
\hline$R$ & Radial \\
\hline$s$ & processo isentrópico \\
\hline$s h$ & Eixo \\
\hline su & sucção do expansor \\
\hline$t$ & máquina térmica \\
\hline$T$ & Tangencial \\
\hline thr & Garganta \\
\hline$v$ & Volumétrico \\
\hline
\end{tabular}




\section{LISTA DE SIGLAS}

CAES Compressed air energy storage (Armazenagem de energia na forma de ar comprimido)

EES Engineering equation solver

ETS Expansor tipo Scroll

IHM Interface homem máquina

ORC Organic Rankine Cycle (Ciclo Rankine Orgânico)

WHR Waste Heat Recovery (recuperação de calor)

UHMWPE Ultra High molecular weight polietilen (Polietileno de ultra alta peso molecular) 


\section{SUMÁRIO}

1 INTRODUÇÃO

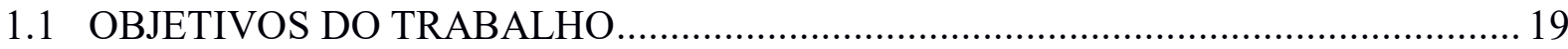

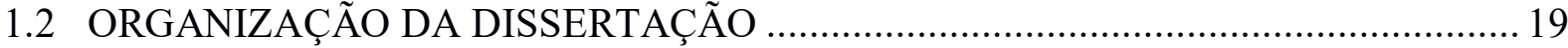

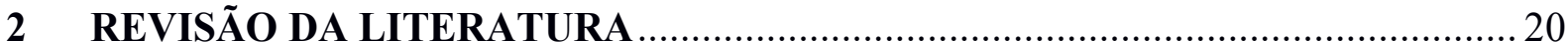

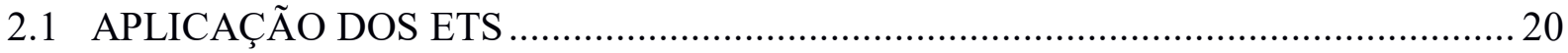

2.2 PRINCIPIO DE OPERAÇÃO DOS EXPANSORES TIPO SCROLL (ETS)................ 24

2.3 ESTÁGIO ATUAL NAS PESQUISAS SOBRE OS ETS EXPANSORES TIPO

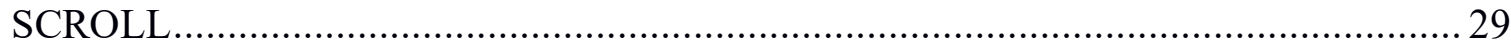

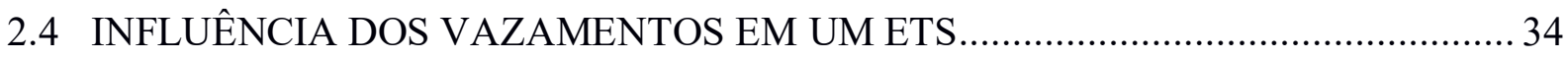

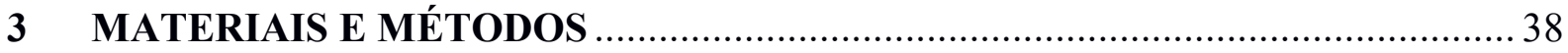

3.1 DADOS CONSTRUTIVOS, GEOMÉTRICOS E FÍSICOS DO PROTÓTIPO............. 38

3.2 DESCRIÇÃO DA BANCADA EXPERIMENTAL .................................................. 42

3.3 MODELO ANALÍTICO PARA EXPANSORES SCROLL ….................................. 47

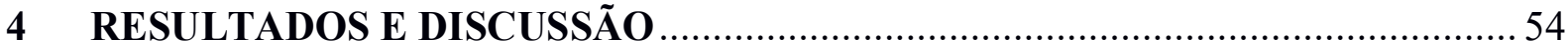

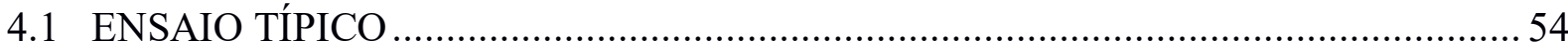

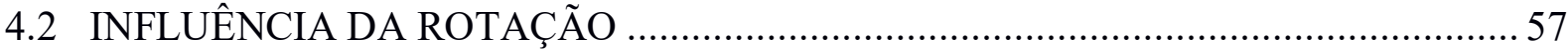

4.2.1 Desempenho do expansor com folga tangencial de projeto igual a $468 \mu \mathrm{m}$ com

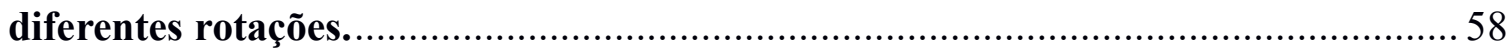

4.2.2 Desempenho do expansor com folga tangencial de projeto igual a $489 \mu \mathrm{m}$ com diferentes rotações.

4.2.3 Desempenho do expansor com folga tangencial de projeto igual a $165 \mu \mathrm{m}$ com diferentes rotações. 60

4.3 INFLUÊNCIA DAS FOLGAS 63

4.3.1 Comparação de desempenho do expansor para uma rotação de $2600 \mathrm{rpm}$, mas com folgas tangenciais distintas. 63

4.3.2 Comparação de desempenho do expansor para uma rotação de $2200 \mathrm{rpm}$, mas com folgas tangenciais distintas. 
4.3.3 Comparação de desempenho do expansor para uma rotação de 1800rpm, mas com folgas tangenciais distintas..

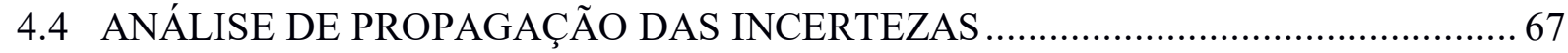

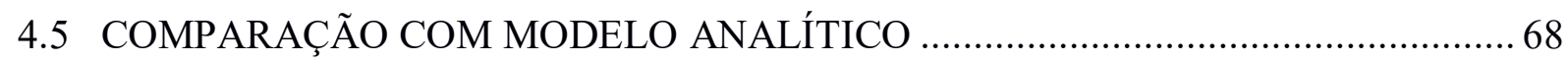

4.5.1 Comparação entre modelo analítico e resultado experimental para folga de $165 \mu \mathrm{m}$

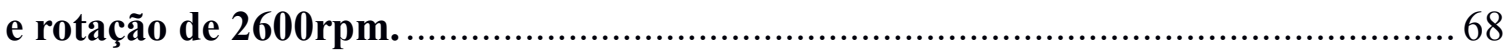

4.5.2 Comparação entre modelo analítico e resultado experimental para folga de $165 \mu \mathrm{m}$

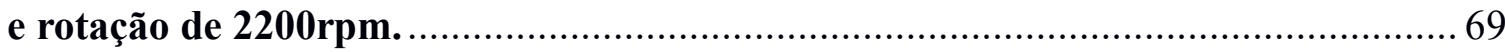

4.5.3 Comparação entre modelo analítico e resultado experimental para folga de $165 \mu \mathrm{m}$

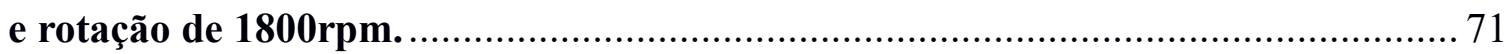

4.6 AVALIAÇÃO DO FILLING FACTOR EM FUNÇÃO DA ROTAÇÃO...................... 72

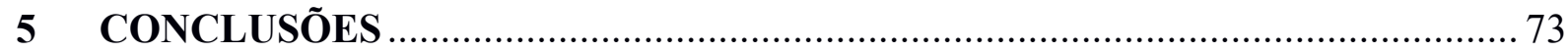

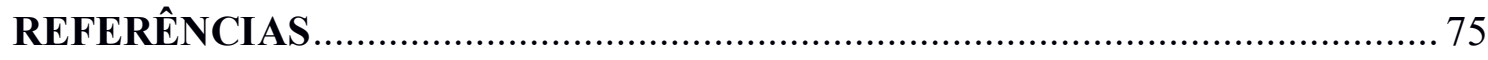

APÊNDICE A - Dados obtidos experimentalmente e utilizados para avaliação do

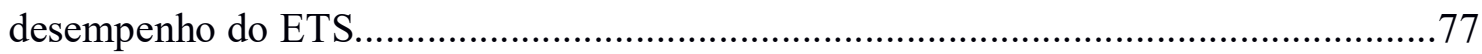

APÊNDICE B - Comparação de desempenho do expansor para uma rotação de 3000 rpm, mas com folgas tangenciais distintas

APÊNDICE C - Algoritmo utilizado no software EES para a comparação entre o modelo analítico e dados levantados experimentalmente .80

APÊNDICE D - Comparação modelo Analítico x Experimental - Folgas de $468 \mu \mathrm{m}$ e $489 \mu \mathrm{m}$ 


\section{INTRODUÇÃO}

A necessidade energética global aumenta continuamente. Um grande salto pode ser observado após a revolução industrial, quando grande parte do trabalho realizado por pessoas ou animais foi substituído por propulsão mecânica. Com exceção da radiação solar que incide sobre o planeta, a maior parte das outras fontes energéticas são finitas de forma que existe um limite entre sua demanda e disponibilidade. Isto leva a uma busca constante por aumento de rendimento de sistemas consumidores e conversores de energia.

Sistemas mecânicos de conversão de energia são baseados em conversão de qualquer forma de energia para energia mecânica, tendo normalmente como resultado final um eixo girante. As máquinas que fazem a conversão de energia de um fluido em energia mecânica podem ser do tipo turbo máquinas ou máquinas de deslocamento positivo. A análise e definição de qual tipo de máquina é o mais adequado para determinada condição de operação depende do fluido de trabalho, pressão, temperatura, vazão e restrições quanto a rotação.

Máquinas térmicas geram trabalho a partir da energia fornecida por um reservatório quente e rejeitam calor para um reservatório frio. Quanto maior o trabalho gerado $(\dot{W})$ para uma mesma quantidade de calor fornecido por um reservatório quente $\left(\dot{Q}_{h}\right)$ maior será a eficiência do ciclo, já que o trabalho gerado é representado pela diferença entre a energia fornecida pelo reservatório quente e rejeitada para a reservatório frio $\left(\dot{Q}_{l}\right)$. A eficiência térmica $\left(\eta_{t}\right)$ é a relação entre trabalho produzido e a energia fornecida pela fonte quente (figura 1).

Figura 1 - Representação do processo de uma máquina térmica.

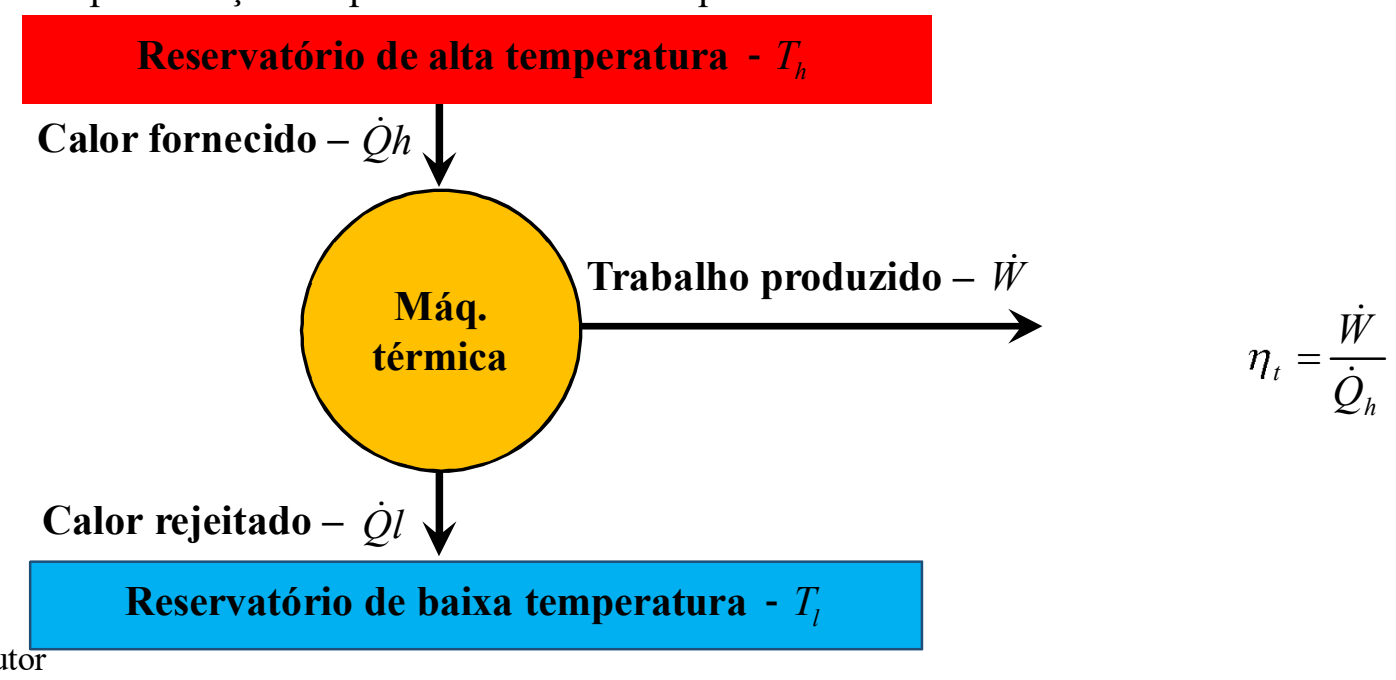

Fonte: Autor 
Como opção para aumento de rendimento de ciclos ou processos térmicos pode-se utilizar o ciclo termodinâmico Rankine orgânico ou Organic Rankine Cycle (ORC), que por trabalhar com baixos diferenciais de temperatura entre os reservatórios, se torna uma alternativa para situações como recuperação de calor, fontes geotérmicas, entre outros. O ciclo termodinâmico ORC é considerado e utilizado como alternativa para aproveitamento de calor em processos para produção de potência mecânica. Apesar da sua baixa eficiência térmica, da ordem de $10 \%$ a $24 \%$, os ciclos ORC são alternativas viáveis quando se trata da utilização de calor que seria rejeitado ao ambiente.

Os ciclos orgânicos apresentam características que permitem fácil implantação quando comparados a outros processos mais utilizados, como o ciclo Rankine de vapor d'água. Quoilin et al. (2013) citam diversas vantagens em se utilizar o ciclo ORC ao invés do ciclo Rankine convencional. Dentre elas, o fato de utilizar fontes de calor de baixa temperatura e instalações de pequenas dimensões, quando comparadas a equipamentos utilizados para ciclos com vapor d'água.

Para fontes de energia renovável, caracterizadas por serem intermitentes, como a energia solar e eólica, observa-se a necessidade de armazenar a energia excedente e utilizá-la ao longo de um período de baixa disponibilidade. Uma alternativa tecnológica para esta situação é a de se utilizar sistemas de armazenamento de energia na forma de ar comprimido, Compressed air energy storage (CAES).

Tanto no ORC quanto no CAES, necessita-se definir qual expansor utilizar. A literatura mostra que ciclos ORC para recuperação de calor costumam usar expansores tipo Scroll de forma que atendem com melhor eficiência potências entre 1 e 10kW. Para expansores tipo parafuso a faixa de potência adequada fica entre 8 e $200 \mathrm{~kW}$ e expansores tipo turbina entre $80 \mathrm{~kW}$ e 10MW. Em geral, estudos indicam que expansores tipo Scroll são para baixas potências, parafuso para potências intermediárias e turbinas para maiores potências (QUOILIN et al., 2013).

Com base nas oportunidades de conversão de energia em pequenas escalas faz-se de grande interesse o estudo do rendimento de expansores tipo Scroll. A análise de seu comportamento em função da pressão de trabalho do fluido, rotação e folgas internas pode apresentar pontos ótimos de operação, viabilizando a sua aplicação em instalações de pequeno porte. Informações verificadas na literatura indicam que para geração de baixas potências, com Scroll de pequenas dimensões, o rendimento isentrópico do expansor encontra-se na faixa de $60 \%$ a $65 \%$. Em seu trabalho, Declaye et al. (2013) obtiveram resultados de até $75 \%$.

A influência das folgas internas sobre o desempenho de compressores e expansores 
Scroll é muito relevante. Modelos analíticos mostram isso claramente, embora não sejam conhecidos resultados experimentais comprovando esta influência de forma sistemática. Para o estudo de eficiência isentrópica em um expansor tipo Scroll duas folgas podem ser analisadas, a folga radial $\left(\delta_{R}\right)$ e a folga tangencial $\left(\delta_{T}\right)$, gerando vazamentos internos que comprometem seu rendimento. As folgas radiais ocorrem pela distância entre os extremos dos rotores radialmente e as tangenciais entre as folgas formadas entre as espirais dos rotores, conforme está indicado na figura 2.

Com base na grande influência das folgas sobre o rendimento do expansor, faz-se de interesse cientifico sua avaliação experimental.

Figura 2 - Representação dos rotores scroll em corte longitudinal e transversal e a indicação de suas folgas.

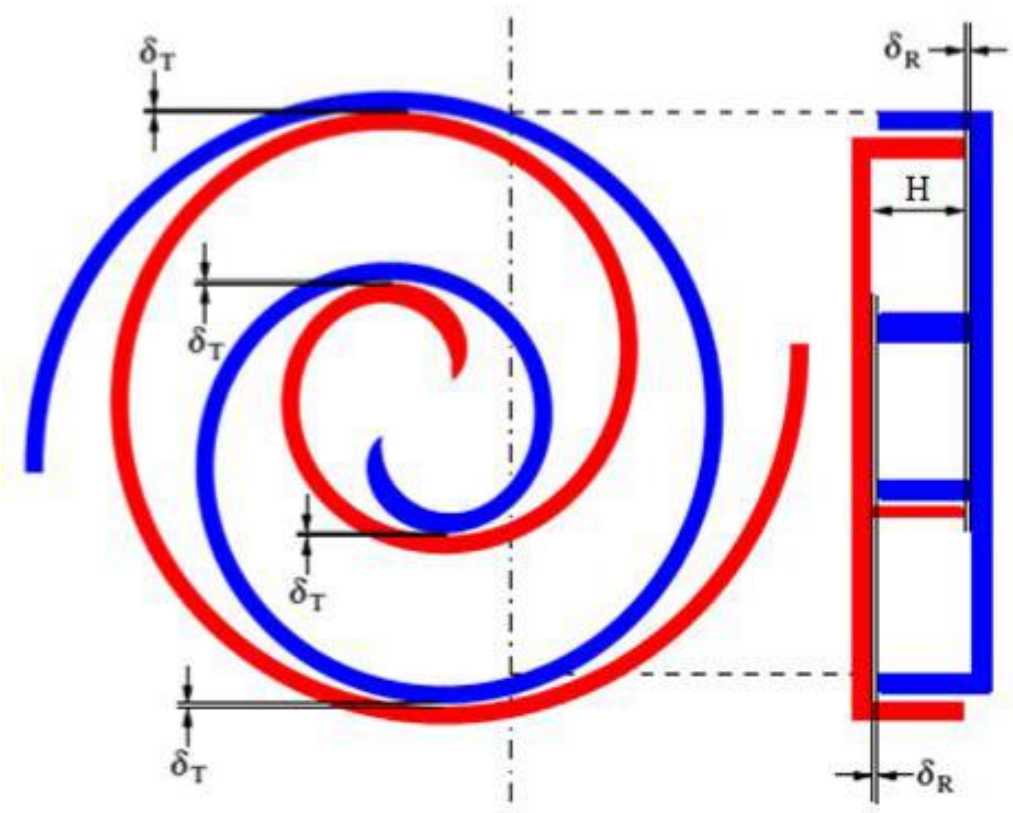

Fonte: Autor "adaptado de" Blunier; Cirrincione, 2009

O presente trabalho faz parte do conjunto de trabalhos desenvolvidos por Fanti (em fase de elaboração) ${ }^{1}$ e Martins (em fase de elaboração) ${ }^{2}$ dentro do Centro Universitário FEI, onde o primeiro realizou o projeto e construção do expansor e sua bancada de testes com o objetivo de se realizar a avaliação experimental da eficiência isentrópica de um expansor do tipo scroll e o segundo estudou a estratégia para simulação CFD de um expansor scroll.

\footnotetext{
${ }^{1}$ Dados retirados da dissertação do Gabriel Fanti, a ser editada pelo Centro Universitário FEI, em abril de 2017.

2 Dados retirados da dissertação do Filipi Martins, a ser editada pelo Centro Universitário FEI, em abril de 2017.
} 


\subsection{OBJETIVOS DO TRABALHO}

Considerando as diversas aplicações potenciais dos expansores tipo Scroll e também o estágio inicial das pesquisas envolvendo este equipamento como expansor, já que o mesmo é consagrado como compressor, o presente trabalho teve por objetivos dar continuidade ao trabalho de Fanti (em fase de elaboração), visando estudar a influência das folgas sobre o desempenho do equipamento.

\subsection{ORGANIZAÇÃO DA DISSERTAÇÃO}

O texto está dividido em cinco partes. Na seção 2 é feita uma revisão da literatura sobre expansores Scroll com comentários de trabalhos anteriores justificando a relevância sobre a influência dos vazamentos internos. Também é apresentado o modelo analítico da literatura que foi escolhido para a comparação com os resultados experimentais utilizados neste trabalho; a seção 3 trata de materiais e métodos usados para a construção do protótipo do expansor tipo Scroll e da bancada de testes; a seção 4 descreve como foram conduzidos os ensaios e a que resultados se chegou; são prestadas informações sobre o processamento dos dados pelo programa EES e, ainda, são feitas análises quanto às incertezas das medições efetuadas. Na seção 5 são apresentadas as conclusões e sugestões para possíveis trabalhos futuros. 


\section{REVISÃO DA LITERATURA}

Esta seção foi dividida em subseções de forma que a explanação confira ao texto uma melhor organização. A subseção 2.1 fornece informações sobre possíveis aplicações dos expansores tipo Scroll (ETS); na subseção 2.2 apresenta-se o ETS e seu princípio de operação; a subseção 2.3 apresenta o estágio atual das pesquisas sobre os ETS e a subseção 2.4 versa sobre a influência dos vazamentos em um ETS.

\subsection{APLICAÇÃO DOS ETS}

Devido a restrições ambientais e limitações em se fornecer toda a energia que a humanidade necessita, o interesse em se aumentar a eficiência dos sistemas de consumo e geração de energia é algo em que se vem trabalhando muito nas últimas décadas.

No quesito geração de energia, uma forma de se aumentar a eficiência do sistema, sendo a fonte térmica, é recuperando parte do calor rejeitado em algum processo.

Um importante número de novas soluções tem sido proposto para gerar eletricidade a partir de fontes de calor a baixa temperatura e são agora aplicadas em diversos campos, como a energia térmica solar, fontes de calor geotérmico, gases de escape do motor de combustão interna e caldeiras domésticas (LEMORT et al., 2009). A definição de fontes de baixa, média e alta temperatura são apresentadas por Mendoza et. al (2014) sendo baixa temperatura as que trabalham em faixas de 80 a $150^{\circ} \mathrm{C}$, media temperatura de 150 a $450^{\circ} \mathrm{C}$ e alta temperatura acima de $450^{\circ} \mathrm{C}$.

Entre as soluções atualmente propostas, o Ciclo Rankine Orgânico (ORC) é o mais utilizado. Suas principais vantagens são a sua simplicidade e seus componentes comumente disponíveis. Em tal ciclo, o fluido de trabalho é um produto orgânico, que apresenta uma temperatura de ebulição inferior ao da água, permitindo evaporação a reduzidas temperaturas. (LEMORT et al., 2009).

O uso de fluidos orgânicos para recuperação de energia de fontes de baixa temperatura é estudado por diversos autores atualmente. Em seu trabalho, Quoilin et al. (2011) têm como objetivo modelar termodinamicamente uma instalação que trabalhe com ORC, conforme figura 3. 
Figura 3 - Modelo de instalação estudada por Quoilin et al.

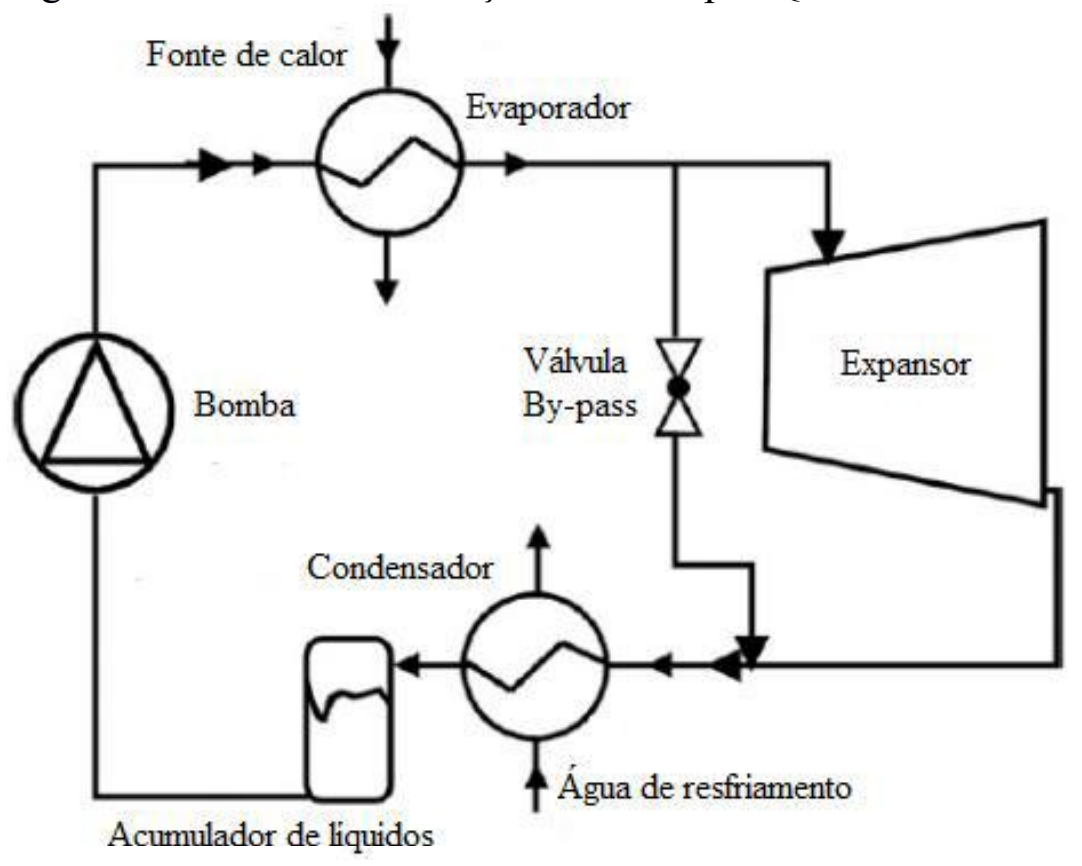

Fonte: Autor “adaptado de" Quoilin et al., 2011

Neste trabalho, o autor cita os expansores de deslocamento positivo (parafuso, scroll, dentre outros) como os melhores candidatos para instalações com ciclos ORC em pequenas escalas. As principais características destes tipos de expansores, que permitem esta afirmação, são poucos componentes que se movimentam durante a expansão, grande produção de energia, grande gama de aplicações (tipos de fluidos de trabalho e instalações) e bom rendimento isentrópico, na faixa de 48\% a 68\% (QUOILIN et al., 2011).

Um ponto de fundamental importância para o ciclo ORC é a seleção adequada do fluido orgânico de trabalho, a figura 4 apresenta um diagrama Temperatura x Entropia comparando fluidos orgânicos e a água. Observa-se pelo diagrama a diferença entre a linha de vapor saturado dos fluidos orgânicos e da água. A inclinação positiva da linha de vapor dos fluidos ORC indica as seguintes vantagens em relação a aplicações utilizando o ciclo de Rankine convencional (água) (QUOILIN et al., 2013):

a) geração de energia para faixas menores de temperatura;

b) não há formação de líquido na saída da turbina, uma vez que o fluido sai da mesma superaquecido. Esta característica também é interessante para o uso de um recuperador na saída da turbina;

c) uso de equipamentos de menores dimensões (instalações reduzidas), devido ao baixo volume específico do fluido ORC nas regiões de baixa pressão (saída da turbina, condensador) menor em relação a água, resultando em equipamentos de menores dimensões; 
d) A pressão na temperatura inferior do ciclo (saída do expansor) é superior a atmosférica, evitando contaminação com ar. Em caso de vazamentos o fluido orgânico vaza, indicando redução de pressão.

Figura 4 - Diagrama Temperatura x Entropia comprando fluidos orgânicos e água.

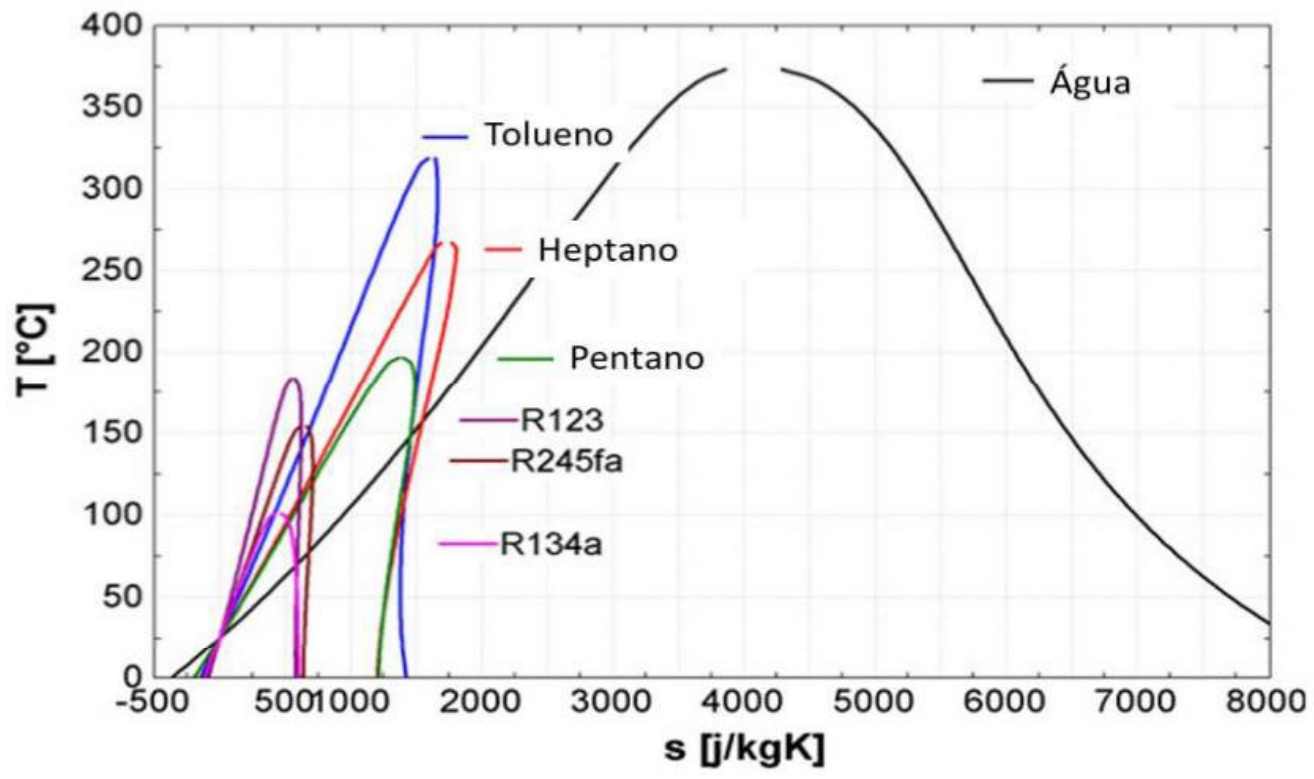

Fonte: Autor “adaptado de" Quoilin et al., 2013

Além dos pontos já apresentados, o desempenho de um sistema ORC se correlaciona fortemente com a eficiência isentrópica do expansor. A escolha da tecnologia depende das condições de operação e do tamanho do sistema. Dois tipos principais de máquinas podem ser citados: as turbo-maquinas e as de deslocamento positivo. (QUOILIN et al., 2013).

Para expansores de pequena capacidade, máquinas de deslocamento positivo se mostram mais atrativas do que turbo máquinas em função da performance de máquinas rotativas depender da velocidade periférica, sendo a velocidade indicada de $1-10 \mathrm{~m} / \mathrm{s}$ para máquinas Scroll e $300 \mathrm{~m} / \mathrm{s}$ para turbo máquinas. Para um mesmo raio, turbo máquinas operam com dezenas de milhares de rotações por minuto, enquanto máquinas Scroll com milhares de rotações por minuto. $\mathrm{O}$ uso de turbo máquinas traz problemas mecânicos com rolamentos e acoplamento com o gerador elétrico, além da necessidade de múltiplos estágios na expansão, em função da baixa taxa de pressão por estágio. Máquinas Scroll têm a vantagem de também expandir com fluidos em duas fases líquido-vapor, o que apresenta uma vantagem para uso em ciclos Rankine (ORALLI et al., 2011)

Outra recomendação para o uso de expansores de deslocamento positivo se dá pela alta relação de expansão e alta eficiência em operações de baixa potência envolvida. O ponto 
negativo da maioria dos expansores de deslocamento positivo é a necessidade de lubrificação, embora já foi demonstrado que os isentos de óleo são viáveis. (MENDOZA et al., 2014)

Semelhante às aplicações em refrigeração, as máquinas de deslocamento positivo são mais adequadas em unidades ORC de pequena escala (Figura 5), uma vez que são caracterizadas por vazões mais baixas, uma pressão mais elevada e velocidades de rotação mais baixas do que turbo-máquinas (QUOILIN et al., 2013).

Figura 5 - Faixa de operação para 3 tipos de expansor em função de sua aplicação em ORC.

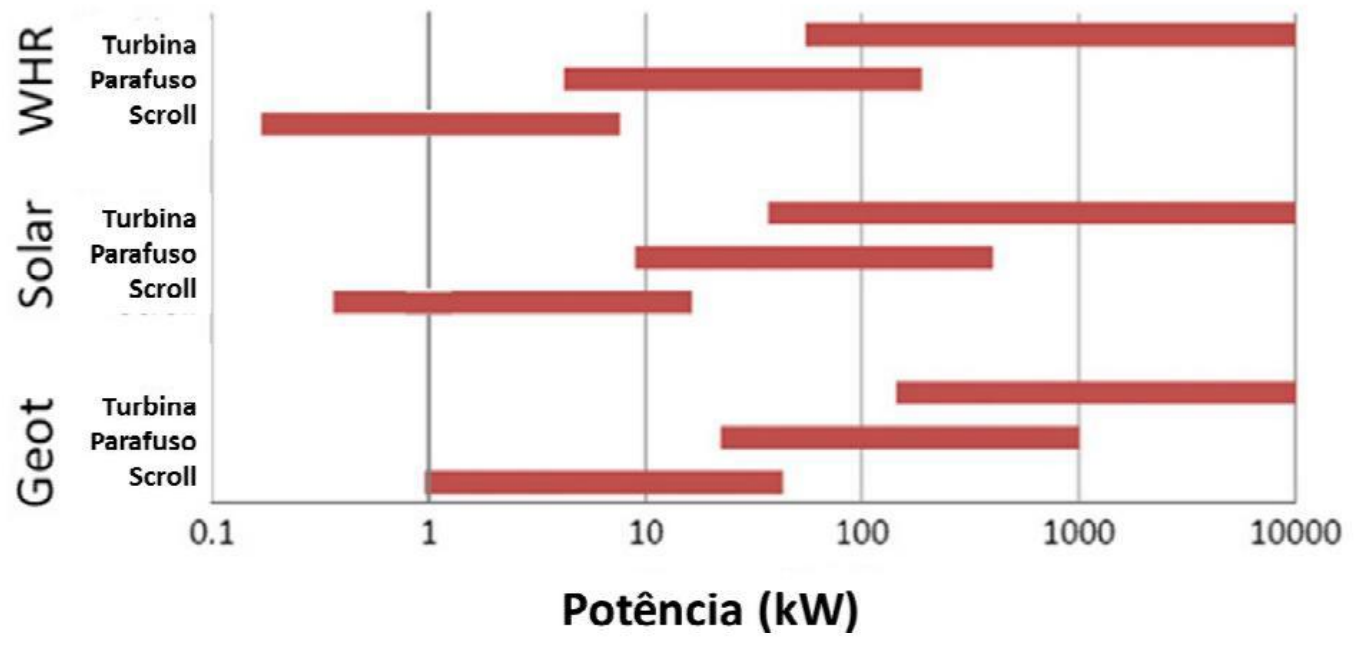

Fonte:Autor “adaptado de” Quoilin et al., 2013

Outras vantagens dos ETS sobre outros expansores para pequenas potências é de terem um número reduzido de peças, capacidade de operar com fluidos em duas fases (que pode acontecer no final da expansão dependendo das condições operacionais) e ter a confiabilidade inerente comprovada em seu modo compressor. A rápida e crescente produção em massa de tais unidades como compressores provavelmente contribui também para uma redução dos custos de produção para aplicações de expansão (ZANELLI; FAVRAT, 1994). Apesar das vantagens citadas acima, o uso de máquinas com geometria Scroll no modo expansor vem sendo limitada a trabalhos experimentais e alguns protótipos estão sendo testados com o uso de diferentes fluidos (LEMORT et al., 2009).

Além do ORC, outra alternativa para o uso de ETS é na aplicação em CAES. A figura 6 apresenta um sistema eólico no qual uma turbina eólica transmite potência a um gerador. A energia elétrica gerada alimenta tanto a rede elétrica como um compressor, que comprime ar para um tanque para armazenamento de ar comprimido. Para períodos de baixa disponibilidade de vento um expansor é acionado, que usa o ar comprimido presente no 
tanque acionando o gerador, gerando energia elétrica para fornecer à rede.

Figura 6 - Representação de um sistema CAES

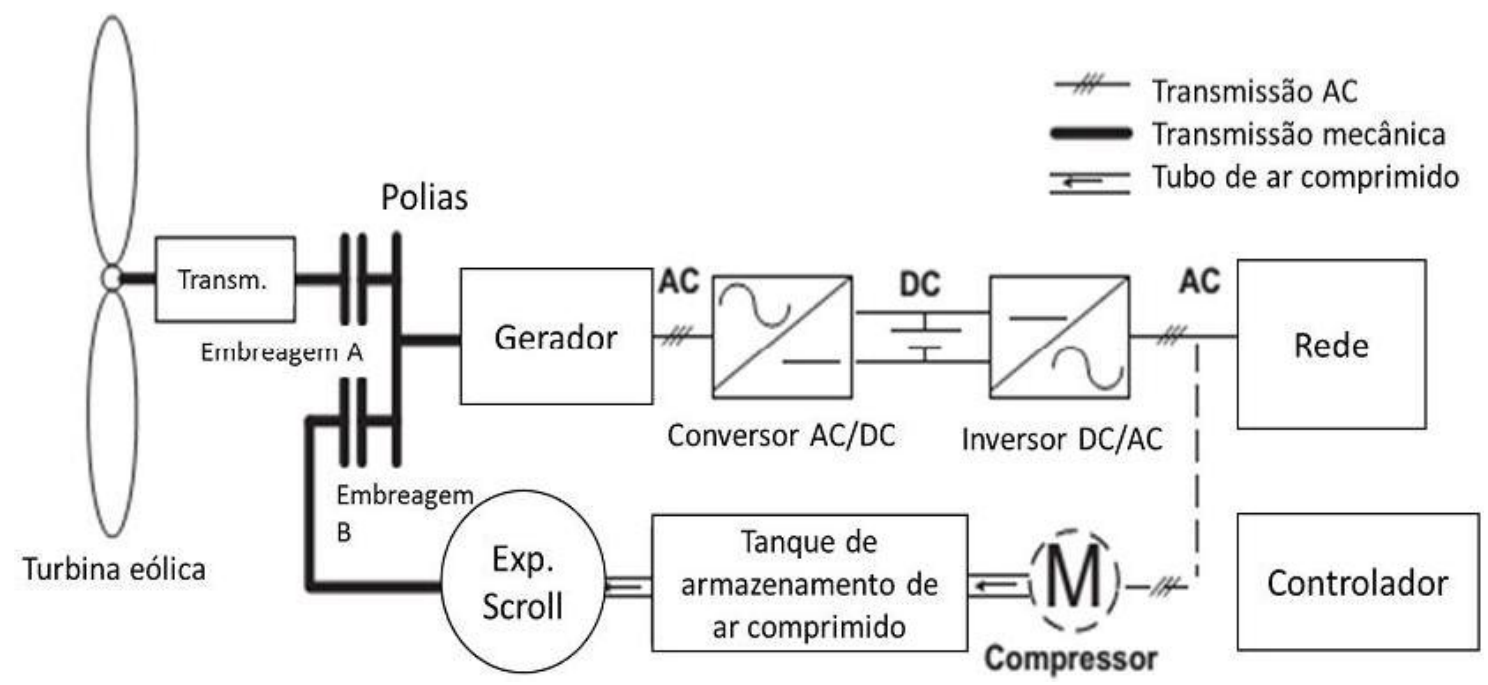

Fonte: Autor “adaptado de" Sun, Luo e Wang, 2015

\subsection{PRINCIPIO DE OPERAÇÃO DOS EXPANSORES TIPO SCROLL (ETS)}

Expansores são máquinas de fluxo projetadas para converter a energia contida em um fluido em escoamento, na fase gasosa, em energia mecânica na forma de torque em um eixo girante. Quando um fluido entra em um expansor sua pressão é reduzida e seu volume aumentado dentro das câmaras de expansão. Sendo os gases compressíveis, um mesmo expansor apresentará resultados distintos para fluidos distintos nas mesmas condições de temperatura e pressão em função das propriedades dos fluidos.

A concepção de uma máquina “Scroll” se deu inicialmente para a compressão de gases (compressor) e sua invenção se deu originalmente em 1905 pelo engenheiro francês chamado Creux (1905), mas seu desenvolvimento somente ocorreu na década de 70, quando houve interesse comercial e a tecnologia já havia avançado de forma a viabilizar a construção do equipamento (MCCULLOUGH; HIRSCHFELD, 1979).

$\mathrm{O}$ equipamento consiste em duas curvas idênticas sobrepostas e projetadas classicamente por uma curva evolvente de círculo. Para estas curvas se dará o nome de Scrolls.

Os dois Scrolls, cujos eixos de origem não encontram com o outro, são gerados com um ângulo relativo $\pi$, de forma que eles podem se tocar em diferentes pontos e formar câmaras com volumes crescentes, no caso de um expansor, ou decrescentes no caso de um 
compressor. (BLUNIER et al., 2009)

A figura 7 apresenta uma vista esquemática de um compressor Scroll, onde a sucção se faz pela região periférica e a descarga pelo centro do equipamento. Os pontos de conjugação são os pontos teóricos de contato entre os rotores móvel e fixo.

Figura 7 - Vista esquemática de um conjunto compressor Scroll, com definição.

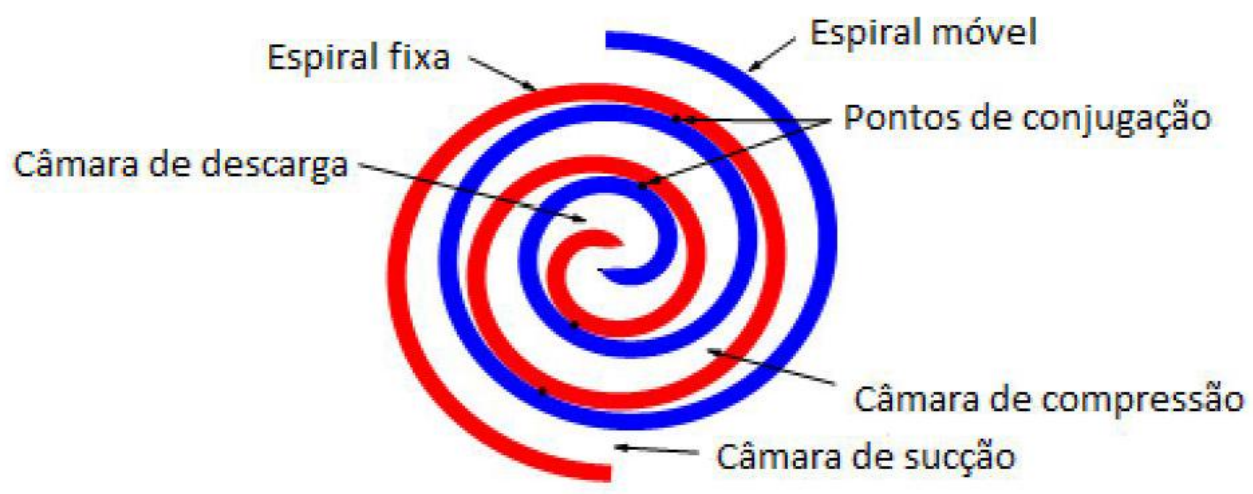

Fonte: Autor "adaptado de" Blunier; Cirrincione, 2009

O expansor tem a admissão de gás em alta pressão pelo centro do equipamento (Figura 8-a) e sua descarga é periférica (radial) de forma que ao ser admitido pelas câmaras o mesmo expande, aumentando seu volume, reduzindo sua pressão e gerando uma distribuição de pressão nas paredes do Scroll móvel que resultam na produção de torque no eixo.

Figura 8 - Ilustração das etapas de expansão de um fluido em um ETS

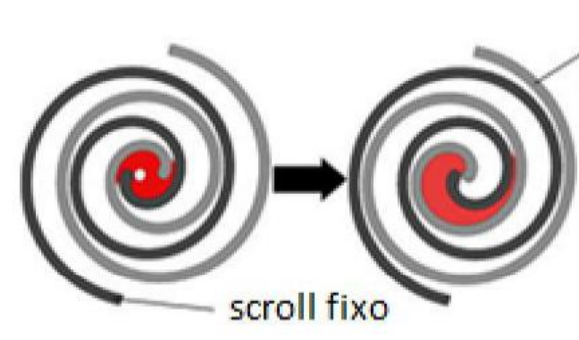

(a) (b)

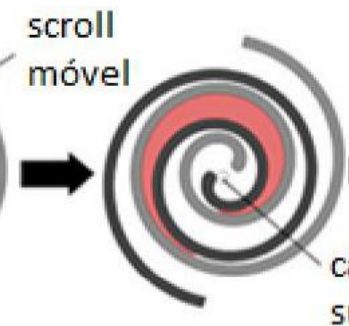

(c)

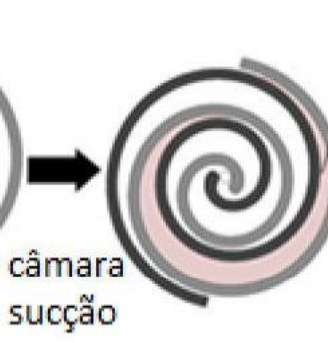

(d)

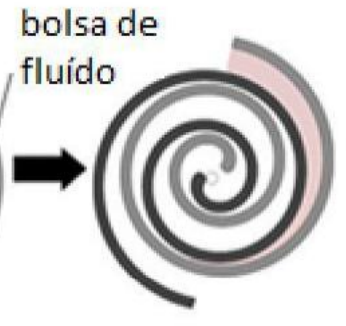

(e)

Fonte: Autor "adaptado de" Quoilin et al., 2013

A relação entre o volume da câmara de expansão no final do processo de expansão e no início é chamado de razão volumétrica $r_{v}$, esta relação é fundamental na análise de potência e eficiência de um ETS. (QUOILIN et al., 2013). Dois tipos de perdas podem ocorrer 
se a taxa de variação de volume especifico do sistema não for igual a razão volumétrica do expansor (DECLAYE et al., 2013). A figura 9 representa graficamente estas perdas. A sub expansão (figura 9.a), que ocorre quando a pressão na descarga do expansor é superior a de sua descarga para o meio externo, perdendo-se energia disponível no fluido para a geração de trabalho e a sobre expansão (figura 9.b), quando a pressão na descarga do expansor é inferior a sua descarga para o meio externo, onde esta diferença de pressão utiliza trabalho do expansor para a descarga dos gases.

Figura 9 - Representação gráfica da sub (9.a) e sobre (9.b) expansão.

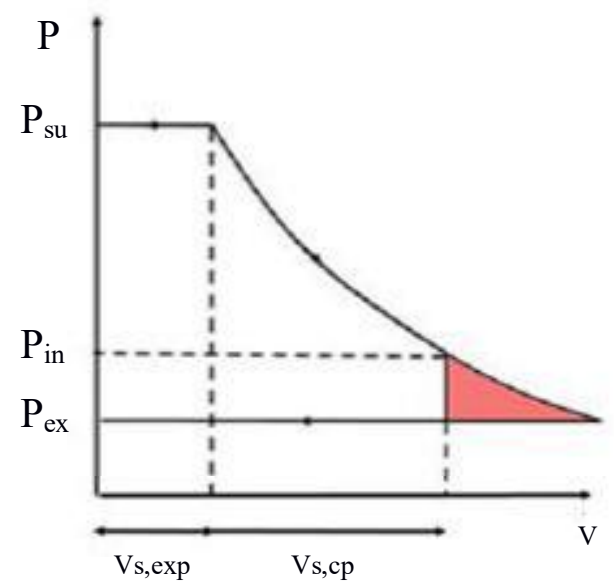

(9.a)

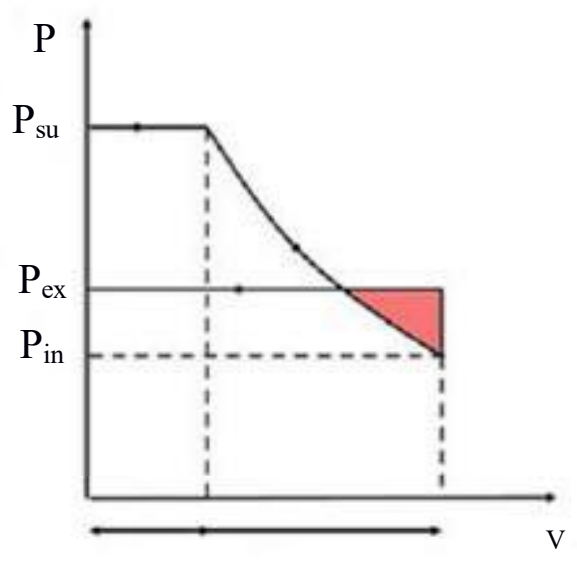

(9.b)

Fonte: Autor “adaptado de” Declaye et al., 2013

Durante o processo de expansão três tipos de câmaras são definidas: sucção, que é a câmara por onde o gás é admitido; expansão, onde o volume é aumentado levando-se consequentemente à expansão; descarga, que é a saída dos gases do equipamento. Todas as câmaras são separadas por pontos de contato (pontos de conjugação) ou por áreas com vazamentos caso os pontos de contatos sejam inexistentes. (BLUNIER et al., 2009).

O modelo adotado para a definição da geometria é o apresentado por Gravensen e Henriksen (2001), o qual define as involutas por estruturas ortonormais, que adota vetores normais e tangenciais para cada ponto. A geometria é fundamental para o desempenho do expansor e sua eficiência.

A eficiência do expansor é diretamente ligada pelo filling factor $(\varphi)$, que é apresentado pela equação 1. Este parâmetro adimensional é definido pela razão entre a vazão em massa e a vazão em massa teórica deslocada pelo expansor. 
O filling factor aumenta com os vazamentos internos e resfriamento do fluido, mas diminui com a perda de carga na entrada (LEMORT et al., 2009). Com o aumento dos vazamentos internos a vazão em massa real aumenta, assim como com o resfriamento do fluido. Com maiores perdas de carga na entrada a vazão em massa real diminui, o que leva a um menor filling factor. Uma forma de se avaliar os vazamentos internos é através do filling factor.

O desempenho do ETS fundamentalmente se dá pelo filling factor $(\varphi)$ e razão volumétrica $\left(r_{v}\right)$.

$\varphi=\frac{\dot{m} \cdot v_{s u}}{\dot{V}_{s u}}=\frac{\dot{m}}{\dot{m}_{\text {teórica }}}$

É esperado que o filling factor aumente conforme se aumenta a pressão de entrada do fluido de trabalho, mas esta tendência é equilibrada em função do aumento de perda de carga proporcional a pressão de entrada. Pela figura 10, observa-se que quanto menor for a rotação, maior será o filling factor, devido a maiores vazamentos internos e menor perda de carga na entrada do expansor (LEMORT ET AL., 2009).

Figura 10 - Relação entre o filling factor e o aumento na pressão de alimentação.

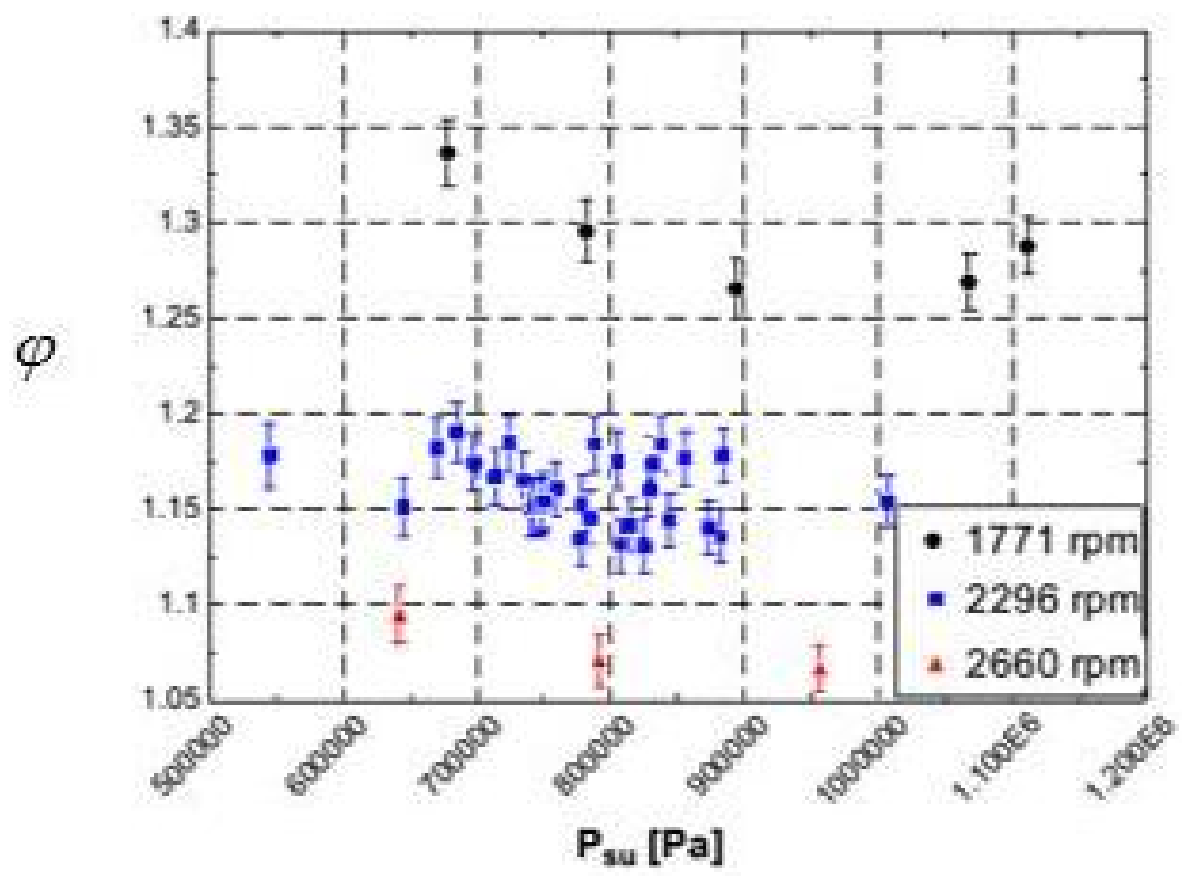

Fonte: Lemort et al., 2009 
Iglesias e Favrat (2014) realizaram testes com um expansor scroll em diferentes rotações, com e sem injeção de água na admissão. A figura 11 apresenta os resultados obtidos onde verifica-se que o rendimento global com injeção de água foi superior ao sem injeção e o filling factor menor. Nota-se um maior desvio do filling factor quando em baixas rotações.

Isso é justificado por:

a) $\mathrm{O}$ efeito da transferência de calor da água com o ar atuando no processo termodinâmico de descarga. A performance é melhorada pela tendência da expansão politrópica ser isotérmica, com um fator politrópico próximo a 1.

b) O efeito de selagem gerado pela água aumenta a eficiência isentrópica do ETS.

c) O efeito lubrificante da água é provavelmente o fator menos importante que influencia na performance do ETS.

Figura 11 - Filling factor e eficiência global em função da rotação do expansor, com e sem injeção de água

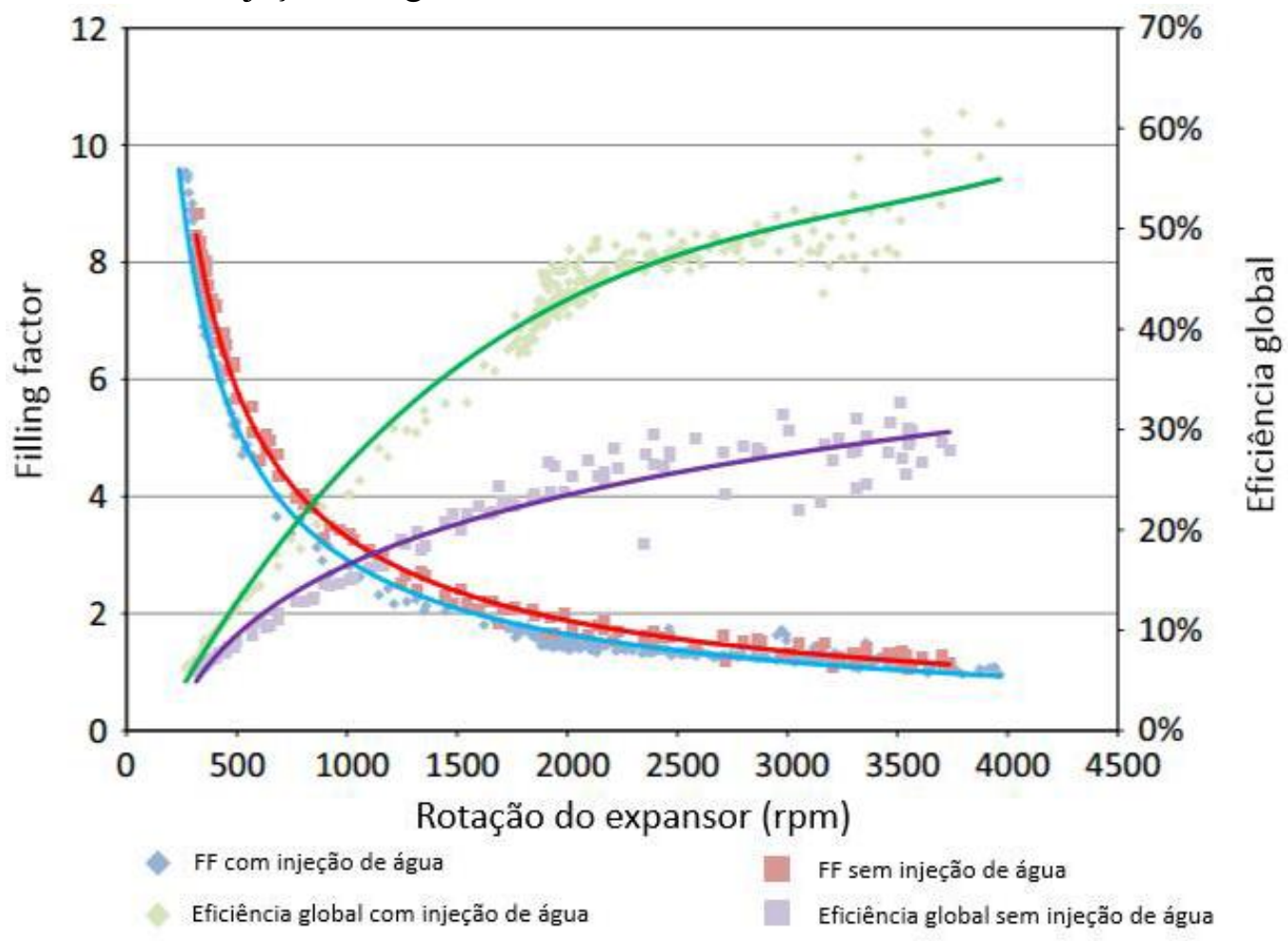

Fonte: Autor "adaptado de" Iglesias; Favrat, 2014

A perda de carga na entrada do expansor é considerada como a perda desde a linha de alimentação até a câmara de sucção. As maiores perdas de carga estão relacionadas com dois fenômenos:

a) Durante parte do processo de sucção, quando o orifício de sucção é parcialmente obstruído pela superfície do rotor móvel, reduzindo a área efetiva do orifício, como 
observa-se pela representação da figura 12 .

b) Ao final do processo de sucção, quando a área de passagem do orifício de sucção é progressivamente reduzido a zero pelo bloqueio realizado pelos scrolls móvel e fixo. (LEMORT et al., 2009)

Figura 12 - Obstrução parcial da câmara de admissão pelo rotor móvel

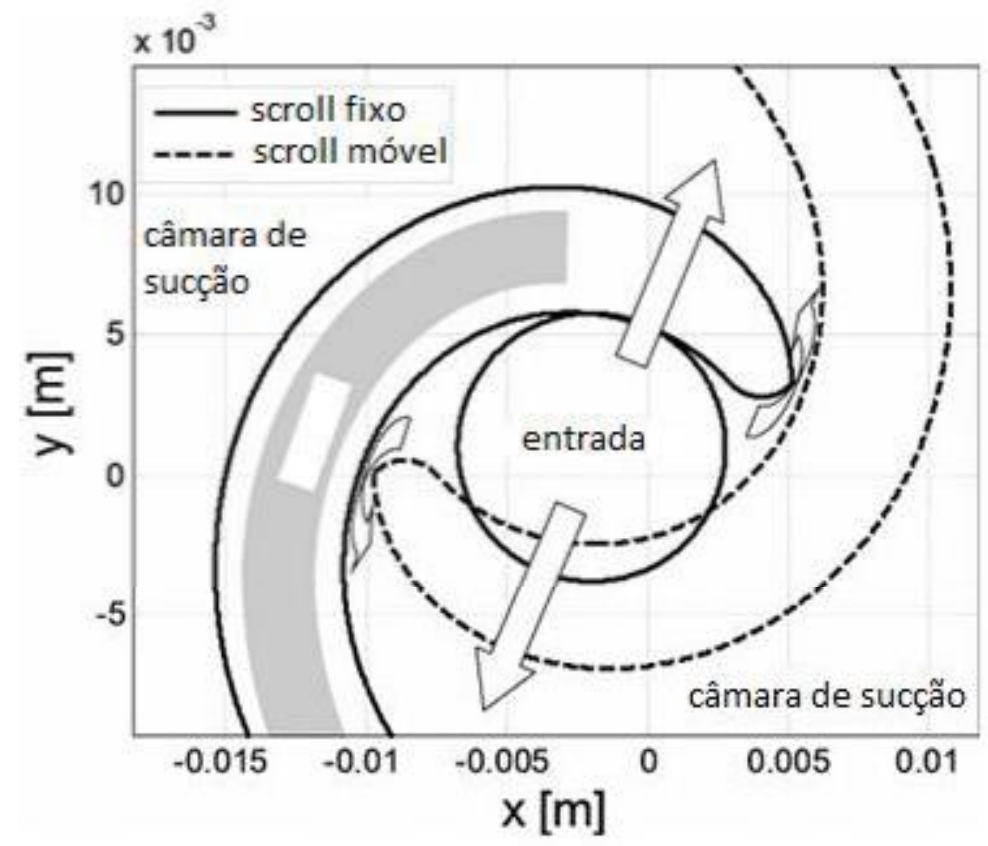

Fonte: Autor "adaptado de" Lemort et al., 2009

\subsection{ESTÁGIO ATUAL NAS PESQUISAS SOBRE OS ETS EXPANSORES TIPO SCROLL}

A primeira tentativa na utilização de um equipamento com geometria Scroll como expansor se deu a aproximadamente 20 anos atrás, quando Zanelli e Favrat (1994) utilizaram um compressor comercial lubrificado a óleo como expansor em um ciclo Rankine orgânico (ORC), atingindo uma eficiência isentrópica de 65\%. Yanagisawa et al. (2001) converteram um compressor de ar isento de óleo como expansor usando ar como o fluido de trabalho, atingindo uma eficiência isentrópica de $60 \%$.

Com o aperfeiçoamento da tecnologia e testes, recentemente Declaye et al. (2013) obtiveram uma eficiência isentrópica máxima de 75,7\%, utilizando um expansor Scroll operando como fluido de trabalho o gás R245fa em um Ciclo Rankine Orgânico. Neste estudo os autores adaptaram um compressor Scroll comercial hermético, isento de lubrificação, para evitar vazamentos de fluido orgânico. Mendoza et al. (2014) adaptaram um compressor 
comercial lubrificado, para uso em sistema de refrigeração automotiva testando a operação com ar e amônia. A máxima eficiência isentrópica foi de $61 \%$ operando com amônia.

Lemort et al. (2009) desenvolveram um modelo matemático para expansores tipo Scroll muito próximo ao verificado experimentalmente, baseado em modelos já desenvolvidos para compressores. Este modelo foi testado com diferentes expansores Scroll por Declaye e Mendoza, apresentando uma ótima concordância. Além do desenvolvimento para expansores Scroll, o modelo proposto por Lemort et al. (2009) foi útil na simulação de sistemas ORC, com um comportamento realístico para o expansor, como no estudo realizado por Giuffrida (2014). Adicionalmente os resultados apresentados pelo modelo permitem identificar as principais perdas do expansor. De acordo com Lemort et al. (2009), os vazamentos internos representam as principais perdas no expansor, seguido pela perda de carga na admissão e atritos mecânicos.

Song et al. (2015) observaram que a maior parte da investigação experimental de expansores Scroll usam compressores Scroll comerciais como ponto de partida. Investigações experimentais com expansores Scroll projetados para esse fim são raros. Eles citam dois trabalhos realizados anteriormente.

Zanelli e Favrat também observaram uma redução no filling factor de 1,2 a 2400 rpm para 0,97 a $4200 \mathrm{rpm}$ com o aumento da rotação. Eles atribuíram este comportamento a redução relativa das perdas por vazamentos internos e aumento das perdas na admissão do expansor quando do aumento da rotação. Yanagisawa et al. (2001) também observaram que a perda por vazamento nas folgas de flanco aumenta com baixas rotações. Iglesias e Favrat (2014) mostram que há um aumento exponencial no filling factor quando a rotação tende a zero.

Mendoza (2014) analisou o comportamento de um compressor operando como expansor com uso de um modelo TRSA05, de fabricação da empresa Sanden, utilizado em refrigeração automotiva. Sua seleção se deu por ser barato, compatível com amônia (componentes internos em alumínio e aço), um dos fluidos a ser testado e pela facilidade em sua modificação para operar como expansor. O compressor apresentava um volume deslocado de $53,9 \mathrm{~cm}^{3} /$ rev e dados pressão de operação de 35 bar, rotação de $166 \mathrm{~Hz}$ e razão volumétrica geométrica de 1,9 .

O estudo de Mendoza et al. (2014) demonstrou que a lubrificação teve uma influência positiva na potência especifica. Embora, para a vazão em massa do lubrificante acima de $2 \%$ do total a influência na potência foi insignificante. Esta melhora na eficiência se deu pela 
redução das folgas entre o Scroll, consequentemente reduzindo os vazamentos. Portanto, o valor de $2 \%$ se apresentou como o valor ótimo a se utilizar um lubrificante.

Como já mencionado em seção anterior, o uso de expansores Scroll vem sendo limitada a trabalhos experimentais de forma que muitos trabalhos científicos foram realizados com a conversão de um compressor tipo Scroll, máquina já consagrada, em expansor com adaptações.

Yanagisawa et al. (2013) realizaram um estudo com um expansor tipo Scroll isento de óleo, tendo como fluido ar, onde foi observado que a performance é muito prejudicada pelas perdas mecânicas, mas as perdas por vazamentos se tornam significantes quando ocorre redução da rotação. Neste estudo a máxima eficiência volumétrica e global foram respectivamente 76 e $60 \%$ como apresentado na figura 13 .

Figura 13 - Desempenho de um expansor em função da pressão de alimentação do fluido

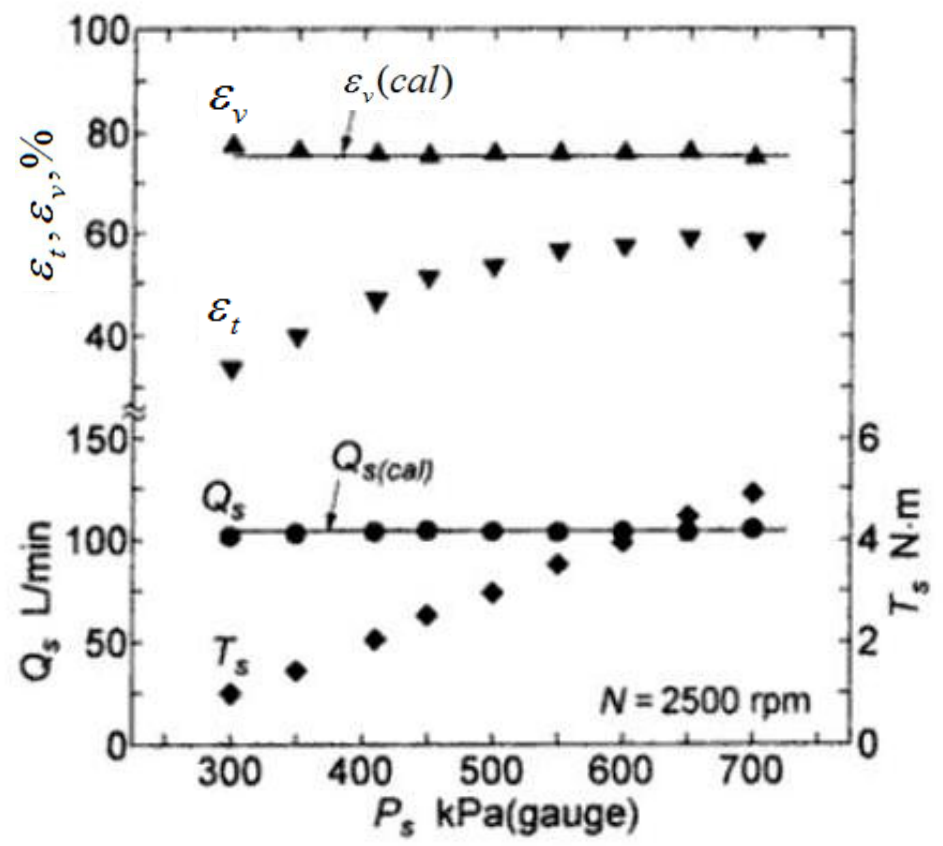

Fonte: Autor "adaptado" de Yanagisawa et al., 2001

Declaye et al. (2013), utilizaram um compressor comercial como expansor e como fluido orgânico fez uso de R245fa, sendo este fluido agressivo ao meio ambiente o equipamento foi instalado em um invólucro de aço de forma a conter vazamentos que viessem a ocorrer. O objetivo do trabalho foi estudar a influência dos parâmetros de entrada no desempenho do expansor. Foi alterada a pressão de entrada entre 9 e 12 bar, a pressão de saída entre 1,5 e 4 bar e sua rotação entre 2000 e 3500rpm. As figuras 14 e 15 apresentam os resultados obtidos. 
Figura 14 - Eficiência isentrópica x Relação de pressão para uma pressão de entrada de 12 bar

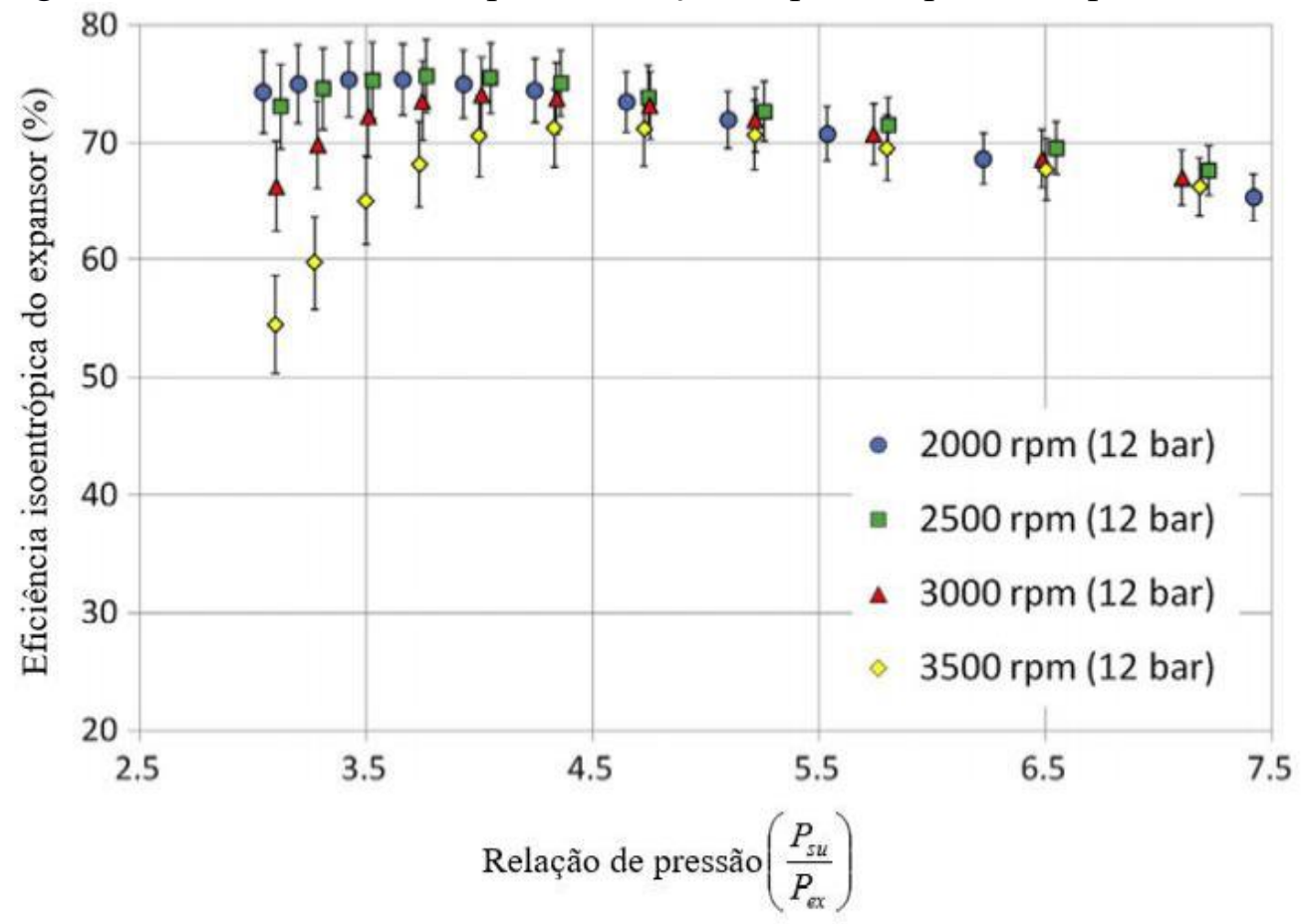

Fonte: Autor "adaptado de" Declaye et al., 2013

Figura 15 - Eficiência isentrópica x Relação de pressão para uma pressão de entrada de 9 bar

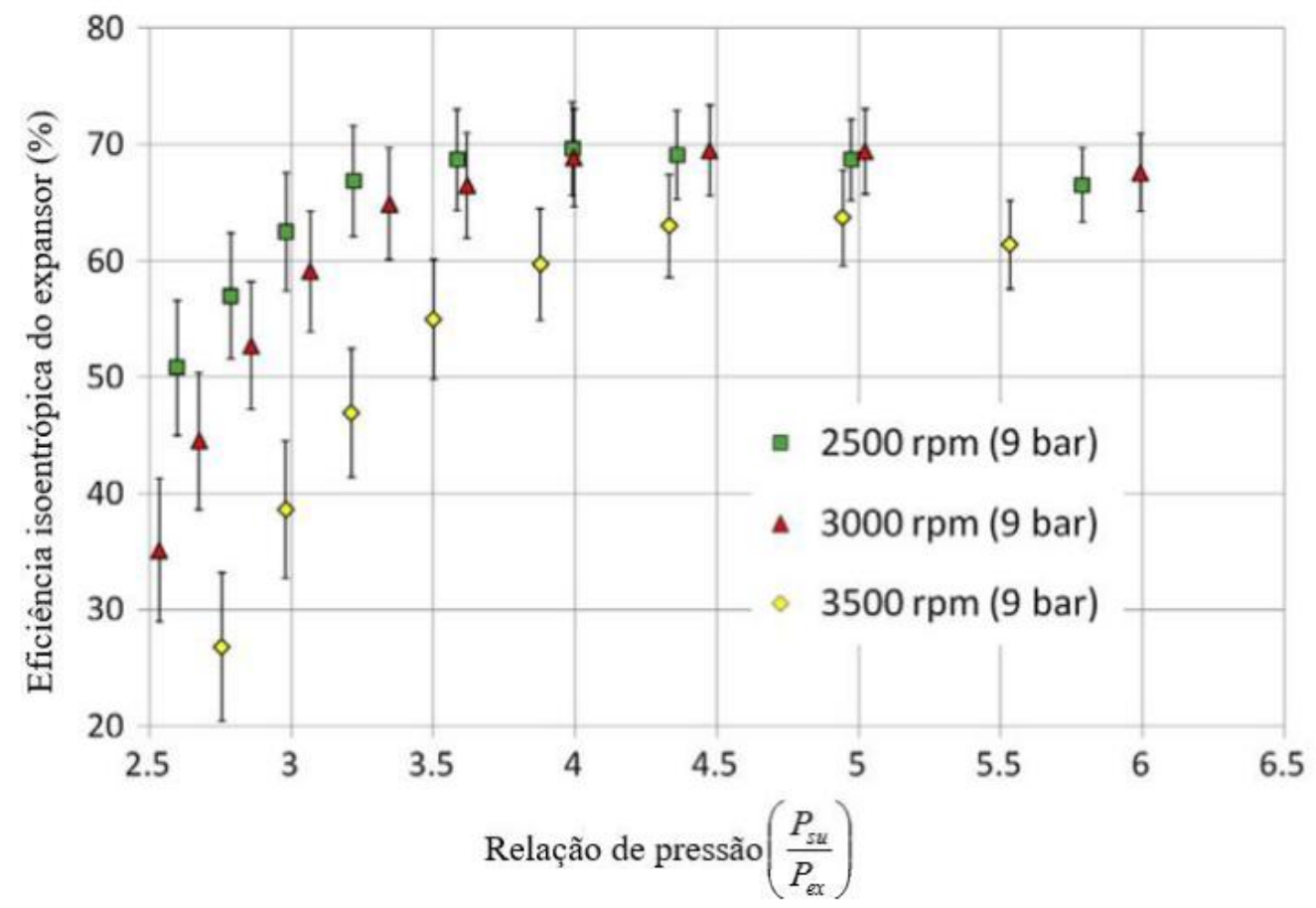

Fonte: Autor "adaptado de" Declaye et al., 2013

Os resultados obtidos demonstram que o aumento nas pressões de linha de expansores trabalhando na mesma faixa de rotação gera aumento no rendimento isentrópico. $\mathrm{O}$ aumento na relação entre pressão de saída e entrada, para pressão de linha constante, gera aumento no 
rendimento até o ponto de máximo (em torno de $75 \%$, voltando a decrescer em seguida). $\mathrm{O}$ rendimento isentrópico é menor para rotações altas.

O ponto máximo observado pelo autor ocorre para pressão de linha de 12 bar, relação de pressão em torno de 3,5 e rotação de $2000 \mathrm{rpm}$. Este comportamento é justificado pelo autor devido a perdas mecânicas e vazamentos internos. Para rotações altas, as perdas mecânicas no funcionamento do expansor tornam-se elevadas, portanto, o mesmo apresenta bom desempenho até determinados limites de rotação. Em contrapartida, para rotações muito baixas, as perdas devido a vazamentos internos tornam-se significantes.

Pode-se analisar de forma similar a variação na relação entre pressões. Para relações altas, o expansor libera o fluido com pressão superior à pressão de descarga, desperdiçando energia que poderia ser aproveitada.

Os ensaios foram realizados variando as condições de entrada do fluido de trabalho (pressão, temperatura, rotação e lubrificação) e fluido de trabalho a fim de identificar a influência destas no desempenho do expansor. Para possibilitar os ensaios, alguns parâmetros geométricos do Scroll tiveram de ser estimados experimentalmente, tais como perdas por vazamentos internos e perdas mecânicas. A figura 16 apresenta os resultados da influência da lubrificação na potência mecânica, eficiência isentrópica e potência específica para ambos os fluidos a diferentes rotações, podendo-se observar que a lubrificação tem uma influência positiva na potência específica, embora para valores abaixo de $2 \%$ da porcentagem em massa de lubrificante a influência foi insignificante para ambos os fluidos. Esta melhoria ocorre em função da redução das folgas pela presença do lubrificante, reduzindo as folgas. O valor de $2 \%$ foi verificado como o ótimo. 
Figura 16 - Influência da lubrificação na potência mecânica, eficiência volumétrica e potência específica para testes com ar (a) e amônia (b)
(a) ar
(b) amônia
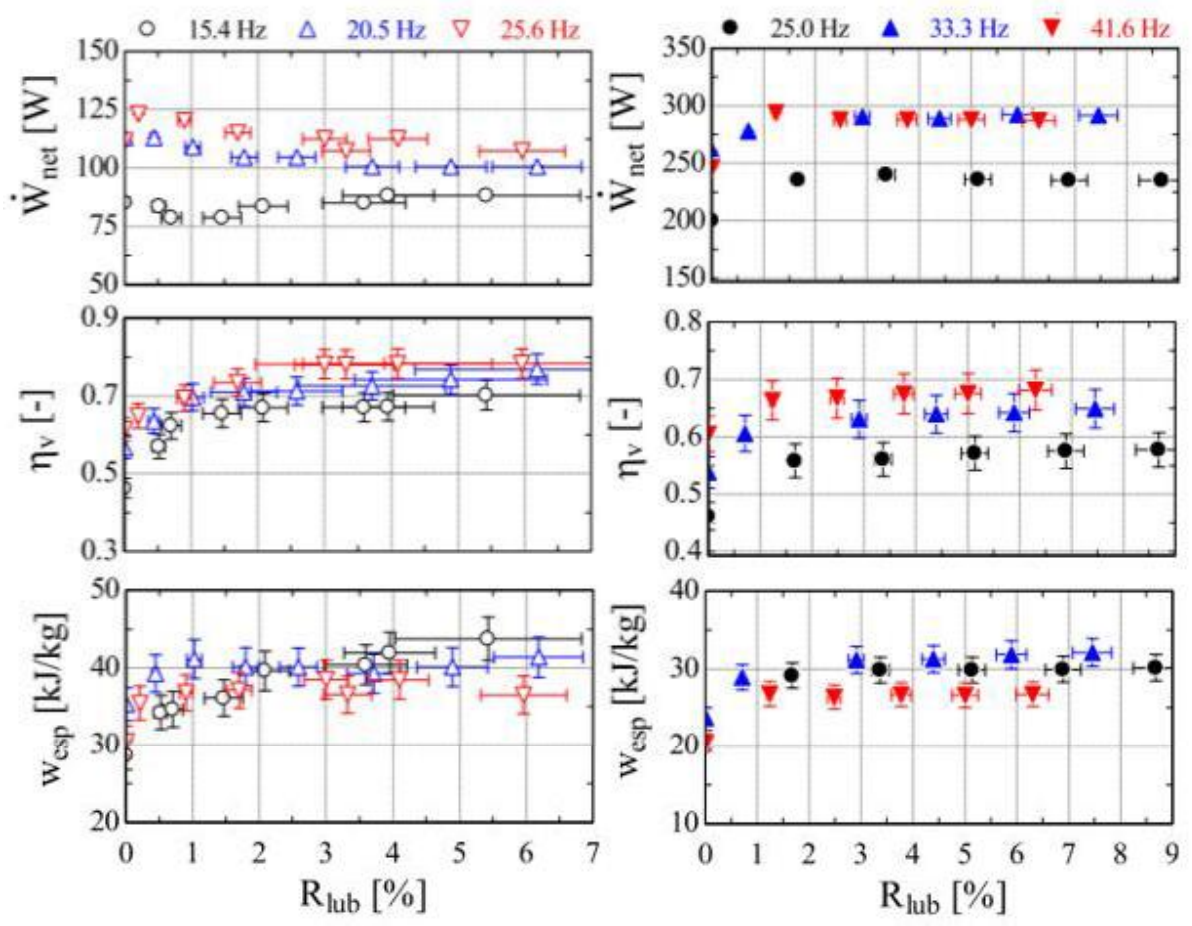

Fonte: Autor “adaptado de" Mendoza et al., 2014

Nesta aplicação, uso de compressores Scroll como expansor, precauções devem ser tomados para a operação em níveis de temperatura e pressão similares ao da compressão. Respeitando-se isso, o único problema encontrado na operação reversa de um compressor (expansão) é a razão volumétrica $\left(r_{v}\right)$ que não é ótima para um expansor, devendo ser modificada para se atingir uma melhor eficiência. A melhor forma de se atingir isso é com a alteração do ângulo final da involuta (rolling angle) (ORALLI et al., 2011).

\subsection{INFLUÊNCIA DOS VAZAMENTOS EM UM ETS}

Um expansor Scroll, assim como qualquer máquina térmica-mecânica apresenta perdas por transferência de calor, perdas mecânicas por atrito, perda de carga, perdas por eficiência volumétrica e vazamentos. Lemort et al. (2009) avaliaram um expansor Scroll e concluíram que a perda mais expressiva se dá por suas folgas (figura 17).

No estudo realizado a perda por vazamentos é de aproximadamente 35 a $40 \%$ para pontos de operação distintos, sendo portanto, muito relevante seu estudo e otimização. 
A figura 17 apresenta graficamente a influência da sub e sobre expansão em relação a razão volumétrica, caso ela seja diferente da relação de pressões de operação haverá perdas na eficiência isentrópica. No expansor estudado por Lemort et al. (2009) a razão volumétrica era de aproximadamente 4,1, que se desprezando as perdas representariam uma eficiência isentrópica de $100 \%$.

$\mathrm{Na}$ mesma figura apresenta-se a influência das perdas por transferência de calor, mecânicas, carga e vazamentos. Nota-se que a maior influência na redução da eficiência isentrópica é a dada por vazamentos internos.

Para um expansor real, as pressões nas câmaras diferem das ideais pois vazamentos ocorrem entre as câmaras. Os vazamentos reduzem a potência a ser gerada pois o fluido que passa de uma câmara de alta pressão vai para uma de menor pressão, não gerando trabalho. Os vazamentos também reduzem a eficiência volumétrica do equipamento (BLUNIER ET AL., 2009).

Figura 17 - Representação gráfica da eficiência isentrópica pela relação de pressão entre sucção e descarga em um ETS

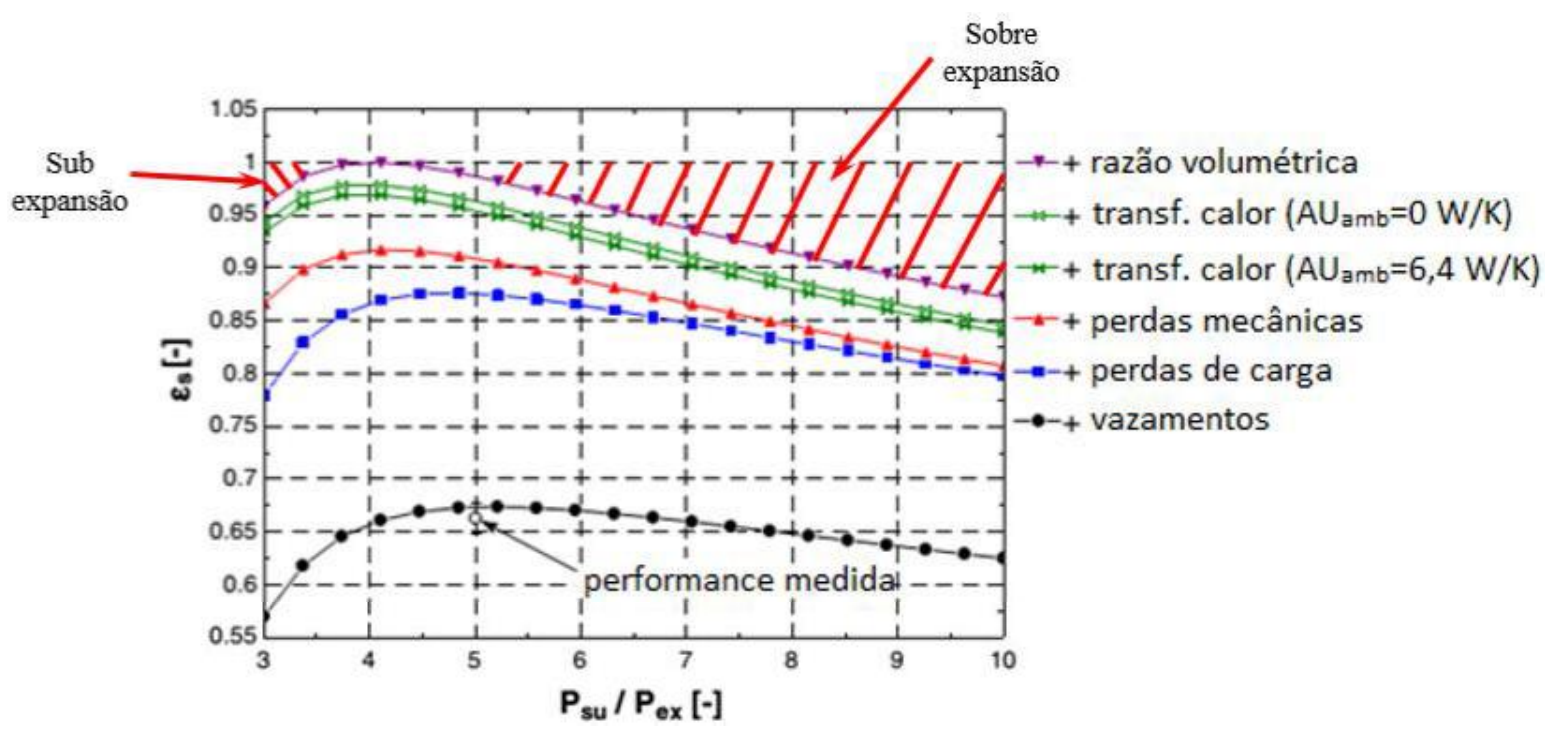

Fonte: Autor "adaptado de" Lemort et al., 2009

Dois tipos de folgas ocorrem em expansores tipo Scroll, tangenciais $\left(\delta_{T}\right)$ e radiais $\left(\delta_{R}\right)$, como ilustrado na figura 3, aqui repetida. Como apresentado em seção anterior o uso de lubrificação no equipamento tem influência positiva para uma certa faixa de quantidade percentual. 
Figura 3 - Representação dos rotores scroll em corte longitudinal e transversal e a indicação de suas folgas.

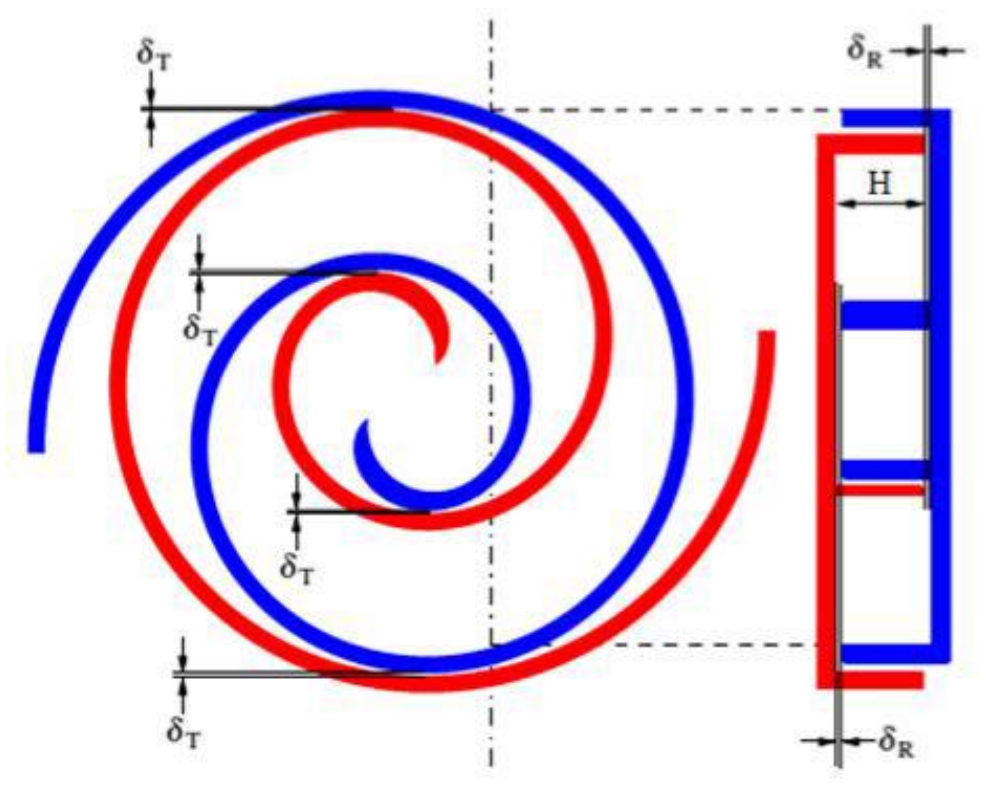

Fonte: Blunier e Cirrincione, 2009

Para os vazamentos tangenciais, ou de flanco, o fluido escoa por uma folga $\left(\delta_{T}\right)$ entre o flanco dos dois Scrolls. Nos vazamentos radiais o gás escoa por uma folga $\left(\delta_{R}\right)$ formada entre o topo e base de cada Scroll (BLUNIER et al., 2009)

Pelo modelo apresentado por Lemort et al. (2009), as folgas radiais e tangenciais são convertidas em uma única folga fictícia, cuja área de seção transversal $A_{\text {leak }}$ é o parâmetro a se identificar. A vazão referente ao vazamento pode ser computada utilizando-se como modelo um escoamento isentrópico em um bocal convergente simples, com área da garganta $A_{\text {leak }}$. A pressão na entrada do bocal é $P_{s u, 2}$. A pressão na garganta corresponde a máxima entre a exaustão e as pressões críticas:

$P_{\text {thr, leak }}=\operatorname{MAX}\left(P_{e x, 2} ; P_{\text {crit leak }}\right)$

A pressão critica, $P_{\text {crit leak }}$, é computada considerando o fluido como gás perfeito: 


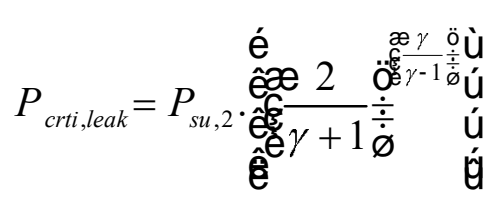

A utilização das equações de energia e massa em um bocal são combinadas para expressar a vazão em massa através da folga:

$\dot{m}_{\text {leak }}=\frac{A_{\text {leak }}}{v_{\text {thr, leak }}} \cdot \sqrt{2 \cdot\left(h_{\text {su }, 2}-h_{\text {thr }, \text { leak }}\right)}=\rho \cdot v \cdot A_{\text {leak }}$,

Onde a velocidade é igual à do som (c) $e h_{t h r}=h_{s u}$

Esta vazão de vazamento é a maior responsável pela baixa eficiência isentrópica de expansores tipo scroll. Será apresentado o cálculo dos nossos vazamentos no capitulo materiais e métodos. 


\section{MATERIAIS E MÉTODOS}

Nesta seção são descritas as características geométricas do expansor tipo Scroll e os parâmetros iniciais definidos para o dimensionamento. Também se apresenta a bancada experimental. Para melhor organização do texto, esta seção foi dividida em subseções: a subseção 3.1 apresenta os dados construtivos, geométricos e físicos do expansor; a subseção 3.2 a descrição da bancada experimental e a subseção 3.3 o modelo analítico utilizado.

\subsection{DADOS CONSTRUTIVOS, GEOMÉTRICOS E FÍSICOS DO PROTÓTIPO}

Para a definição do projeto e construção do expansor foram estudados compressores tipo Scroll comerciais, e baseado neles chegou-se a concepção construtiva do expansor tratada no estudo. A definição da curva do scroll para o protótipo é determinada por uma involuta de círculo, a qual foi proposta e apresentada por Blunier et al. (2009). Utilizaram-se as equações 5 e 6 para descrever as curvas do scroll fixo. O principal parâmetro que descreve esta curva é o raio do círculo básico da involuta $\left(r_{b}\right)$.

$$
\begin{array}{ll}
\mathbf{S}_{f e}\left(\varphi^{\prime}\right)=r_{b} \mathbf{t}\left(\varphi^{\prime}\right)-r_{b}\left(\varphi^{\prime}-\varphi_{e 0}^{\prime}\right) \mathbf{n}\left(\varphi^{\prime}\right) & \forall \varphi^{\prime} \in I_{e}=\left[\varphi_{e s}^{\prime}, \varphi_{\text {max }}^{\prime}\right], \\
\mathbf{S}_{f i}\left(\varphi^{\prime}\right)=r_{b} \mathbf{t}\left(\varphi^{\prime}\right)-r_{b}\left(\varphi^{\prime}-\varphi_{i 0}^{\prime}\right) \mathbf{n}\left(\varphi^{\prime}\right) \quad \forall \varphi^{\prime} \in I_{i}=\left[\varphi_{i s}^{\prime}, \varphi_{\text {max }}^{\prime}\right],
\end{array}
$$

As estruturas ortonormais que aparecem nas equações 5 e 6 são dadas pelas equações 7 e 8 que são respectivamente o vetor tangente e o vetor unidade normal.

$$
\begin{aligned}
& \mathbf{t}\left(\varphi^{\prime}\right)=\left(\cos \varphi^{\prime}, \sin \varphi^{\prime}\right), \\
& \mathbf{n}\left(\varphi^{\prime}\right)=\left(-\sin \varphi^{\prime}, \cos \varphi^{\prime}\right),
\end{aligned}
$$

A espessura (e) da parede do scroll é dada pela equação 9.

$$
e=r_{b}\left(\varphi_{i 0}^{\prime}-\varphi^{\prime}{ }_{e 0}\right)
$$


Como comentado por Blunier et al. (2009), a geometria do scroll móvel é igual à fixa, mas com uma defasagem de $\pi$. Nas equações 10 e 11, que definem o scroll móvel, o parâmetro $\theta$ é o ângulo de orbitação.

$\mathbf{S}_{m e}\left(\varphi^{\prime}\right)=-\mathbf{S}_{f e}\left(\varphi^{\prime}\right)-r_{o} \mathbf{n}(\theta)$,
$\mathbf{S}_{m i}\left(\varphi^{\prime}\right)=-\mathbf{S}_{f i}\left(\varphi^{\prime}\right)-r_{o} \mathbf{n}(\theta)$,

O raio de orbitação nominal $\left(r_{o}\right)$, dado pela equação 12 , é uma referência para o dimensionamento do eixo excêntrico.

$r_{o}=r_{b}\left(\varphi^{\prime}{ }_{e 0}-\varphi^{\prime}{ }_{i 0}+\pi\right)$

A figura 18 apresenta graficamente as curvas e linhas de construção para a geometria Scroll.

Figura 18 - Representação gráfica das curvas e linhas de construção da geometria scroll.

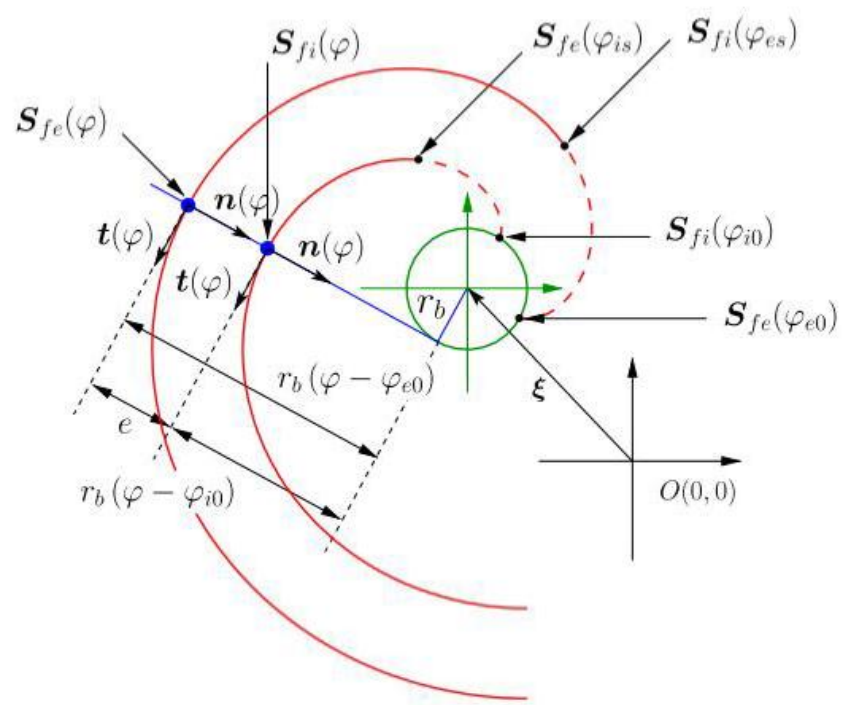

Fonte: Blunier et. al, 2009

Para o estudo da influência das folgas no desempenho do expansor definiu-se a construção de três conjuntos de eixos excêntricos, sendo cada conjunto projetado para operar com uma da folga de flanco de $200 \mu \mathrm{m}, 100 \mu \mathrm{m}$ e $50 \mu \mathrm{m}$, sendo a excentricidade de $6,3 \mathrm{~mm}$, $6,4 \mathrm{~mm}$ e $6,45 \mathrm{~mm}$ respectivamente.

Além da função de definir a folga radial entre rotores, os eixos excêntricos também têm as funções de garantir alinhamento dos rotores fixo e móvel e garantir que o rotor móvel 
não gire em torno de seu centro. Sua montagem tem um ângulo de $120^{\circ}$ entre cada eixo (figura 19b e 19c).

Figura 19 - (a) Eixos excêntricos, sua excentricidade define a folga tangencial, (b) Scroll fixo e (c) Scroll móvel, indicando a posição de montagem dos eixos excêntricos

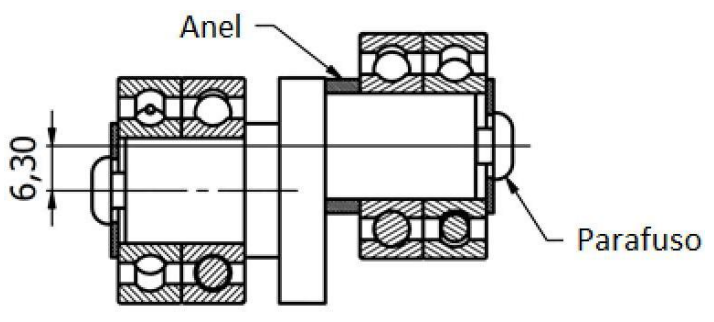

(a)

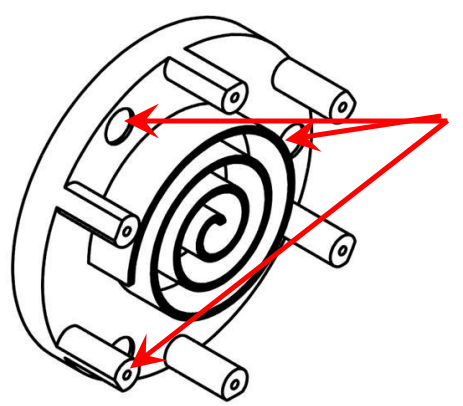

(b)

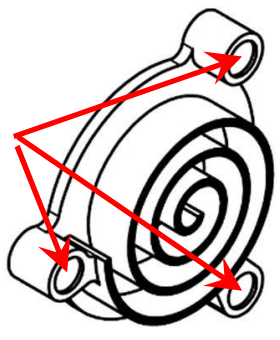

(c)

Fonte: Autor

Em função do processo de fabricação dos eixos excêntricos usinados na oficina mecânica do Centro Universitário da FEI os eixos ficaram com as medidas apresentadas no quadro 1. Para estas medições foi utilizado o aparelho de fabricação Mitutoyo, modelo QMMeasure-353, disponível no laboratório de metrologia. As medidas ficaram significativamente diferentes do projetado e são causa de ineficiência do expansor.

Quadro 1 - Medida dos eixos excêntricos

\begin{tabular}{|l|l|l|l|}
\hline & Projetado - 6,3mm & Projetado - 6,4mm & Projetado - 6,45mm \\
\hline Eixo 1 & $6,040 \mathrm{~mm}$ & $6,012 \mathrm{~mm}$ & $6,244 \mathrm{~mm}$ \\
\hline Eixo 2 & $6,054 \mathrm{~mm}$ & $6,021 \mathrm{~mm}$ & $6,328 \mathrm{~mm}$ \\
\hline Eixo 3 & $6,002 \mathrm{~mm}$ & $6,001 \mathrm{~mm}$ & $6,434 \mathrm{~mm}$ \\
\hline Média & $6,032 \mathrm{~mm}$ & $6,011 \mathrm{~mm}$ & $6,335 \mathrm{~mm}$ \\
\hline Folga real & $468 \mu \mathrm{m}$ & $489 \mu \mathrm{m}$ & $165 \mu \mathrm{m}$ \\
\hline
\end{tabular}

Fonte: Autor

Deste ponto em diante os conjuntos de eixos serão tratados neste trabalho pela sua folga real, sendo $468 \mu \mathrm{m}, 489 \mu \mathrm{m}$ e $165 \mu \mathrm{m}$, para a apresentação dos resultados obtidos nos testes. 
Para manter a configuração experimental a menos complexa possível, definiu-se que o fluido de trabalho seria o ar comprimido, fluido disponível à pressão de 6 bar (absoluto) no laboratório. Foi determinado para fins de projeto que o expansor teria uma potência nominal de $1 \mathrm{~kW}$ a $2000 \mathrm{rpm}$, com pressão de alimentação de ar comprimido de 4 bar (absoluto) a $20^{\circ} \mathrm{C}$. A vazão em massa e volume das câmaras são consequência destes parâmetros prédefinidos.

Os parâmetros que caracterizam a geometria das paredes do protótipo foram definidos por Fanti (em fase de elaboração) ${ }^{1}$ e são apresentados no quadro 2. Estes parâmetros foram determinados considerando os volumes de entrada e saída das câmaras, usando um procedimento iterativo. Estas curvas influenciam a performance esperada do expansor: razão volumétrica, vazão em massa, relação de pressão e potência. Deve ser notado que para um determinado deslocamento e razão volumétrica é possível obter muitas combinações geométricas diferentes de $r_{b}$, o raio do círculo básico da involuta e altura das paredes dos scrolls $(H)$. Bell et al. (2012), tratam deste assunto e sua influência sobre os vazamentos internos. O aumento do raio do círculo básico da involuta $\left(r_{0}\right)$ produz maiores vazamentos radiais.

Quadro 2 - Parâmetros utilizados para a construção dos scrolls fixo e móvel

\begin{tabular}{|l|c|r|}
\hline Parâmetro & Símbolo & Valor \\
\hline Raio do círculo básico da involuta & $r_{b}$ & $23 / 2 \pi \mathrm{mm}$ \\
\hline Espessura da parede & $e$ & $5 \mathrm{~mm}$ \\
\hline Ângulo inicial da involuta externa & $\varphi_{e 0}$ & $-\mathrm{e} / 2 r_{b}$ \\
\hline Ângulo inicial da involuta interna & $\varphi_{i 0}$ & $\mathrm{e} / 2 r_{b}$ \\
\hline Ângulo final da involuta & $\varphi_{\text {mas }}$ & $15 \pi / 2$ \\
\hline Ângulo inicial externo & $\varphi_{e s}$ & $\pi / 2$ \\
\hline Ângulo inicial interno & $\varphi_{i s}$ & $\pi / 2$ \\
\hline Altura das paredes & $H$ & $40 \mathrm{~mm}$ \\
\hline Raio orbitante nominal & $r_{o}$ & $6,5 \mathrm{~mm}$ \\
\hline
\end{tabular}

Fonte: Fanti (em fase de elaboração) ${ }^{1}$

Com os dados apresentados no quadro 2 determina-se a razão volumétrica $\left(r_{v}\right)$, que é igual a 3 e o volume deslocado por revolução $\left(V_{d}\right)$, com valor igual a $75,12 \mathrm{~cm}^{3} / \mathrm{rev}$. O quadro 3 apresenta os valores operacionais do expansor. 
Quadro 3 - Dados operacionais do expansor para $2000 \mathrm{rpm}$ e $1 \mathrm{~kW}$

\begin{tabular}{|l|c|r|}
\hline Parâmetro & Símbolo & Valor \\
\hline Pressão do ar na entrada do expansor & $P_{s u}$ & $4,3 \mathrm{bar}$ abs \\
\hline Temperatura do ar na entrada do expansor & $T_{s u}$ & $20^{\circ} \mathrm{C}$ \\
\hline Pressão do ar na saída do expansor & $P_{e x}$ & $0,92 \mathrm{bar}$ abs \\
\hline Vazão em massa & $\dot{m}$ & $42,09 \mathrm{~kg} / \mathrm{h}$ \\
\hline Área sucção & $A_{s u}$ & $1,878 \times 10^{3} \mathrm{~m}^{2}$ \\
\hline Área descarga & $A_{e x}$ & $5,636 \times 10^{3} \mathrm{~m}^{2}$ \\
\hline Vazão volumétrica sucção & $\dot{V}_{s u}$ & $9,01 \mathrm{~m}^{3} / \mathrm{h}$ \\
\hline Volume câmara sucção & $V_{s u}$ & $75,12 \times 10^{-6} \mathrm{~m}^{3}$ \\
\hline Volume câmara descarga & $V_{e x}$ & $225,4 \times 10^{-6} \mathrm{~m}^{3}$ \\
\hline Razão volumétrica geométrica & $r_{v}$ & 3 \\
\hline
\end{tabular}

Fonte: Autor

As paredes do expansor scroll foram construídas com ranhuras em seu topo onde se montou um selo de UHMWPE (ultra high molecular weight polyethylene) de forma a reduzir a folga radial e consequentemente o seu vazamento.

A relação volumétrica do expansor, o fluido de trabalho e a temperatura de operação definem qual a pressão ótima de operação do protótipo, ponto este que não terá efeitos de perdas por sub e sobre expansão. A equação 13 apresenta o equacionamento que define a relação de pressão ótima.

$$
r v=r p^{\frac{1}{\gamma}} \quad r p \cdot p_{a t m}=4,3 b a r
$$

No caso, para o protótipo construído o valor de rp é igual a 4,65, que multiplicado pelo valor da pressão atmosférica apresenta o ponto ótimo de pressão, que é igual a 4,3 bar. Espera-se o máximo rendimento próximo a este valor, ou superior, já que a perda de carga na entrada do expansor pode ser significativa.

\subsection{DESCRIÇÃO DA BANCADA EXPERIMENTAL}

A bancada experimental é alimentada por ar comprimido e é composta por dois medidores de vazão volumétrica do tipo turbina, instalados em paralelo de forma que a vazão total de ar admitido no expansor é representado pela soma das duas vazões medidas. Um 
transdutor de pressão e um termopar foram instalados na entrada do expansor. O termopar foi instalado na parte externa da tubulação e é isolado termicamente.

Como dados de saída temos o sinal de rotação e força, dadas respectivamente por um encoder e uma célula de carga. Para a alimentação de carga no sistema é utilizado um freio tipo Foucault controlado por um regulador de tensão com uma ponte retificadora.

Todos os sinais são enviados para um módulo de aquisição de dados que se comunica com um computador (IHM), onde os sinais são processados. A figura 20 apresenta o fluxo do ar com o posicionamento dos instrumentos de medição e na figura 21 é apresentado uma foto da bancada.

Figura 20 - Fluxograma do ar comprimido na bancada experimental

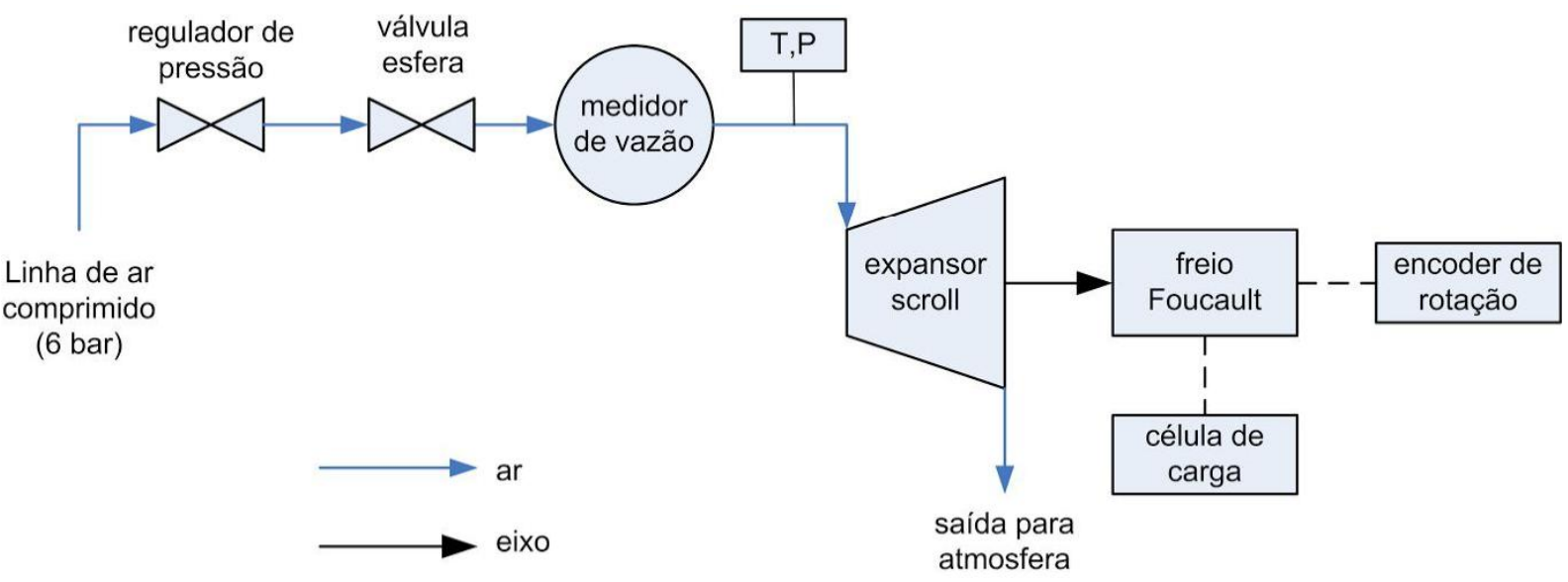

Fonte: Fanti (em fase de elaboração) ${ }^{1}$

Figura 21 - Freio de Foucault e encoder ligados ao eixo do expansor

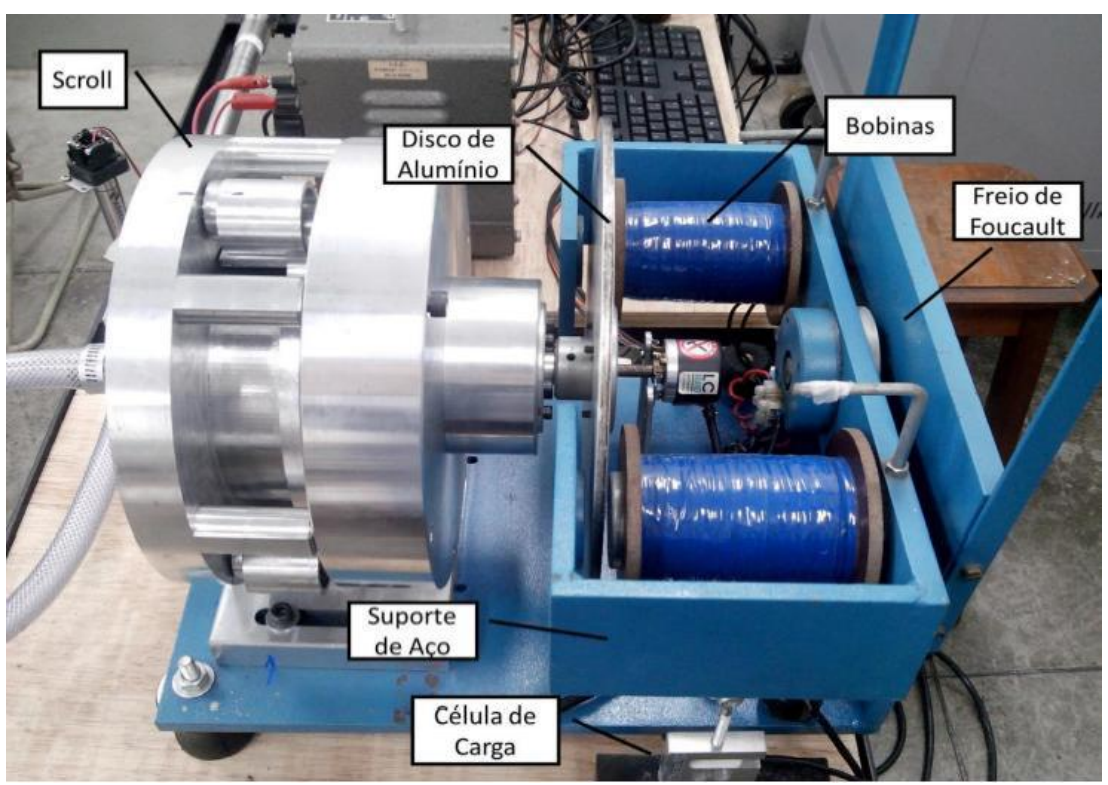

Fonte: Autor 
Sendo as informações de rotação e força valores de interesse indireto para a análise de dados, o computador se utiliza de algoritmos para a determinar a potência $(\dot{W})$, eficiência isentrópica $\left(\eta_{s}\right)$, vazão em massa $(\dot{m})$ e densidade do ar na entrada do expansor $(\rho)$.

Com as informações de vazão volumétrica, temperatura e pressão de ar na entrada do expansor obtém-se a densidade e vazão em massa no expansor.

Para a realização dos experimentos a diferentes potências, se fez necessário definir qual seria a forma de se demandar carga no expansor, sendo a bancada para fins experimentais e a faixa de análise entre 200 e $1200 \mathrm{~W}$, a melhor solução se deu com a aplicação de um dinamômetro que apresentasse frenagem suave e contínua e que não perdesse desempenho ao longo dos testes em função de atritos.

Killedar (2012) apresenta as características do dinamômetro tipo Foucault, também conhecido como freio de correntes parasitas, sendo destacado pelo seu design simples, precisão, facilidade de controle e trabalhar adequadamente com mudanças bruscas de carga em altas rotações, por estas razões este tipo de dinamômetro é o mais utilizado nas análises de torque em motores.

Dentre as opções estudadas, pelas características citadas acima, o freio de Foucault foi a opção escolhida pelo fácil controle de carga, não exigir dispositivos especiais para arrefecimento, apresentar frenagem suave e contínua além de não ter atrito que possa alterar o resultado dos experimentos ao longo dos testes em função de desgastes.

O freio de Foucault é composto por duas bobinas, alimentadas por um regulador de tensão e ponte retificadora, de forma que a corrente de alimentação é contínua. Ao se alimentar as bobinas com tensão, uma corrente elétrica circula pelas mesmas, gerando um campo magnético com sentido oposto à rotação do expansor. Este campo magnético se converte em torque oposto ao movimento, pelo uso de um disco de alumínio acoplado ao eixo do expansor.

O torque mecânico necessário para vencer este torque resistivo induzido pelo disco é determinado pela célula de carga que fica instalada a uma distância de $200 \mathrm{~mm}$ da linha de centro do eixo do expansor, esta distância (b) é necessária para a determinação da potência gerada.

A figura 22 apresenta a medida "b", que representa o braço de aplicação de força, entre o centro do eixo do expansor e a posição da célula de carga. Este parâmetro é utilizado para a definição do torque. 
Figura 22 - Freio de Foucault, encoder e a distância "b" entre o eixo do expansor e a posição da célula de carga

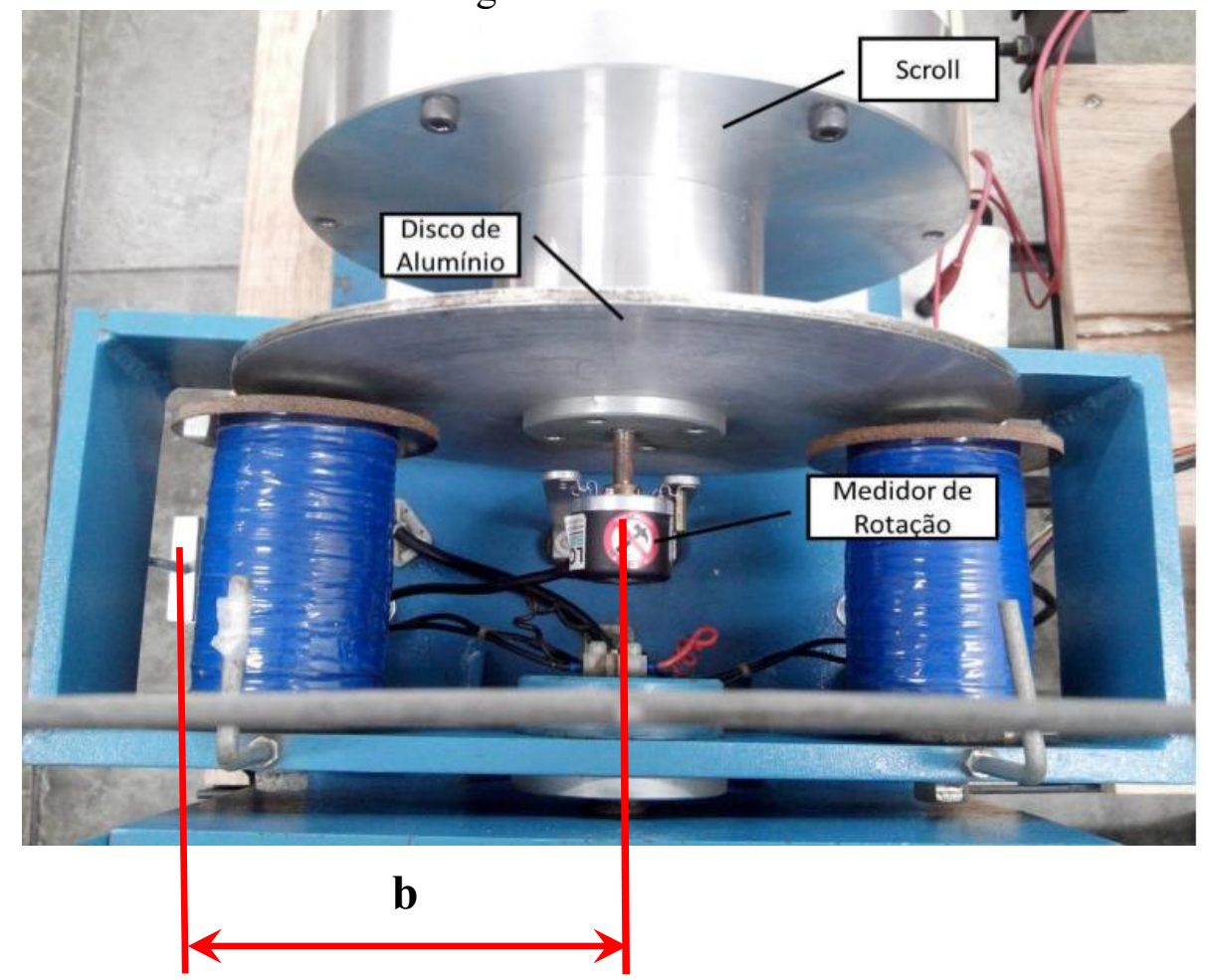

Fonte: Autor

O quadro 4 informa dados técnicos dos instrumentos utilizados. 
Quadro 4 - Dados dos instrumentos

\begin{tabular}{|c|c|c|}
\hline $\begin{array}{ll}\text { Tipo } & \text { de } \\
\text { instrumento }\end{array}$ & Fabricante / Modelo & Incerteza / Repetibilidade \\
\hline $\begin{array}{l}2 \text { unidades - } \\
\text { Transmissor de } \\
\text { vazão tipo turbina }\end{array}$ & $\begin{array}{l}\text { Contech - SVTG 3/4" G19 - Saída de } \\
4 \text { a } 20 \text { mA - faixa de medição de } \\
\text { vazão } 3,4 \text { a } 34 \mathrm{~m}^{3} / \mathrm{h} \text { - Temperatura } \\
\text { de operação de }-50 \text { a } 100^{\circ} \mathrm{C}\end{array}$ & $\begin{array}{r} \pm 1 \% \text { para vazões de } 10 \text { a } \\
100 \% \text { da máxima / Dispersão } \\
\text { menor que } 0,3 \%\end{array}$ \\
\hline $\begin{array}{l}\text { Transmissor de } \\
\text { pressão }\end{array}$ & $\begin{array}{l}\text { Ashcroft - TP K1 } 050 \text { 1⁄2" - Saída de } \\
4 \text { a } 20 \text { mA - Faixa de medição de } \\
\text { pressão de } 0 \text { a } 10 \text { bar - Temperatura } \\
\text { de operação de } 0 \text { a } 70^{\circ} \mathrm{C}\end{array}$ & $\pm 0,5 \%$ TP ou $\pm 0,4 \%$ BFSL \\
\hline Termopar tipo "J" & & $\begin{array}{r}2,5^{\circ} \mathrm{C} \text { ou } \pm 0,75 \% \text { (referência } \\
\text { para instrumento não } \\
\text { calibrado) }\end{array}$ \\
\hline Célula de carga & $\begin{array}{c}\text { Alfa instrumentos }-\mathrm{S} 10 \mathrm{RS}- \\
\text { Capacidade nominal } 10 \mathrm{~kg}- \\
\text { sensibilidade } 2000 \mathrm{mV} / \mathrm{V}(+-10 \%)- \\
\text { Temperatura de trabalho }-5 \text { a } 60^{\circ} \mathrm{C}\end{array}$ & $\pm 0,2 \%$ \\
\hline Encoder rotativo & $\begin{array}{c}\text { Autonics - E40H8-1000-6-L-5 } \\
\text { Faixa de operação entre } 0 \text { e } 5000 \\
\text { rpm }\end{array}$ & \\
\hline
\end{tabular}

Fonte: Autor

A potência do expansor é calculada pela equação 14, onde utilizam-se os sinais de força (célula de carga) e rotação (encoder) para a sua determinação.

$\dot{W}=F \cdot b \cdot n \cdot \frac{2 . \pi}{60}$

Com os dados do fluido de trabalho na entrada e saída do expansor e potência, obtida pela IHM, determina-se a eficiência isentrópica em um pós-processamento utilizando-se o software EES (equação 15). 
$\eta_{s}=\frac{\dot{W}}{\dot{m} \cdot\left(h_{1}-h_{2 s}\right)}$

\subsection{MODELO ANALÍTICO PARA EXPANSORES SCROLL}

O modelo analítico utilizado para a avaliação da eficiência isentrópica do expansor foi o apresentado por Lemort et al. (2008) para um expansor tipo Scroll, o qual foi aplicado com sucesso em diversos estudos, mas com pequenas modificações. Este modelo, o qual usa parâmetros semi-empíricos obtidos por testes experimentais, é capaz de prever a potência mecânica liquida $\left(\dot{W}_{n e t}\right)$, vazão em massa na sucção $\left(\dot{m}_{s u}\right)$ e temperatura de exaustão $\left(T_{e x}\right)$ baseando-se na rotação da máquina $(n)$, pressão e temperatura de alimentação $\left(P_{s u}, T_{s u}\right)$ e pressão de saída $\left(P_{e x}\right)$ como variáveis de entrada. A figura 23 apresenta um esquema do modelo (Mendoza et al., 2014).

Figura 23 - Esquema do modelo analítico do expansor

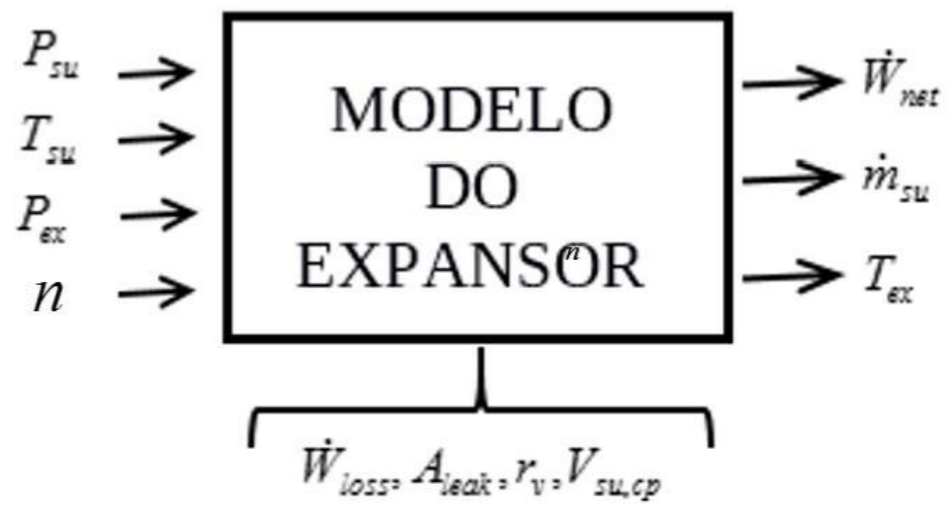

Fonte: Mendoza et al., 2014

Para este modelo, são desconsideradas perdas devido à troca de calor com o ambiente. A superfície externa do expansor apresentou pequena diferença de temperatura com a ambiente, assim como a área de troca de calor reduzida (aproximadamente 0,16 $\mathrm{m}^{2}$ ). A lubrificação também não foi considerada pois o protótipo não requer óleo misturado ao ar comprimido.

O esboço conceitual é apresentado na figura 24, no qual o escoamento do fluido descreve os seguintes processos: a vazão do fluido na entrada do expansor $\left(\dot{m}_{s u}\right)$ é dividida em dois fluxos, um que gera potência mecânica $\left(\dot{m}_{i n}\right)$ e outro que representa os vazamentos 
pelas folgas internas do expansor $\left(\dot{m}_{\text {leak }}\right)$; potência mecânica é produzida por dois processos de expansão, um adiabático e reversível (de su para int) e outro à volume constante (de int para $\mathrm{ex}_{2}$ ) como pode ser observado na figura 24. Então, o fluxo expandido no estado $\mathrm{ex}_{2}$ é misturado com o fluxo de vazamento $\left(\dot{m}_{\text {leak }}\right)$ obtendo-se o fluxo no ponto $\mathrm{ex}_{1}$. Subsequentemente este fluxo reduz a temperatura dos rolamentos e partes móveis do expansor que tenham aquecido em função de atritos mecânicos. Isto gera o fluxo de exaustão ex (MENDOZA et al., 2014).

Figura 24 - Esquema do modelo analítico do expansor

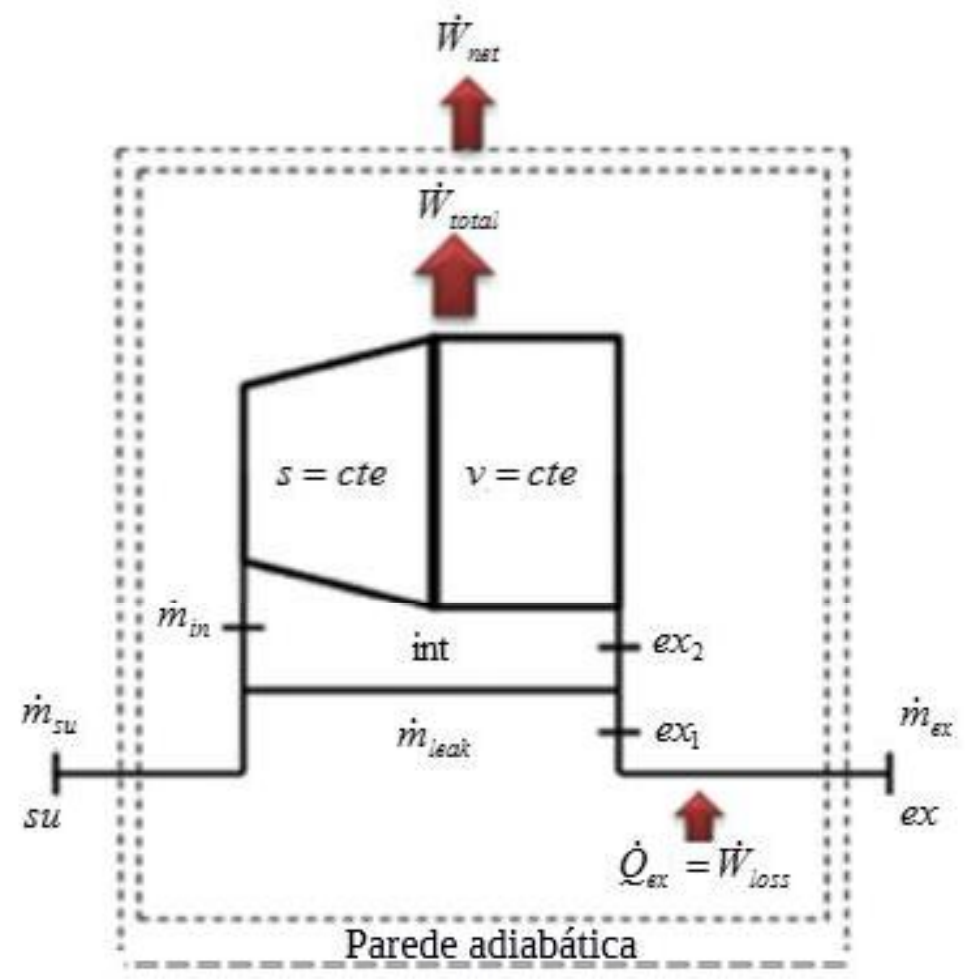

Fonte: Mendoza et al., 2014

A potência mecânica gerada pelo expansor é o resultado da expansão do ar onde também é afetado pela sub ou sobre expansão, o qual acontece quando a taxa de variação de volume nominal $\left(r_{v}\right)$ é diferente da relação de pressão do sistema (equação 16).

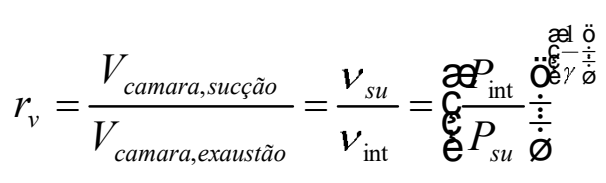


A potência mecânica produzida ( $\dot{W}_{\text {pred }}$ ) pelo expansor é dado pela equação 17 , o qual compreende os processos isentrópico e isocórico. A potência mecânica liquida $\left(\dot{W}_{n e t}\right)$ é dada pela diferença entre a potência mecânica produzida e a potência mecânica das perdas por atrito $\left(\dot{W}_{\text {loss }}\right)$, equação 18 .

$$
\begin{aligned}
& \dot{W}_{\text {pred }}=\dot{m}_{i n}\left[\left(h_{s u}-h_{\text {int }}\right)+v_{\text {int }}\left(P_{\text {int }}-P_{e x}\right)\right] \\
& \dot{W}_{n e t}=\dot{W}_{\text {pred }}-\dot{W}_{\text {loss }}
\end{aligned}
$$

A equação 19 é utilizada para calcular a vazão em massa do expansor. A equação que apresenta a quantidade teórica da vazão em massa para preencher a câmara de admissão do expansor é a 20 e a equação 21 a vazão em massa que vaza pelas folgas do Scroll.

$$
\begin{aligned}
& \dot{m}_{s u}=\dot{m}_{\text {in }}+\dot{m}_{\text {leak }} \\
& \dot{m}_{\text {in }}=\frac{n \cdot V_{c h, s u}}{v_{s u}} \\
& \dot{m}_{\text {leak }}=A_{\text {leak }} \frac{c_{t h r}}{v_{t h r}}
\end{aligned}
$$

A vazão em massa escoando pelas folgas do Scroll são modeladas por um fluxo isentrópico por um bocal convergente divergente, no qual a velocidade na garganta é calculado por condição de blocagem, número de Mach ( $\mathrm{M}$ ) igual a 1. A representação do fluxo de vazamento pelo bocal introduz um parâmetro no modelo que é a "área de vazamento". Portanto, a velocidade na garganta do bocal pode ser expressa pela equação que fornece a velocidade do som na garganta. (Equação 22).

$$
c_{t h r}=\sqrt{2\left(h_{s u}-h_{t h r}\right)}
$$

Para calcular a entalpia teórica na garganta é necessário se conhecer a pressão na garganta e entropia na entrada do expansor (equação 23). 
$h_{t h r}=f\left(P_{t h r}, s_{s u}\right)$

Para a determinação da pressão na garganta do bocal, a pressão crítica do fluido na garganta ou a pressão de exaustão (subsônica) são usadas, onde a pressão mais elevada é a escolhida, conforme equação 24. Contudo, quando a pressão crítica é menor que a pressão de exaustão o bocal opera em um regime subsônico.

$P_{t h r}=\max \left(P_{c r i t}, P_{e x}\right)$

A pressão crítica é calculada usando a razão entre calores específicos do fluido $(\gamma)$ e a pressão na entrada do expansor $\left(P_{s u}\right)$ (equação 25).

$P_{c r i t}=P_{s u} \cdot\left[\left(\frac{2}{\gamma+1}\right)^{\left(\frac{\gamma}{\gamma-1}\right)}\right]$

O valor pressão na garganta do bocal permite encontrar as propriedades termodinâmicas do ar na garganta, dentre elas o volume específico do ar (equação 26) e a entalpia (equação 23), possibilitando o cálculo da vazão em massa dos vazamentos internos (equação 21).

$v_{t h r}=f\left(P_{t h r}, s_{s u}\right)$

A eficiência isentrópica é definida pela relação entre a potência medida no eixo e a potência disponível no eixo caso a expansão fosse isentrópica (equação 27), esta última é o produto da vazão em massa medida pelo trabalho específico de expansão associado a uma expansão isentrópica, das condições de entrada à pressão de escape.

$\varepsilon_{s}=\frac{\dot{W}_{\text {medido-eixo }}}{\dot{W}_{\text {iso }}}=\frac{\dot{W}_{\text {medido-eixo }}}{\dot{m}_{\text {medido }} \cdot w_{\text {iso }}}=\frac{\dot{W}_{\text {medido-eixo }}}{\dot{m}_{\text {medido }} \cdot\left(h_{\text {su }}-h_{\text {ex-iso }}\right)}$

Como citado anteriormente, no final do processo ocorre a mistura da massa de ar utilizada para geração da potência com a massa de ar de vazamentos internos. Para avaliar as 
condições reais de saída do ar no expansor, o autor considera uma mistura adiabática dos fluxos de ar, utilizando a expressão apresentada pela equação 28.

$\dot{m}_{i n} \cdot h_{e x 2}+\dot{m}_{l e a k} \cdot h_{s u}=\dot{m}_{s u} \cdot h_{e x 1}$

A temperatura do ar pode ser definida a partir da entalpia da mistura de ar na saída do Scroll, apresentada pelas equações 29 e 30 . Em função de não ser considerado as perdas por atrito, a equação 29 não é utilizada no modelo analítico deste trabalho.

$$
\begin{aligned}
& h_{e x}=h_{e x 1} \cdot \frac{Q_{e x}}{\dot{m}_{s u}} \\
& T_{e x}=f\left(h_{e x}\right)
\end{aligned}
$$

A comparação entre os resultados do modelo e os resultados obtidos experimentalmente por Mendoza et al. (2014) são apresentados na figura 25, onde (a) representa a comparação da potência mecânica medida pela prevista, (b) a comparação da vazão em massa medida pela prevista e (c) a comparação temperatura de exaustão medida pela prevista, sendo amônia o fluido utilizado. 
Figura 25 - Comparação entre a potência mecânica medida pela prevista (a), vazão em massa medida pela prevista (b) e a temperatura de exaustão medida pela prevista (c), sendo amônia o fluido utilizado

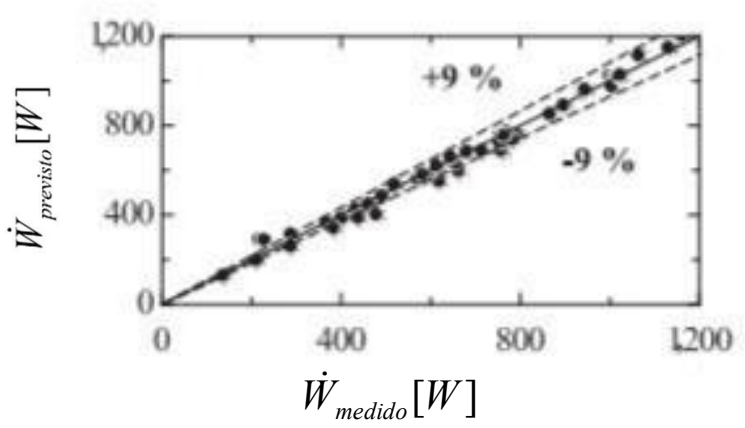

(a)

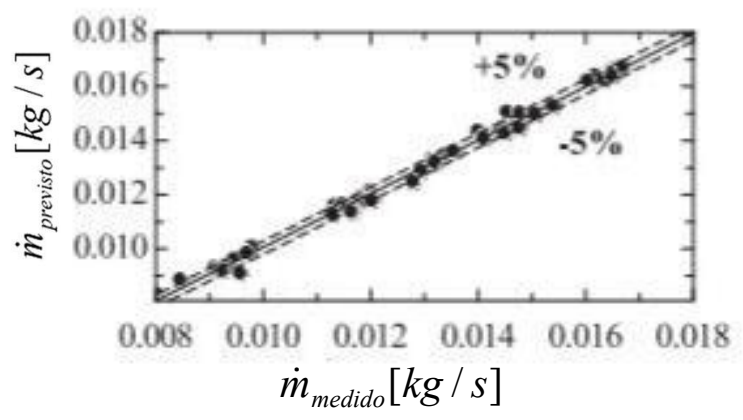

(b)

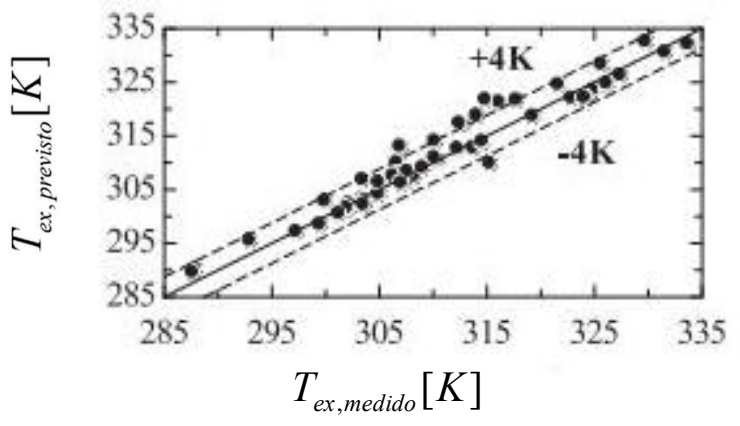

(c)

Fonte: Mendoza et al., 2014

Conforme observado, o modelo utilizado por Mendoza et al. (2014) apresentou baixa margem de erro (de 5 à 9\%) quando comparado aos resultados obtidos experimentalmente. Isso demonstra a validade do modelo para utilização do expansor do tipo Scroll para trabalhar com os fluidos estudados no trabalho e futuramente com diferentes fluidos. Com base nos resultados definiu-se que este seria o modelo a ser utilizado no presente trabalho.

Para o uso do modelo semi empírico, quatro parâmetros devem ser determinados, o volume da câmara de admissão $\left(V_{s u}\right)$, razão volumétrica $\left(r_{v}\right)$, potência mecânica das perdas por atrito $\left(\dot{W}_{\text {loss }}\right)$ e a área de vazamento $\left(A_{\text {leak }}\right)$. Os dois primeiros parâmetros são geométricos e foram definidos quando da concepção do expansor, sendo o volume da câmara de admissão igual a $75,12 \times 10^{-6} \mathrm{~m}^{3}$ e a razão volumétrica igual a 3. 
A área de vazamento teórica, considerando que a folga radial é igual a zero (vedação total com o uso dos selos de topo), é representada na figura 26. A mesma é função somente da geometria do conjunto de eixos excêntricos utilizados.

Figura 26 - Representação das folgas entre os scrolls. Dimensões em milímetros

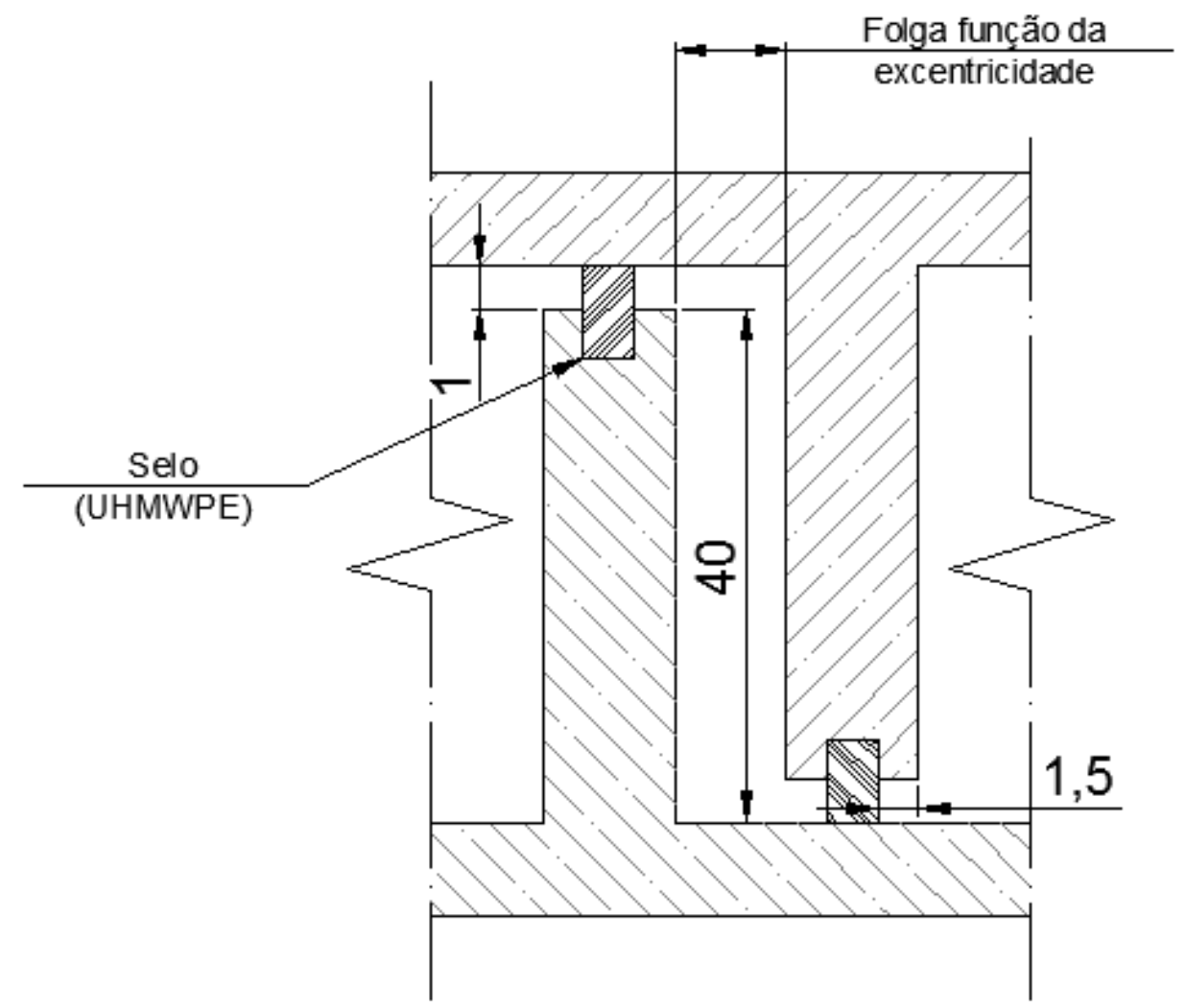

Fonte: Autor

Quando a área do orifício de admissão diminui consideravelmente, a vazão em massa que entra no expansor reduz, levando também a uma redução nos vazamentos. Com um aumento de rotação do expansor a frequência desta ocorrência diminui os vazamentos internos no expansor.

Para as perdas por atrito Mendoza et al. (2014) fizeram uso de um motor elétrico acoplado ao ETS, de forma que foi levantado uma curva de Potência de atrito em função da rotação, para o presente trabalho não determinado esta curva, sendo portanto as perdas por atrito não computadas. 


\section{RESULTADOS E DISCUSSÃO}

Esta seção mostra os resultados dos ensaios experimentais e faz uma discussão comparando-os com resultados obtidos por outros autores e disponíveis na literatura.

A exposição está dividida em seis subseções. Na primeira, é descrito e comentado um ensaio típico. Na segunda é apresentado a influência da rotação no desempenho do expansor. A terceira apresenta a influência das folgas no desempenho do expansor; na quarta se discorre sobre a propagação das incertezas, na quinta se faz a comparação entre o modelo analítico e os resultados experimentais e a sexta faz a avaliação do filling factor em função da rotação do expansor.

\subsection{ENSAIO TÍPICO}

O ensaio típico para a coleta de dados no experimento se faz com a alteração manual da pressão da rede de ar comprimido na entrada do expansor e definição da rotação via controlador de velocidade. Conforme se aumenta a pressão de alimentação de ar e a rotação do expansor, obtém-se respectivo aumento na potência disponível no eixo do expansor.

A pressão de descarga do expansor é a atmosférica, valor este medido em barômetro digital de fabricação KIMO Instruments, modelo MP55, o valor medido foi de $691,4 \mathrm{mmHg}$. A temperatura do ar na entrada do expansor foi medida com uso de um termopar fixado na linha de admissão de ar para o expansor, a temperatura ambiente observada durante os ensaios ficou entre $18^{\circ} \mathrm{C}$ e $20^{\circ} \mathrm{C}$. Observou-se que a temperatura da linha de ar comprimido oscilava poucas vezes em $1{ }^{\circ} \mathrm{C}$ abaixo da temperatura ambiente, e por um curto período de tempo.

A vazão de ar é medida com uso de dois medidores de vazão tipo turbina instalados em paralelo na linha de alimentação de ar. A rotação do expansor é medida com uso de um encoder e a força aplicada no braço por uma célula de carga. Todos os instrumentos se comunicam e são processados por um codificador e visualizados por um IHM. A taxa de aquisição de leitura dos dados foi de 0,2 segundos.

Foi utilizado o software EES para a avaliação de desempenho do expansor avaliandose os parâmetros Potência $(\dot{W})$, Eficiência isentrópica $\left(\eta_{s}\right)$ e Filling factor ( $\varphi$ - equação 1$)$ em função da relação de pressão ( $P s u / P e x)$. 
Os ensaios eram limitados em 12 minutos em função do aquecimento do disco do freio de Foucault, que pela proximidade poderia prejudicar o encoder de rotação em função da dissipação de calor para o mesmo (ambos ligados diretamente ao mesmo eixo).

A figura 27 apresenta os dados coletados durante um ensaio típico. Durante este ensaio a temperatura ambiente era de $18^{\circ} \mathrm{C}$ e o tempo total de ensaio durou 584 segundos. Pode-se verificar que o controlador de rotação que atua sobre o freio Foucault teve sucesso em manter este parâmetro constante ao longo do tempo. As pequenas variações de rotação observadas na figura 27 estão relacionadas a momentos em que se alterou a abertura da válvula para variação da pressão na entrada do expansor. Com o fechamento da válvula e redução da pressão na entrada do expansor, a rotação tende a reduzir. Neste instante, o controlador reduz a tensão nas bobinas do freio de forma a manter a rotação no valor especificado. 
Figura 27 - Representação dos dados obtidos durante o ensaio com eixo projetado para folga
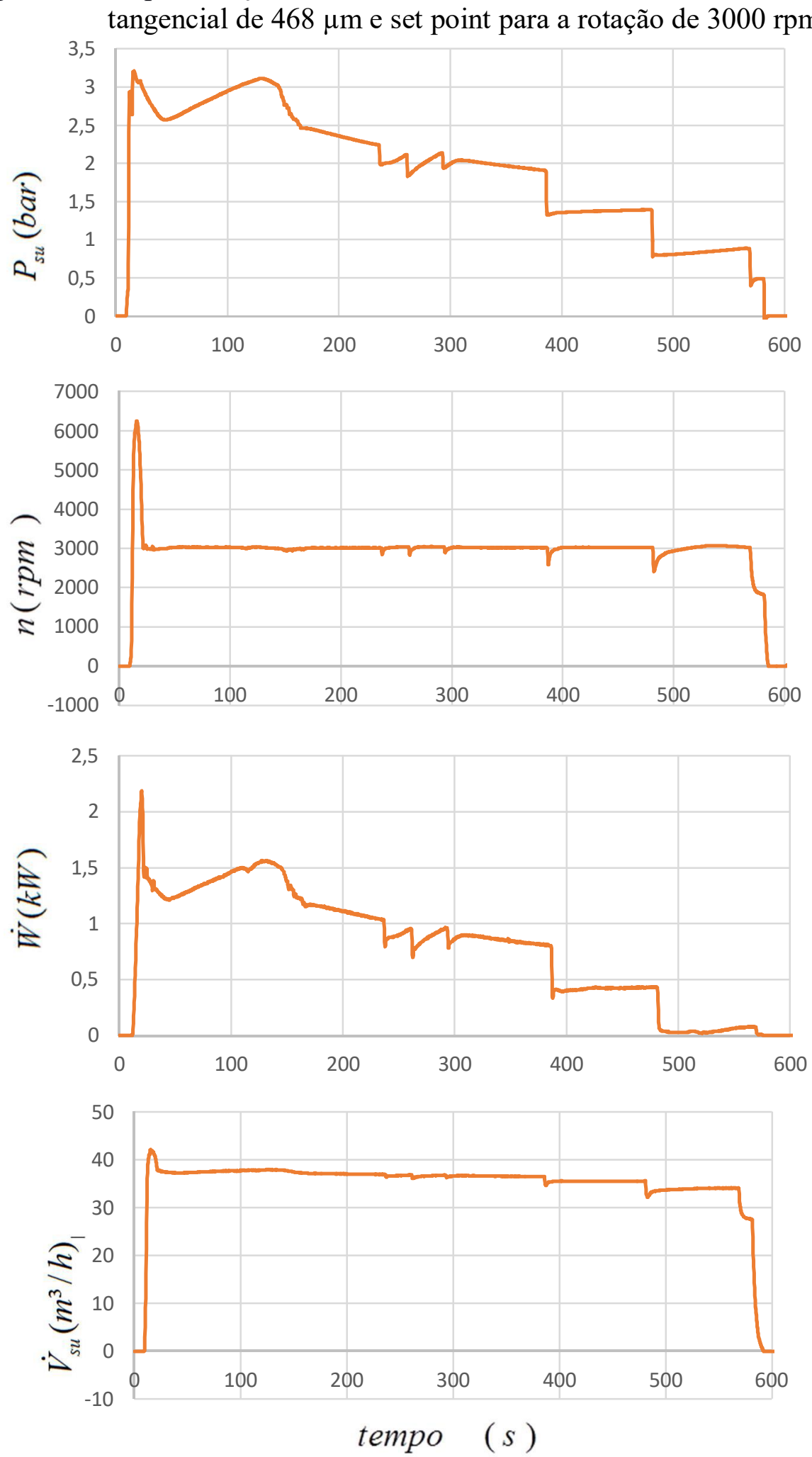

Fonte: Autor

Pelo gráfico obtido durante o ensaio apresentado na figura 27, observa-se que a pressão da linha de alimentação não se manteve estável ao longo do tempo. Isto se dá em função da partida do compressor de alimentação do sistema de ar comprimido dos 
laboratórios, onde verifica-se um aumento de pressão, assim como sua parada representa a queda de pressão no sistema pelo consumo do ar comprimido armazenado no reservatório. No início dos testes utilizou-se uma válvula reguladora de pressão na rede de ar, mas em função da elevada perda de carga decidiu-se por sua retirada.

Para o processamento dos dados via EES, foram avaliados os pontos apresentados no quadro 5. A seleção dos pontos foi feita quando da estabilização da rotação por parte do controlador de forma a se ter valores confiáveis.

Quadro 5 - Dados coletados durante o ensaio representado na figura 27

\begin{tabular}{|c|c|c|c|c|c|c|c|}
\hline Tempo (s) & $\begin{array}{c}\text { Célula } \\
\mathbf{( N )}\end{array}$ & $\begin{array}{c}\text { Psup } \\
(\mathbf{m B a r})\end{array}$ & $\begin{array}{c}\text { Rotação } \\
(\mathbf{r p m})\end{array}$ & $\begin{array}{c}\text { Vazão 2 } \\
\mathbf{( m 3 / h )}\end{array}$ & $\begin{array}{c}\text { Vazão 1 } \\
\mathbf{( m 3 / h )}\end{array}$ & $\begin{array}{c}\text { Potência } \\
(\mathbf{W a t t s})\end{array}$ & $\begin{array}{c}\text { Vazão Total } \\
\mathbf{( m 3 / h )}\end{array}$ \\
\hline 65,6 & 20,66 & 2702,73 & 3031,38 & 17,07 & 20,46 & 1311,45 & 37,53 \\
\hline 107,4 & 23,56 & 2992,61 & 3023,83 & 17,25 & 20,57 & 1492,24 & 37,82 \\
\hline 179,6 & 18,26 & 2433,85 & 3008,51 & 17,11 & 20,01 & 1150,51 & 37,12 \\
\hline 222,6 & 16,79 & 2281,09 & 3012,85 & 17,11 & 19,88 & 1059,16 & 36,99 \\
\hline 320,8 & 14,04 & 2025,08 & 3015,18 & 16,63 & 20,04 & 886,40 & 36,67 \\
\hline 363,4 & 13,15 & 1943,70 & 3017,61 & 16,55 & 20,01 & 830,79 & 36,56 \\
\hline 412,0 & 6,47 & 1365,05 & 3029,75 & 16,08 & 19,49 & 410,37 & 35,57 \\
\hline 452,0 & 6,78 & 1381,88 & 3020,35 & 16,06 & 19,48 & 428,81 & 35,54 \\
\hline 504,2 & 0,42 & 811,87 & 2956,41 & 15,07 & 18,70 & 26,31 & 33,77 \\
\hline 545,2 & 0,83 & 860,64 & 3067,41 & 15,13 & 18,96 & 53,32 & 34,09 \\
\hline
\end{tabular}

Fonte: Autor

Para os demais ensaios os valores foram apresentados no anexo 1.

\subsection{INFLUÊNCIA DA ROTAÇÃO}

Os demais ensaios foram realizados da mesma forma que o apresentado no subcapitulo anterior. As únicas diferenças entre os ensaios foram a rotação de operação e a excentricidade dos eixos, com a consequente alteração das folgas internas.

A partir dos pontos selecionados pode-se comparar o desempenho do expansor com folga tangencial de $468 \mu \mathrm{m}, 489 \mu \mathrm{m}$ e $165 \mu \mathrm{m}$, para diferentes modos de operação avaliados durante os ensaios. O motivo de se usar estes valores para as folgas já foi discutido na seção 3.1, e está relacionada ao processo de fabricação dos eixos.

Resultados apresentados pela literatura demonstram que há um aumento de potência conforme se aumenta a rotação e a pressão de entrada do expansor. Também pode ser observado o aumento de rendimento até o ponto ótimo, que no presente caso é representado pela relação de pressão de sucção pela pressão atmosférica (rp) igual a 4,65. Esta questão foi discutida anteriormente na seção 3.1 deste trabalho. Com o aumento da rotação também se 
espera o aumento do rendimento, já que este aumento minimiza a importância relativa dos vazamentos internos. Quanto ao filling factor, espera-se uma redução conforme se aumenta a rotação e aumento conforme maior a pressão na entrada do expansor, já que os vazamentos também aumentarão.

\subsubsection{Desempenho do expansor com folga tangencial de projeto igual a $468 \mu \mathrm{m}$ com diferentes rotações.}

A figura 28 apresenta a comparação no desempenho do expansor para uma folga tangencial igual a $468 \mu \mathrm{m}$ e rotação variando entre 1800 e $3000 \mathrm{rpm}$, com intervalos de 400 rpm. 
Figura 28 - Comparação de desempenho do expansor em função de diferentes rotações para uma mesma folga tangencial - $468 \mu \mathrm{m}$
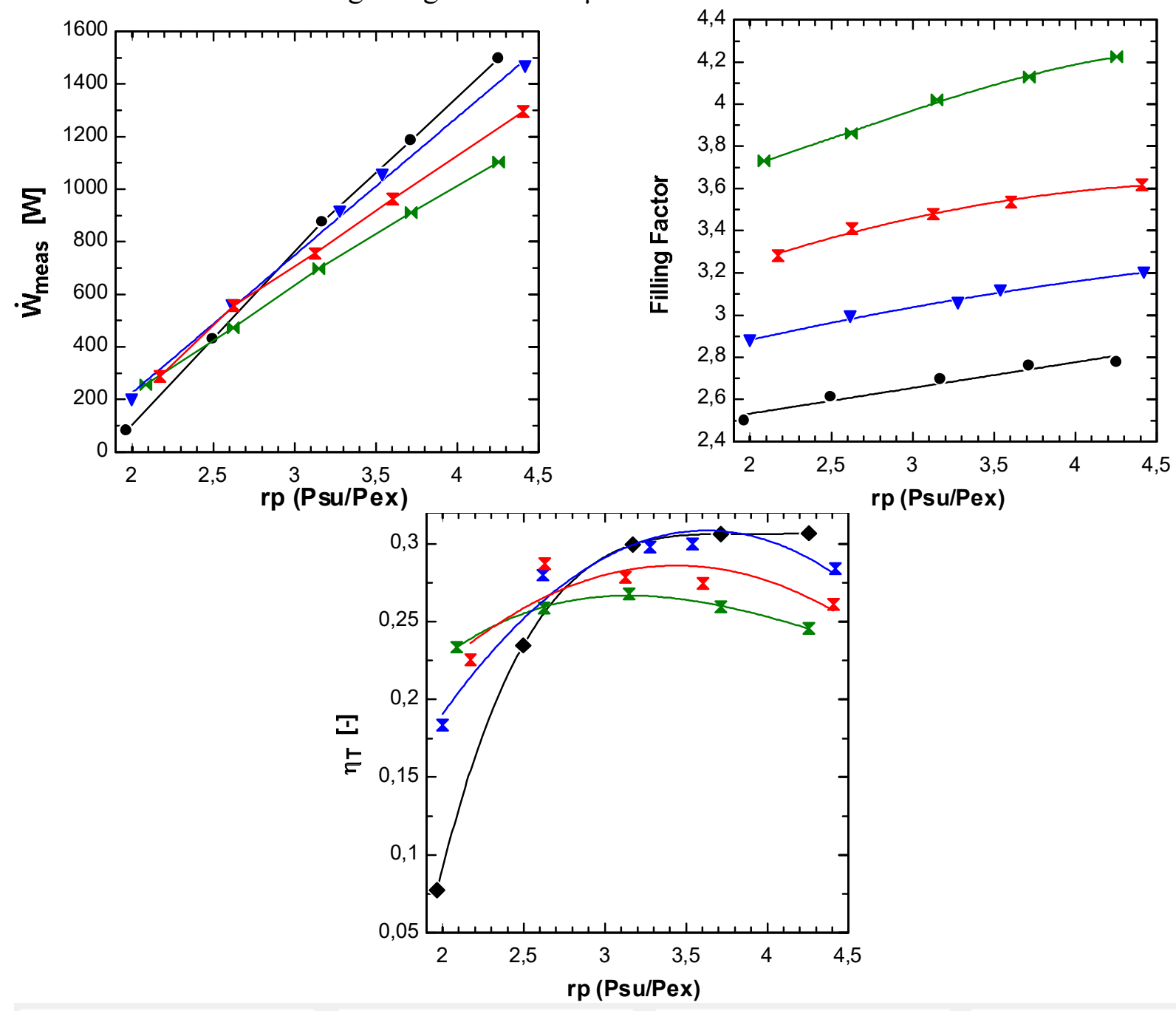

$3000 \mathrm{rpm}-468 \mu \mathrm{m}$

$2600 \mathrm{rpm}-468 \mu \mathrm{m}$

$1800 \mathrm{rpm}-468 \mu \mathrm{m}$

Fonte: Autor

Nota-se para os testes realizados que os resultados foram de acordo com o esperado, tendo somente um rendimento muito baixo para $3000 \mathrm{rpm}$ e relação de pressão igual a 2, o que se explica por este ponto estar muito fora da faixa de operação do equipamento e para o rendimento que apresentou o rendimento máximo entre a faixa de $\mathrm{rp}$ de 3,0 a 3,7 onde esperava-se este valor próximo a 4,65.

\subsubsection{Desempenho do expansor com folga tangencial de projeto igual a $489 \mu \mathrm{m}$ com diferentes rotações.}

A figura 29 apresenta a comparação no desempenho do expansor para uma folga tangencial igual a $489 \mu \mathrm{m}$ e rotação variando entre 1800 e $3000 \mathrm{rpm}$, com passo de $400 \mathrm{rpm}$. 
Figura 29 - Comparação de desempenho do expansor em função de diferentes rotações para uma mesma folga tangencial - $489 \mu \mathrm{m}$
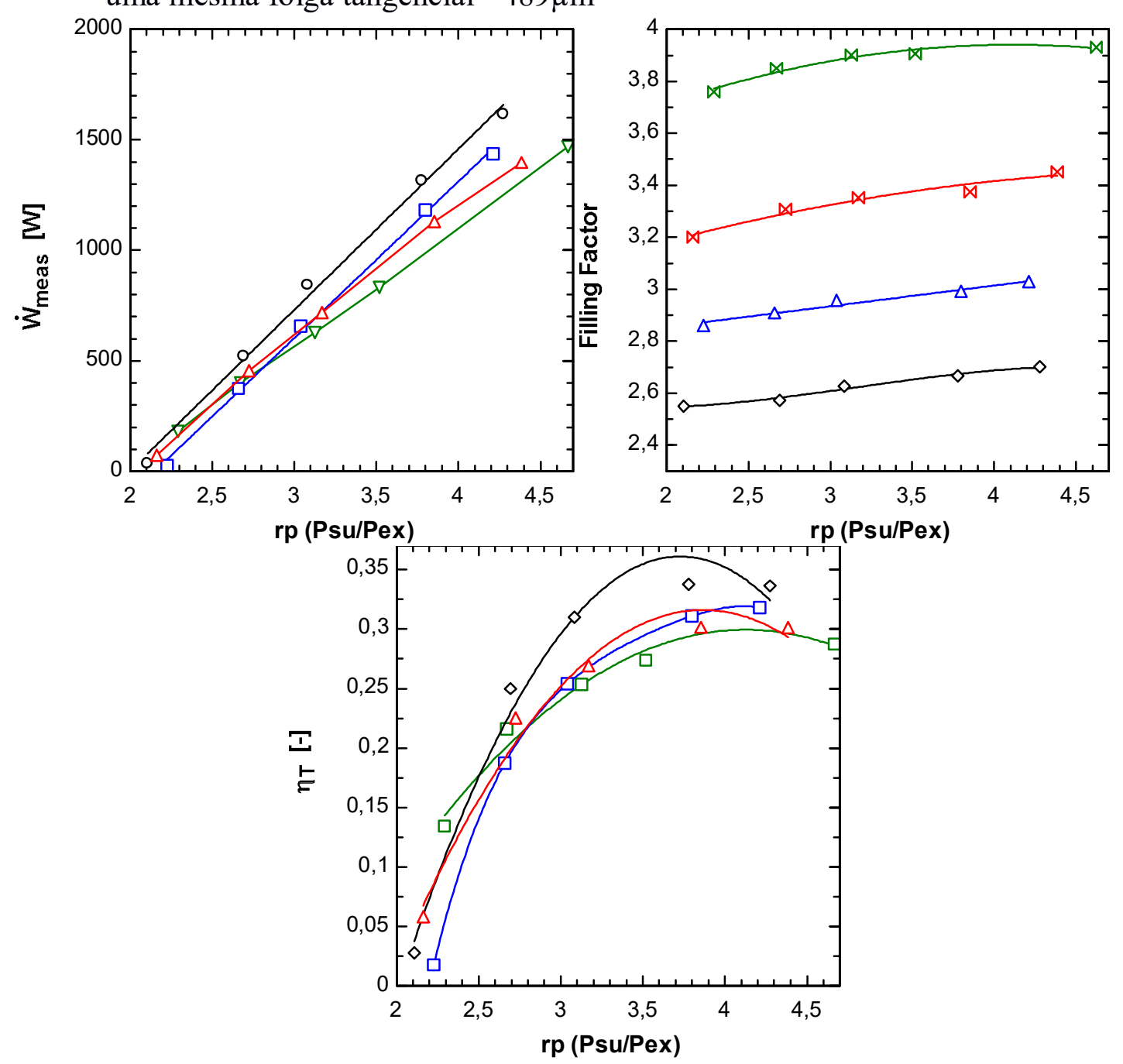

$\multimap-3000 \mathrm{rpm}-489 \mu \mathrm{m} \longrightarrow 2600 \mathrm{rpm}-489 \mu \mathrm{m} \longrightarrow-2200 \mathrm{rpm}-489 \mu \mathrm{m} \longrightarrow-\prec 1800 \mathrm{rpm}-489 \mu \mathrm{m}$ Fonte: Autor

Os resultados para o ensaio também foram de acordo com o esperado, exceto para o rendimento que apresentou o rendimento máximo entre a faixa de rp de 3,5 a 3,7 onde esperava-se este valor próximo a 4,65 .

\subsubsection{Desempenho do expansor com folga tangencial de projeto igual a $165 \mu \mathrm{m}$ com diferentes rotações.}

Para este conjunto de excêntricos não foi possível a realização do ensaio a $3000 \mathrm{rpm}$ em função de instabilidade do controlador de velocidade, que apresentou grandes oscilações nos modos automático e manual, desta forma os dados não teriam validade. $\mathrm{O}$ controlador de 
velocidade tem a capacidade de fornecer um valor máximo de corrente elétrica para as bobinas do freio. Durante a condução do teste a $3000 \mathrm{rpm}$ verificou-se que o controlador estava trabalhando próximo do seu limite de corrente, impossibilitando o controle adequado da rotação.

A figura 30 apresenta a comparação no desempenho do expansor para uma folga tangencial igual a $165 \mu \mathrm{m}$ e rotação variando entre $2600 \mathrm{rpm}$ e $1800 \mathrm{rpm}$, com passo de 400 rpm. 
Figura 30 - Comparação de desempenho do expansor em função de diferentes rotações para uma mesma folga tangencial - $165 \mu \mathrm{m}$
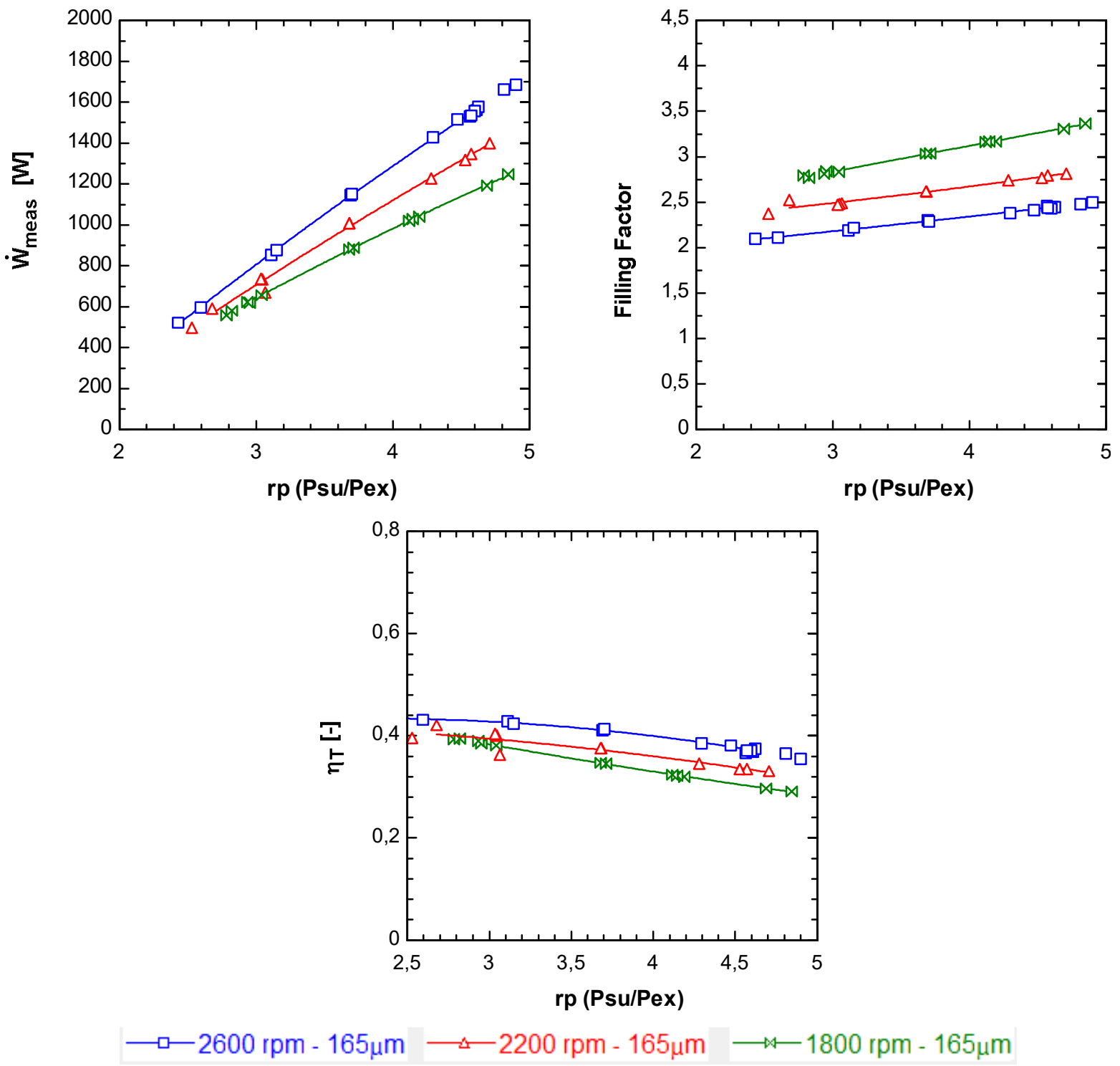

Fonte: Autor

Os resultados para a potência e filling factor seguiram o esperado. Para o rendimento esperava-se um aumento com ponto máximo próximo a rp igual a 4,65, mas o comportamento verificado nos três ensaios foi de redução praticamente linear. 


\subsection{INFLUÊNCIA DAS FOLGAS}

Nesta seção é apresentado o resultado comparativo de operação para eixos distintos com uma mesma rotação. Não é discutido este comparativo para a rotação de $3000 \mathrm{rpm}$ em função deste teste não ter sido possível de ser realizado para a folga de $165 \mu \mathrm{m}$. Para os outros conjuntos de eixos, que operaram a $3000 \mathrm{rpm}$ mas que apresentam excentricidade muito próximas, não se teria discussão. Este resultado é apresentado no anexo 2.

Espera-se que com a redução das folgas se tenha maior rendimento e menor filling factor, já que as folgas impactam negativamente no rendimento do expansor e o filling factor é um valor adimensional que expressa os vazamentos internos, que são diretamente ligados às folgas internas. Quanto à potência, a mesma não deve ser alterada significativamente em função das folgas já que depende da distribuição de pressão nas câmaras.

\subsubsection{Comparação de desempenho do expansor para uma rotação de $2600 \mathrm{rpm}$, mas com folgas tangenciais distintas.}

A figura 31 apresenta a comparação de desempenho do expansor para uma rotação de 2600rpm, mas com folgas tangenciais distintas. 
Figura 31 - Comparação de desempenho do expansor para uma rotação de 2600rpm, mas com folgas tangenciais distintas
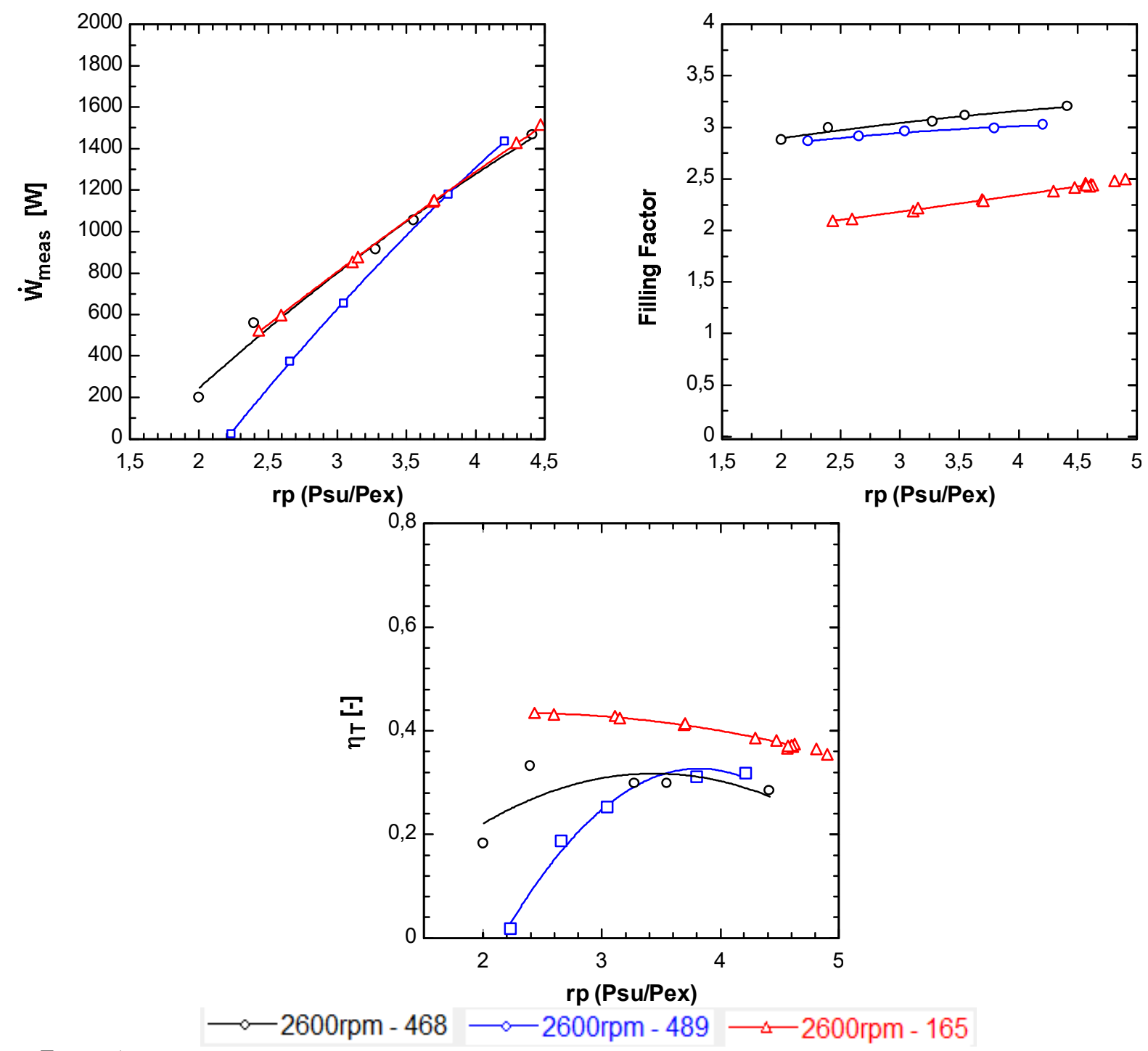

Fonte: Autor

Como previsto a potência entre eixos apresentou valores próximos. Para menores vazamentos (folgas internas) o filling factor foi menor e o rendimento maior.

4.3.2 Comparação de desempenho do expansor para uma rotação de 2200rpm, mas com folgas tangenciais distintas.

A figura 32 apresenta a comparação de desempenho do expansor para uma rotação de $2200 \mathrm{rpm}$, mas com folgas tangenciais distintas. 
Figura 32 - Comparação de desempenho do expansor para uma rotação de 2200rpm, mas com folgas tangenciais distintas
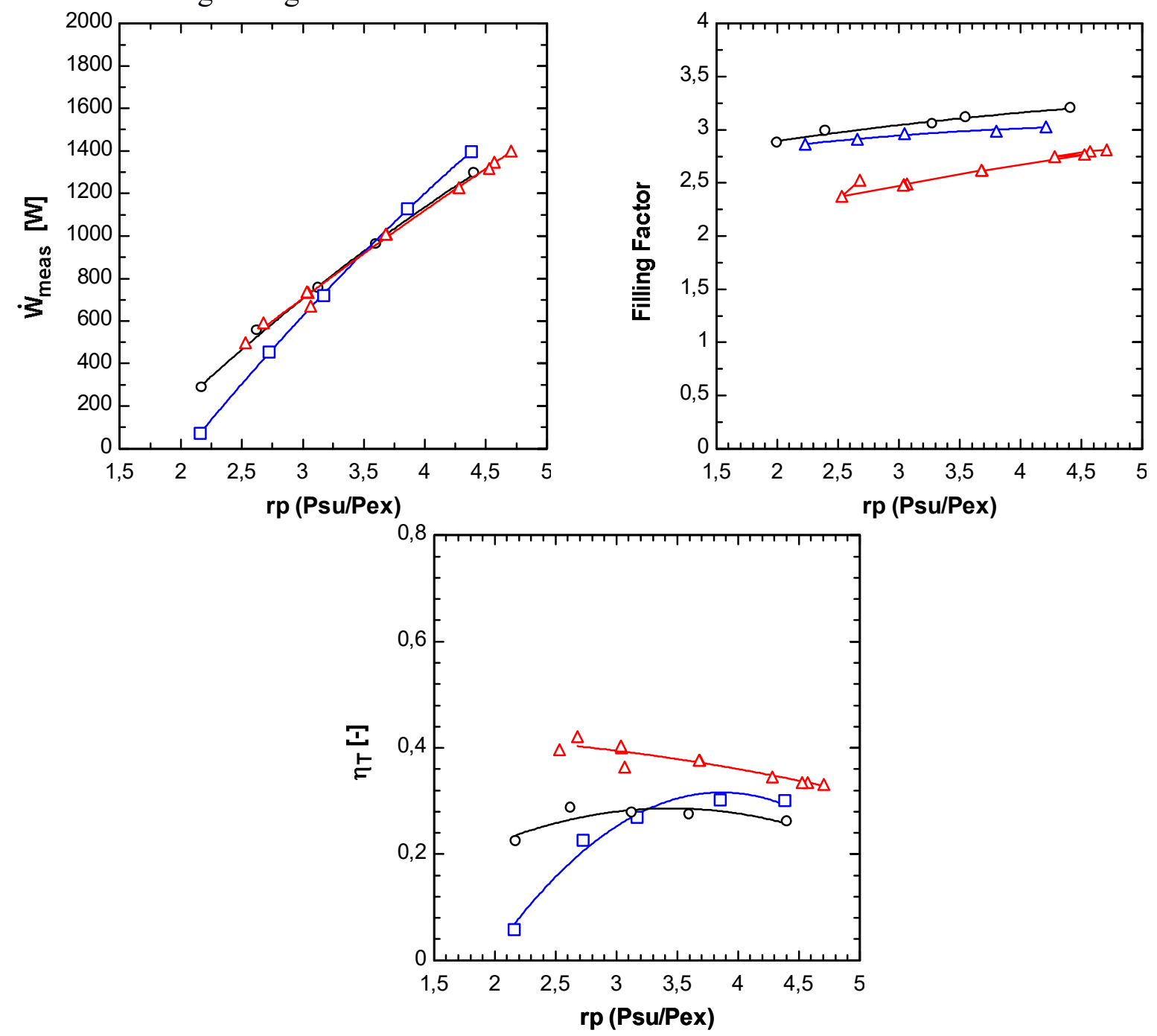

Fonte: Autor

$\multimap 2200 \mathrm{rpm}-468 \mu \mathrm{m} \longrightarrow-2200 \mathrm{rpm}-489 \mu \mathrm{m} \longrightarrow 2200 \mathrm{rpm}-165 \mu \mathrm{m}$

Como previsto a potência entre eixos apresentou valores próximos, para menores vazamentos (folgas internas) o filling factor foi menor e o rendimento maior.

4.3.3 Comparação de desempenho do expansor para uma rotação de 1800rpm, mas com folgas tangenciais distintas.

A figura 33 apresenta a comparação de desempenho do expansor para uma rotação de 1800rpm, mas com folgas tangenciais distintas. 
Figura 33 - Comparação de desempenho do expansor para uma rotação de 1800rpm, mas com folgas tangenciais distintas
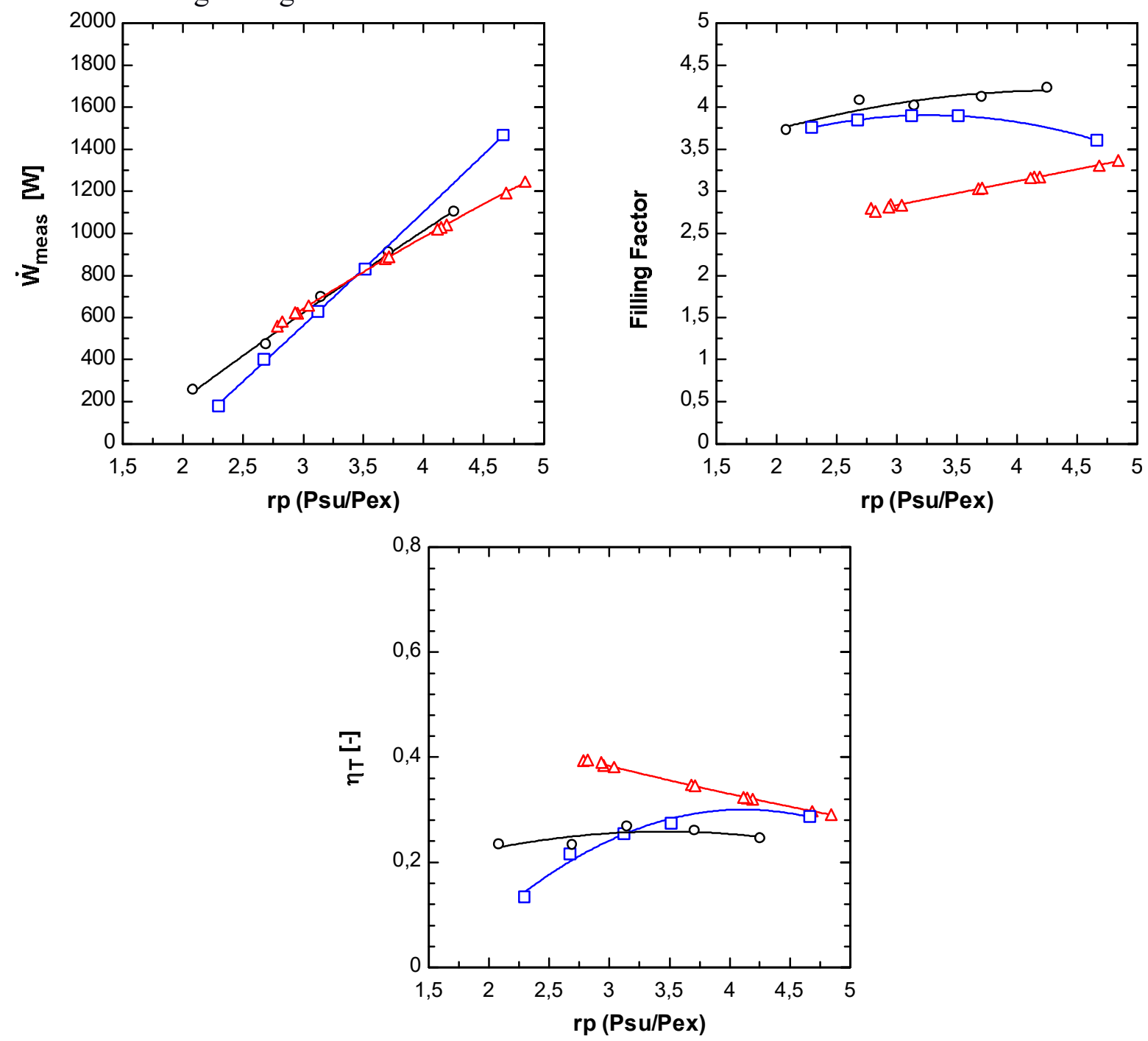

\section{$\multimap-1800 \mathrm{rpm}-468 \mu \mathrm{m} \longrightarrow \square-1800 \mathrm{rpm}-489 \mu \mathrm{m} \longrightarrow 1800 \mathrm{rpm}-165 \mu \mathrm{m}$}

Fonte: Autor

Como previsto a potência entre eixos apresentou valores próximos, para menores vazamentos (folgas internas) o filling factor foi menor e o rendimento maior. 


\subsection{ANÁLISE DE PROPAGAÇÃO DAS INCERTEZAS}

Sendo este trabalho continuidade do realizado por Fanti (em fase de elaboração) ${ }^{1}$, são apresentadas no quadro 6 as incertezas relativas dos parâmetros que estão sendo estudados e que já haviam sido avaliados por Fanti. Estes valores foram obtidos a partir da incerteza de cada um dos instrumentos e do modelo em EES para a propagação de erros elaborado por Fanti.

Quadro 6 - Incertezas dos parâmetros medidos

\begin{tabular}{|l|c|r|}
\hline Parâmetro & Símbolo & Incerteza \\
\hline Potência do eixo & $\dot{W}_{s h}$ & $2.9 \%$ \\
\hline Eficiência isentrópica & $\eta_{s}$ & $6.8 \%$ \\
\hline Filling factor & $\varphi$ & $1.5 \%$ \\
\hline Vazão em massa & $\dot{m}$ & $2.6 \%$ \\
\hline
\end{tabular}

Fonte: Fanti (em fase de elaboração) ${ }^{1}$

A figura 34 apresenta a eficiência isentrópica para a comparação dos eixos com uma rotação de $2600 \mathrm{rpm}$, mostrando graficamente a incerteza da eficiência isentrópica, resultado que apresenta maior incerteza relativa.

Figura 34 - Comparação de desempenho do expansor para uma rotação de 2600rpm, mas com folgas tangenciais distintas, incluindo as incertezas

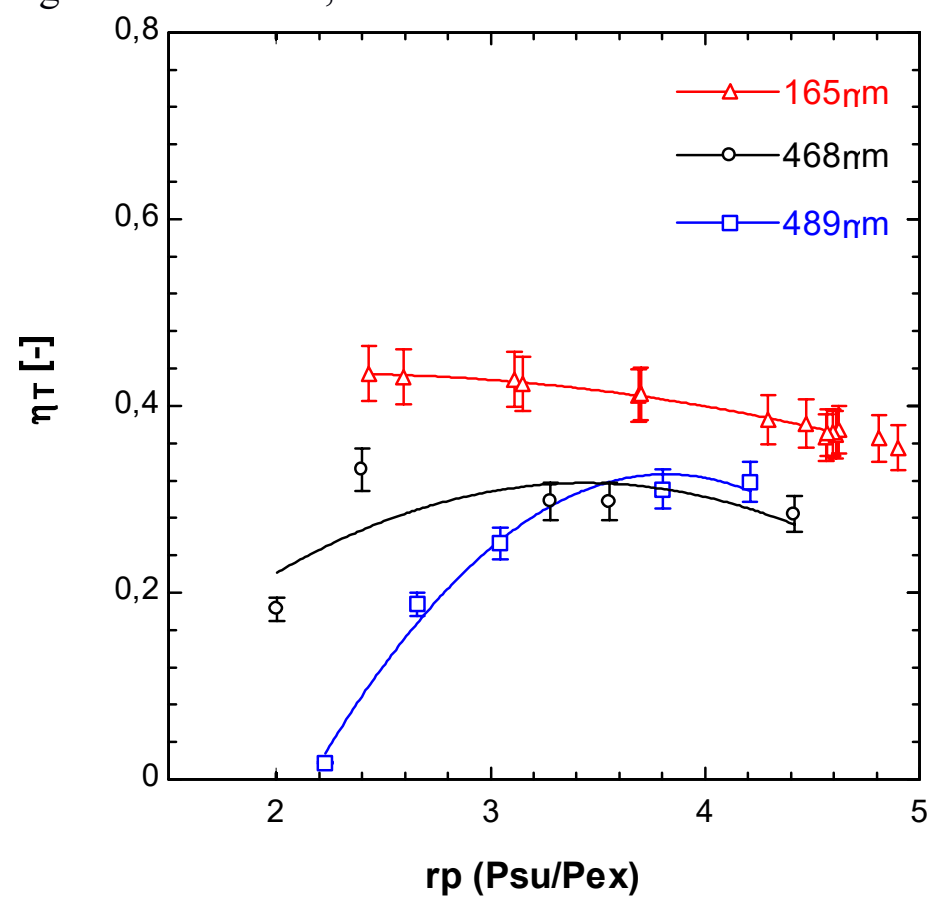

Fonte: Autor 
Como observado, a influência das incertezas para os eixos que são muito parecidos faz com que as diferenças medidas fiquem mais próximas para a faixa entre 3 e 4,2 da rp, faixa esta próxima da condição de projeto. Para os eixos de $165 \mu \mathrm{m}$ a incerteza inferior aproxima os resultados com os outros eixos, mas ainda demonstra desempenho superior para as menores folgas.

\subsection{COMPARAÇÃO COM MODELO ANALÍTICO}

O modelo analítico aqui tratado é o mesmo apresentado no capitulo 3, seção 3, com a diferença de não serem consideradas as perdas mecânicas, que não foram avaliadas para o protótipo construído. Utilizou-se o software EES para a comparação entre o modelo analítico e o experimental, onde o anexo 3 apresenta o algoritmo desenvolvido.

Optou-se por apresentar somente a comparação da menor folga $(165 \mu \mathrm{m})$ em função da grande extensão de dados obtidos. As demais comparações são apresentadas no anexo 4.

Em função de não se ter determinado no experimento a avaliação das perdas mecânicas espera-se um acréscimo de desvio entre os resultados.

\subsubsection{Comparação entre modelo analítico e resultado experimental para folga de $165 \mu \mathrm{m}$ e rotação de $2600 \mathrm{rpm}$}

A figura 35 apresenta as comparações entre o modelo analítico e experimental para as folgas de $165 \mu \mathrm{m}$ e $2600 \mathrm{rpm}$. 
Figura 35 - Comparação entre o modelo analítico e o experimental para folga de $165 \mu \mathrm{m}$ e rotação de $2600 \mathrm{rpm}$
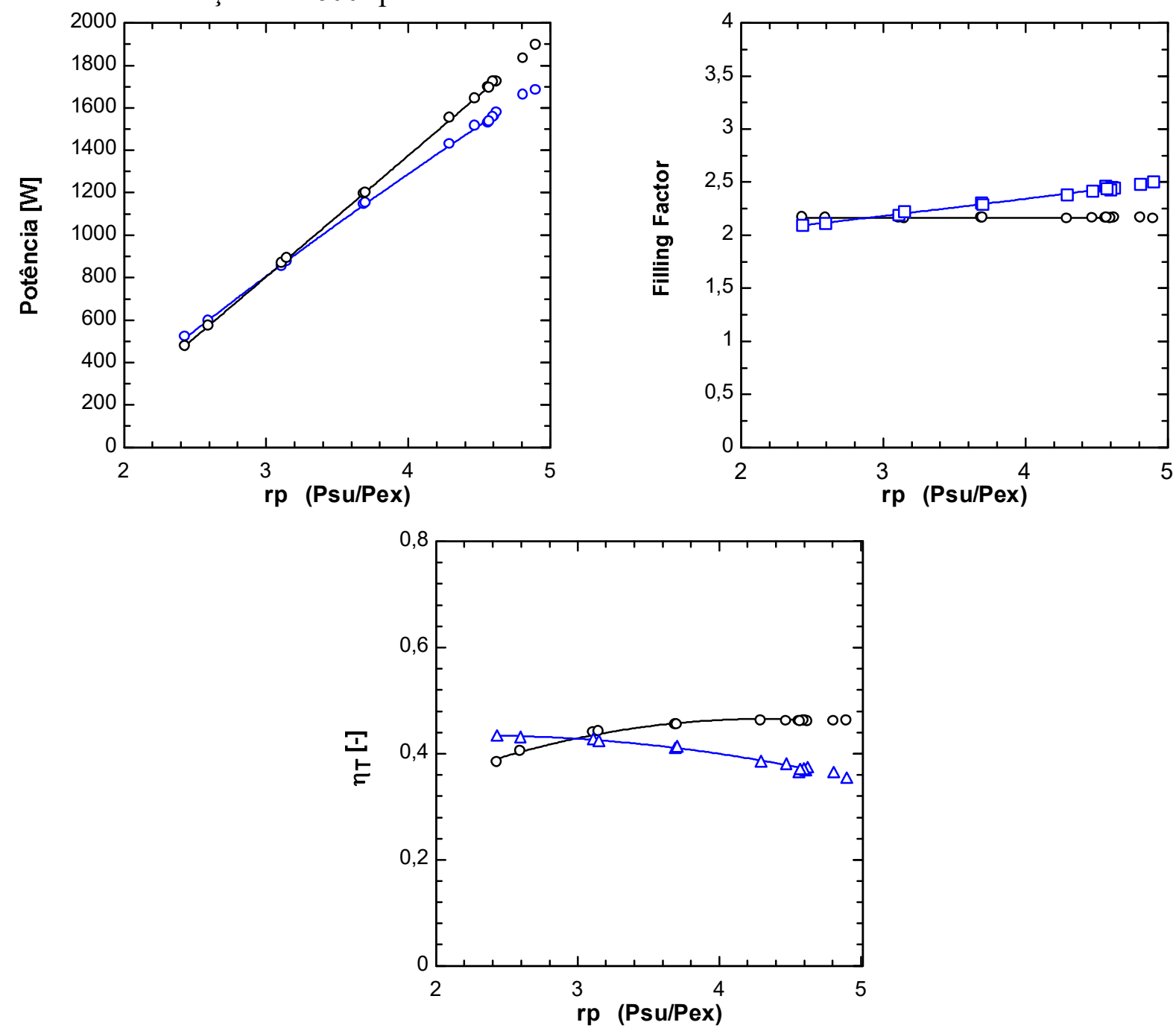

$\multimap$ Anal tico $165 \mu \mathrm{m} 2600 \mathrm{rpm} \longrightarrow$ Experimertal $165 \mu \mathrm{m} 2600 \mathrm{rpm}$

Fonte: Autor

Observa-se que o desvio entre a potência para modelo analítico e os resultados experimentais foram baixos, com $9,5 \%$ para $\mathrm{rp}=4,6$, apesar de não se ter incluído as perdas mecânicas. Para o filling factor e a eficiência isentrópica o modelo analítico apresenta melhor desempenho que o observado experimentalmente, mas não ocorrendo grandes discrepâncias.

4.5.2 Comparação entre modelo analítico e resultado experimental para folga de $165 \mu \mathrm{m}$ e rotação de $2200 \mathrm{rpm}$ 
A figura 36 apresenta as comparações entre o modelo analítico e experimental para as folgas de $165 \mu \mathrm{m}$ e $2200 \mathrm{rpm}$.

Figura 36 - Comparação entre o modelo analítico e o experimental para folga de $165 \mu \mathrm{m}$ e
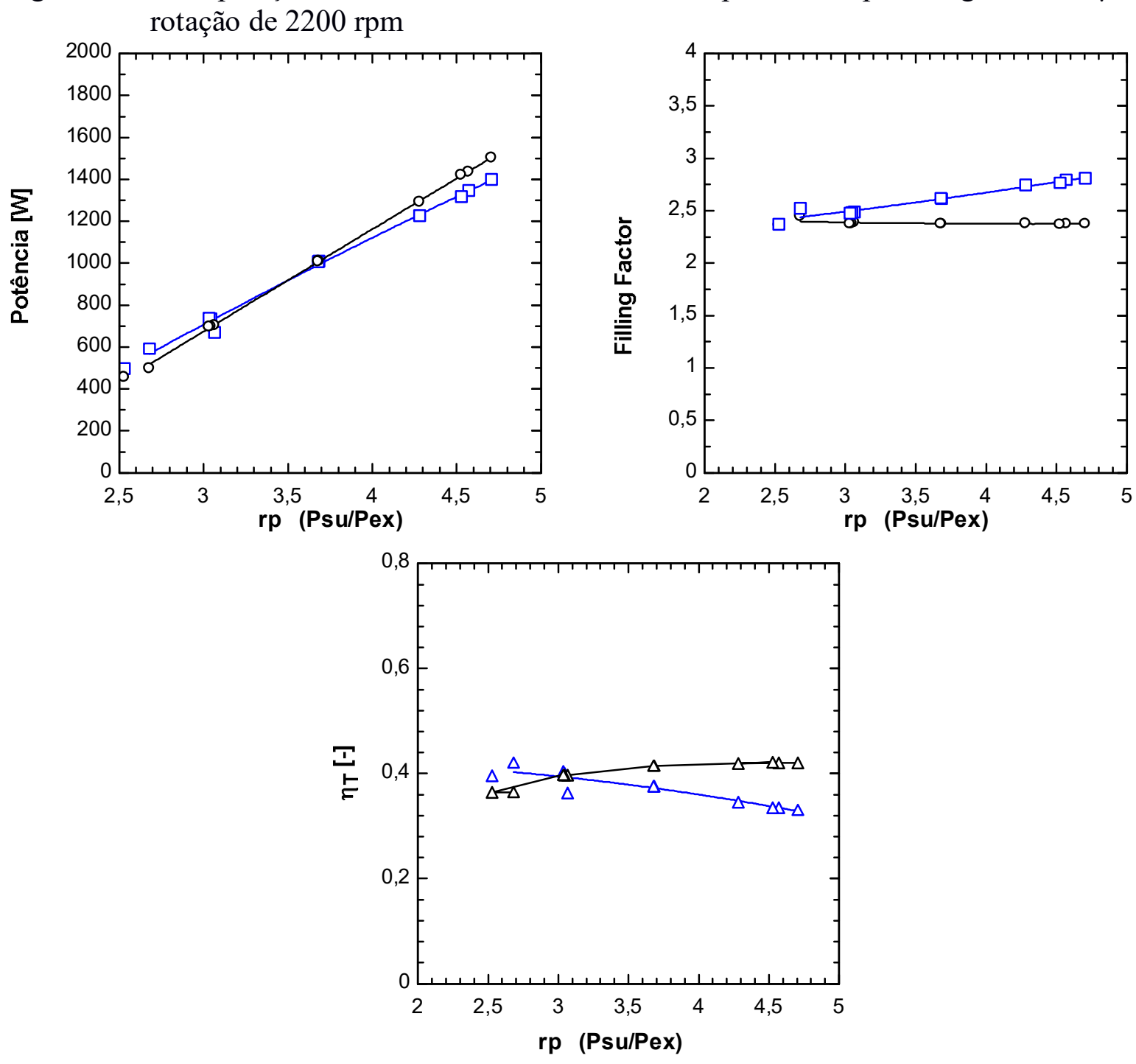

—Anal tico $165 \mu \mathrm{m} 2200 \mathrm{rpm} \quad \square$ Experimertal $165 \mu \mathrm{m} 2200 \mathrm{rpm}$

Fonte: Autor

Observa-se que o desvio entre a potência para modelo analítico e os resultados experimentais foram baixos, com valor de $7 \%$ para a relação rp de 4,7 , apesar de não se ter incluído as perdas mecânicas. Para o filling factor e a eficiência isentrópica o modelo analítico apresenta melhor desempenho que o observado experimentalmente, mas não ocorrendo grandes discrepâncias. 


\subsubsection{Comparação entre modelo analítico e resultado experimental para folga de $165 \mu \mathrm{m}$} e rotação de $1800 \mathrm{rpm}$

A figura 37 apresenta as comparações entre o modelo analítico e experimental para as folgas de $165 \mu \mathrm{m}$ e $1800 \mathrm{rpm}$.

Figura 37 - Comparação entre o modelo analítico e o experimental para folga de $165 \mu \mathrm{m}$ e rotação de $1800 \mathrm{rpm}$
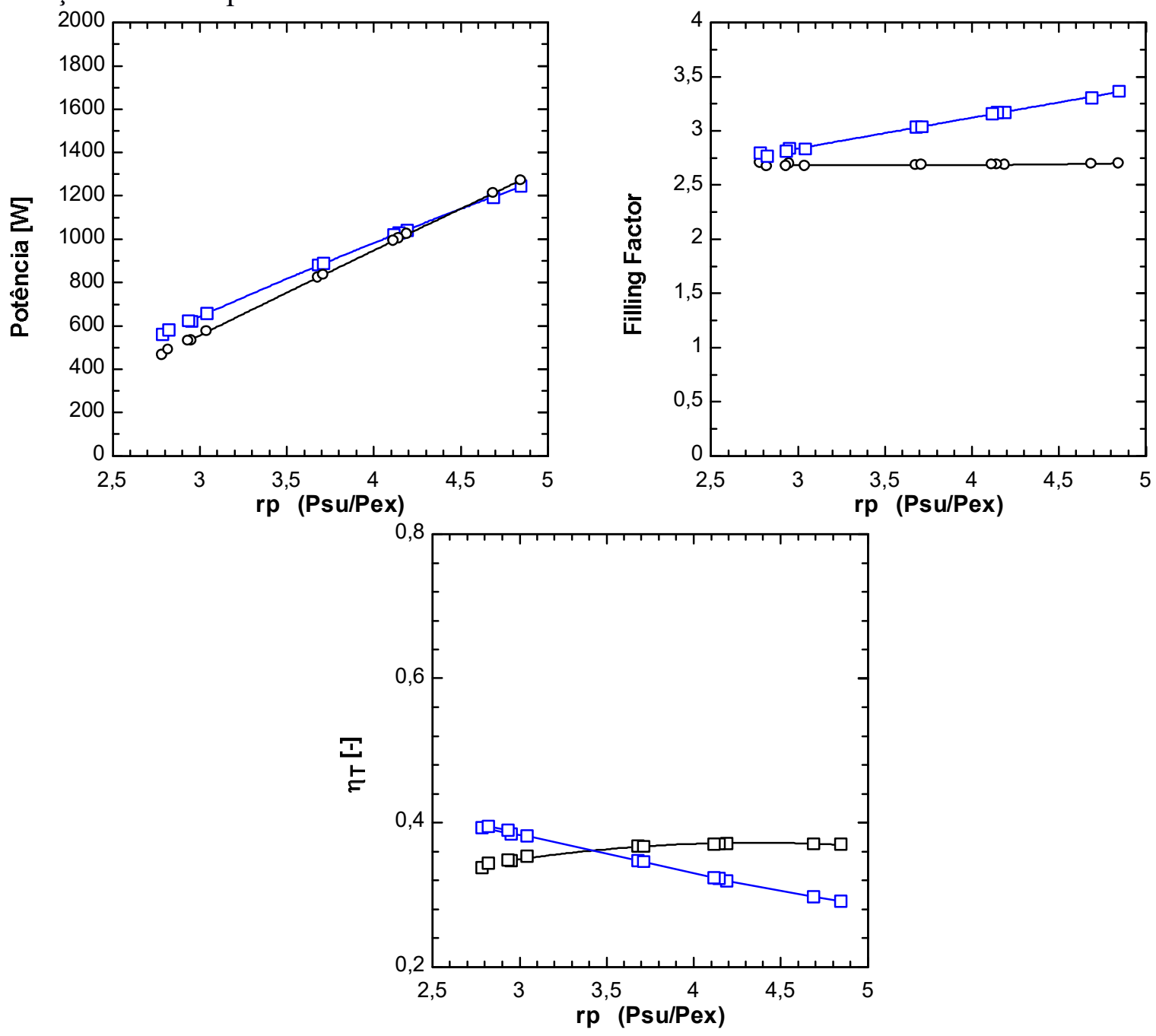

$\multimap$ Anal tico $165 \mu \mathrm{m} 1800 \mathrm{rpm} \longrightarrow$ - Experimertal $165 \mu \mathrm{m} 1800 \mathrm{rpm}$

Fonte: Autor

Observa-se que o desvio entre a potência para modelo analítico e os resultados experimentais foram baixos, com valor de 7\% para a relação rp de 3,5. Para o filling factor e a eficiência isentrópica o modelo analítico apresenta melhor desempenho que o observado experimentalmente, mas não ocorrendo grandes discrepâncias. 


\subsection{AVALIAÇÃO DO FILLING FACTOR EM FUNÇÃO DA ROTAÇÃO}

Nesta seção será apresentado a avaliação do filling factor em função da rotação para o eixo de $165 \mu \mathrm{m}$. Espera-se que com o aumento de rotação o filling factor diminua, já que com este aumento de vazão a influência dos vazamentos não aumenta proporcionalmente a vazão de entrada do expansor, ou seja, os vazamentos não aumentam na mesma proporção que a vazão de entrada.

A figura 38 apresenta a curva do filling factor pela rotação, para o eixo de $165 \mu \mathrm{m}$. Observa-se que o comportamento está de acordo com o previsto, aumentando-se a vazão diminui-se o filling factor. $\mathrm{O}$ valor obtido demostra que se poderia ter melhor rendimento do expansor já que o filling factor muito superior a 1 representa grande presença de vazamentos internos.

Figura 38 - Avaliação do filling factor pela rotação, para o eixo de $165 \mu \mathrm{m}$.

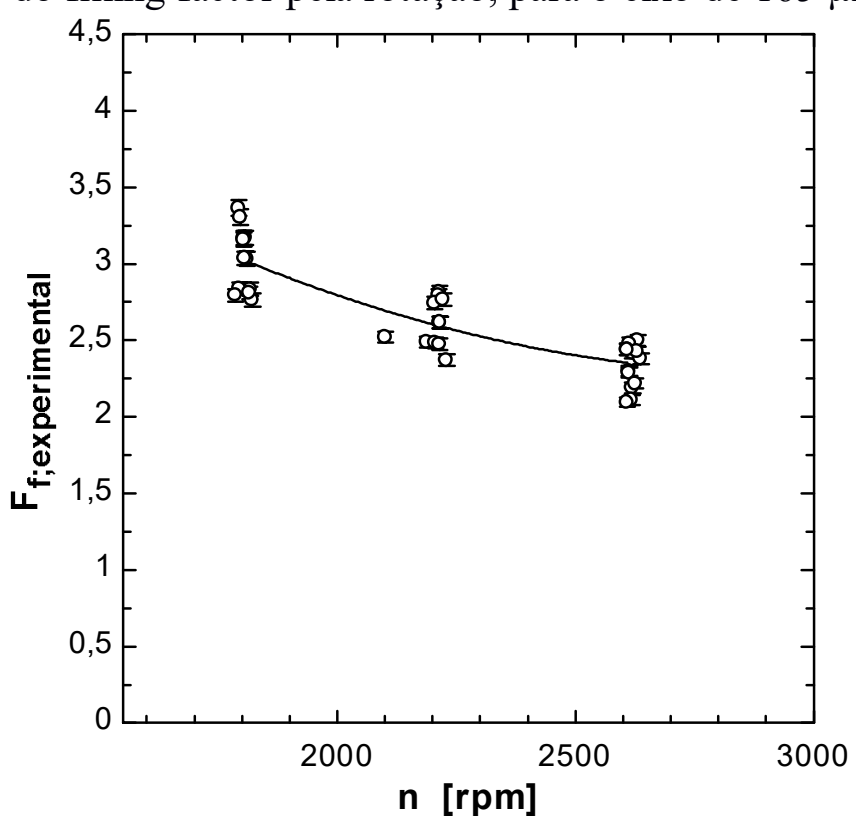

Fonte: Autor

A dispersão entre pontos para uma mesma rotação é função da pressão de operação na entrada ser diferente entre pontos a mesma rotação. 


\section{CONCLUSÕES}

O objetivo do presente trabalho era dar continuidade ao trabalho de Fanti (em fase de elaboração $)^{1}$ visando estudar a influência das folgas no desempenho do equipamento. No trabalho de Fanti (em fase de elaboração) ${ }^{1}$ um único conjunto de eixos excêntricos foi construído, com folga especificada de $200 \mu \mathrm{m}$. Para alcançar este objetivo, no presente trabalho foram construídos dois conjuntos adicionais de eixos excêntricos, projetados para a excentricidade de $100 \mu \mathrm{m}$ e $50 \mu \mathrm{m}$.

A medição no laboratório de metrologia realizada para estes conjuntos de eixos, assim como para o utilizado por Fanti, apresentaram desvios em relação ao projetado sendo que os eixos que deveriam ter $200 \mu \mathrm{m}$ e $100 \mu \mathrm{m}$ de folga apresentaram medição final muito próximas, com $468 \mu \mathrm{m}$ e $489 \mu \mathrm{m}$ respectivamente. Como o terceiro conjunto de eixos excêntricos apresentou $165 \mu \mathrm{m}$ folga, se conseguiu fazer a verificação da influência das folgas para praticamente dois valores distintos. Não foi possível a construção de novos conjuntos de eixos em função de indisponibilidade do serviço do Centro de Laboratórios Mecânicos do Centro Universitário da FEI.

Como resultado foi possível avaliar o desempenho do expansor quanto à potência, ao filling factor e ao rendimento isentrópico para as três diferentes folgas. Para um mesmo conjunto de eixos pode-se avaliar o comportamento do expansor com a variação de rotação e comparar o desempenho entre eixos distintos.

Além das verificações obtidas experimentalmente, estes resultados foram comparados com um modelo analítico disponível na literatura, com adaptações. Para o modelo analítico, o autor do mesmo ajustou a área de vazamento $\left(A_{\text {leak }}\right)$ para atender à vazão de vazamento $\left(\dot{m}_{\text {leak }}\right)$, assim como se considerou que todo vazamento presente era de flanco. Para o presente trabalho, por se ter fabricado o expansor no centro universitário a FEI, se conhecia a geometria. Portanto, a área de vazamento $\left(A_{\text {leak }}\right)$ e os vazamentos considerados foram de flanco e parte do de topo, já que para este segundo se tem uma difícil medição. Como resultado os desvios ficaram maiores no presente trabalho em comparação com o utilizado como referência para o modelo analítico, mas apresentando uma boa concordância.

Os ensaios realizados comprovaram o apresentado pela literatura referente à influência das folgas no desempenho dos expansores tipo scroll, onde se espera maior eficiência e menor filling factor para menores folgas internas e maiores potências para maiores pressões de alimentação na entrada do expansor. 
O número reduzido de conjuntos de eixos excêntricos comprometeu a análise conduzida no presente trabalho, ainda mais se for considerado que dois dos conjuntos são praticamente idênticos. Com o intuito de melhorar a análise conduzida, sugere-se a repetição destes testes com maior variação entre folgas, podendo melhor demonstrar a sua influência. Seria desejável entender melhor o processo de fabricação dos eixos excêntricos para se controlar adequadamente as dimensões desejadas, possibilitando uma reavaliação mais detalhada e definitiva.

Quanto ao selo de topo, foram verificados dois modelos: um fabricado na impressora 3D sendo o material Nylon e outro modelo fabricado na máquina de corte à jato d'agua sendo o material UHMWPE. O de nylon apresentou maiores vazamentos apesar do processo de fabricação ser mais preciso, motivo pelo qual optou-se pelo UHMWPE, mas o mesmo pode ser melhorado em função do seu processo de fabricação não garantir planicidade. Provavelmente o mesmo contém variações de medida, que fazem como que apareçam vazamentos de topo, sendo esta outra oportunidade de melhora para estudos futuros.

O controlador de velocidade utilizado apresentou problemas de controle para a rotação de $3000 \mathrm{rpm}$ e folga de $165 \mu \mathrm{m}$. A causa provável é que a corrente que deve alimentar as bobinas para gerar o torque contrário ao movimento pelo freio de Foucault estava no limite do aparelho, não sendo possível se operar estavelmente nesta condição. Possivelmente, se eixos com folga inferior a $165 \mu \mathrm{m}$ forem testados futuramente, o mesmo problema será observado com o controlador se não forem tomadas providências.

O trabalho apresenta possibilidades para a sua continuidade, embora os resultados obtidos estejam de acordo com similares encontrados na literatura. 


\section{REFERÊNCIAS}

BELL, Ian H. et al. Optimization of a scroll compressor for liquid flooding. International journal of refrigeration, v. 35, n. 7, p. 1901-1913, 2012.

BLUNIER, B. et al. A new analytical and dynamical model of a Scroll compressor with experimental validation. International Journal of Refrigeration, v. 32, n. 5, p. 874-891, 2009.

CREUX, Leon. Rotary engine. U.S. Patent n. 801,182, 3 out. 1905.

DECLAYE, Sébastien et al. Experimental study on an open-drive Scroll expander integrated into an ORC (Organic Rankine Cycle) system with R245fa as working fluid. Energy, v. 55, p. 173-183, 2013.

DUTTA, Asit K.; YANAGISAWA, Tadashi; FUKUTA, Mitsuhiro. An investigation of the performance of a Scroll compressor under liquid refrigerant injection. International Journal of Refrigeration, v. 24, n. 6, p. 577-587, 2001.

GIUFFRIDA, Antonio. Modelling the performance of a Scroll expander for small organic Rankine cycles when changing the working fluid. Applied Thermal Engineering, v. 70, n. 1, p. 1040-1049, 2014.

GRAVESEN, Jens; HENRIKSEN, Christian. The geometry of the Scroll compressor. Siam Review, v. 43, n. 1, p. 113-126, 2001.

IGLESIAS, A.; FAVRAT, D. Innovative isothermal oil-free co-rotating Scroll compressorexpander for energy storage with first expander tests. Energy Conversion and Management, v. 85, p. $565-572,2014$.

KILLEDAR, Jyotindra S. Dynamometer: Theory and Application to Engine Testing. Xlibris Corporation, 2012.

LEMORT, Vincent; QUOILIN, Sylvain; LEBRUN, Jean. Numerical simulation of a Scroll Expander for Use in a Rankine Cycle. In: INTERNATIONAL COMPRESSOR

ENGINEERING CONFERENCE, $19^{\text {th }}, 2008$, Disponivel em:

$<$ http://orbi.ulg.ac.be/handle/2268/1307>. Acesso em: 29 Mar.2017.

LEMORT, Vincent et al. Testing and modeling a Scroll expander integrated into an Organic Rankine Cycle. Applied Thermal Engineering, v. 29, n. 14, p. 3094-3102, 2009.

MCCULLOUGH, John E.; HIRSCHFELD, Fritz. The Scroll machine- An old principle with a new twist. Mechanical Engineering, v. 101, p. 46-51, 1979.

MENDOZA, Luis Carlos et al. Characterization and modeling of a Scroll expander with air and ammonia as working fluid. Applied Thermal Engineering, v. 70, n. 1, p. 630-640, 2014.

ORALLI, E. et al. A study on Scroll compressor conversion into expander for Rankine cycles. International Journal of Low-Carbon Technologies, v. 6, n. 3, p. 200-206, 2011. 
QUOILIN, Sylvain et al. Dynamic modeling and optimal control strategy of waste heat recovery Organic Rankine Cycles. Applied Energy, v. 88, n. 6, p. 2183-2190, 2011.

QUOILIN, Sylvain et al. Techno-economic survey of Organic Rankine Cycle (ORC) systems. Renewable and Sustainable Energy Reviews, v. 22, p. 168-186, 2013.

SONG, Panpan et al. A review of Scroll expanders for organic Rankine cycle systems. Applied Thermal Engineering, v. 75, p. 54-64, 2015.

SUN, Hao; LUO, Xing; WANG, Jihong. Feasibility study of a hybrid wind turbine systemIntegration with compressed air energy storage. Applied Energy, v. 137, p. 617-628, 2015.

YANAGISAWA, Tadashi et al. Performance of an oil-free Scroll-type air expander. In: PROC. OF THE IMECHE CONF. TRANS. ON COMPRESSORS AND THEIR SYSTEMS. 2001. p. 167-174.

ZANELLI, Robert; FAVRAT, Daniel. Experimental investigation of a hermetic Scroll expander-generator. In: INTERNATIONAL COMPRESSOR ENGINEERING CONFERENCE. 1994. Disponível em:

$<$ http://docs.lib.purdue.edu/cgi/viewcontent.cgi?article=2020\&context=icec $>$. Acesso em: 29 Mar.2017 


\begin{tabular}{|c|c|c|c|c|c|c|c|c|c|}
\hline \multirow{4}{*}{8} & $\Sigma$ & 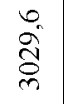 & $\overrightarrow{\overrightarrow{\vec{D}}}$ & 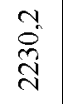 & $\begin{array}{l}\overrightarrow{0} \\
\stackrel{\vec{\infty}}{\mathscr{\infty}}\end{array}$ & 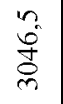 & $\overrightarrow{\overrightarrow{\hat{O}}}$ & $\begin{array}{l}\text { 导 } \\
\underset{\sim}{\sim}\end{array}$ & 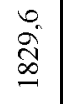 \\
\hline & $\equiv$ & $\begin{array}{l}0 \\
\infty\end{array}$ & $\begin{array}{l}\vec{\infty} \\
\stackrel{0}{\triangle}\end{array}$ & $\begin{array}{l}{ }_{2} \\
\stackrel{0}{\infty} \\
\sim \\
\sim\end{array}$ & $\begin{array}{l}\ddot{b} \\
\ddot{n}\end{array}$ & $\begin{array}{l}0 \\
m \\
m\end{array}$ & $\begin{array}{l}m \\
\stackrel{d}{d}\end{array}$ & $\frac{a}{i}$ & $\begin{array}{l}\dot{\hat{0}} \\
\dot{\infty}\end{array}$ \\
\hline & $\therefore$ & Ff & $\vec{m}$ & $\stackrel{\leftrightarrow}{m}$ & 今े & 얼 & $\stackrel{0}{\infty}$ & $\underset{\text { di }}{+}$ & $\stackrel{\circ}{-}$ \\
\hline & $\stackrel{\bar{z}}{2}$ & $\begin{array}{l}\vec{J} \\
\stackrel{\infty}{\infty} \\
\infty\end{array}$ & $\begin{array}{l}\stackrel{ }{ \pm} \\
\stackrel{2}{\alpha}\end{array}$ & $\begin{array}{l}\overrightarrow{\tilde{\theta}} \\
\dot{\infty}\end{array}$ & $\frac{n}{\vec{\Xi}}$ & $\begin{array}{l}\tilde{\mathrm{d}} \\
\hat{\mathrm{g}}\end{array}$ & $\begin{array}{l}n \\
\hat{\tilde{c}} \\
\vec{\exists}\end{array}$ & $\begin{array}{l}\infty \\
\stackrel{0}{0} \\
\stackrel{\Xi}{\Xi}\end{array}$ & $\frac{a}{a}$ \\
\hline \multirow{8}{*}{ 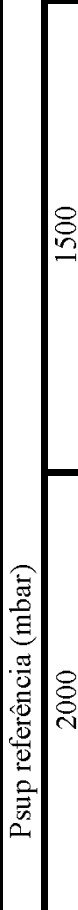 } & $\approx$ & $\begin{array}{l}\overline{\text { I }} \\
\text { gू }\end{array}$ & $\begin{array}{l}\vec{\infty} \\
\stackrel{\infty}{\vec{c}}\end{array}$ & $\begin{array}{l}\tilde{\infty} \\
\stackrel{\infty}{N}\end{array}$ & $\begin{array}{l}= \\
\text { 离 } \\
\infty\end{array}$ & $\begin{array}{l}\text { o. } \\
\text { ळi }\end{array}$ & $\begin{array}{l}\text { सే } \\
\text { ḋ }\end{array}$ & $\begin{array}{l}\infty \\
\text { त } \\
\text { N }\end{array}$ & $\begin{array}{l}\infty \\
\overrightarrow{\widehat{d}} \\
\underline{\infty}\end{array}$ \\
\hline & $\equiv$ & $\begin{array}{l}\infty \\
\stackrel{\infty}{q}\end{array}$ & $\begin{array}{l}\vec{b} \\
\text { in }\end{array}$ & $\hat{n}$ & $\begin{array}{l}\hat{\tilde{I}} \\
\mathrm{~g}\end{array}$ & $\underset{i}{\vec{N}}$ & $\stackrel{0}{\stackrel{0}{+}}$ & 离 & $\vec{\partial}$ \\
\hline & $\therefore$ & $\begin{array}{l}0 \\
\ddot{m}\end{array}$ & $\stackrel{m}{m}$ & $\vec{m}$ & $\overrightarrow{\vec{m}}$ & $\bar{m}$ & $\begin{array}{l}J_{j} \\
\text { (j) }\end{array}$ & $\vec{m}$ & $\frac{0}{m}$ \\
\hline & 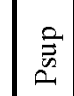 & $\begin{array}{l}0 \\
\infty \\
\infty \\
\cdots\end{array}$ & $\begin{array}{r}\vec{a} \\
\stackrel{\infty}{ \pm}\end{array}$ & $\begin{array}{l}\vec{a} \\
\text { aे } \\
\text { aे }\end{array}$ & $\begin{array}{l}\infty \\
\stackrel{\infty}{0} \\
\stackrel{\sim}{n}\end{array}$ & $\begin{array}{l}\infty \\
b^{\circ} \\
n \\
n\end{array}$ & $\begin{array}{l}\infty \\
\stackrel{\sim}{\sim} \\
\stackrel{\sim}{\sim}\end{array}$ & 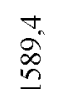 & $\overline{\mathrm{f}}$ \\
\hline & $\approx$ & $\begin{array}{l}0 \\
i n \\
0\end{array}$ & $\begin{array}{l}\overrightarrow{0} \\
0 \\
0\end{array}$ & 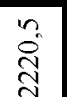 & $\begin{array}{l}\stackrel{\oplus}{0} \\
\text { त) }\end{array}$ & $\stackrel{n}{\circ}$ & $\begin{array}{l}\vec{v} \\
\stackrel{0}{0} \\
0\end{array}$ & $\begin{array}{l}\stackrel{\leftrightarrow}{0} \\
\stackrel{0}{\approx}\end{array}$ & $\begin{array}{l}\bar{\Xi} \\
\underline{\infty}\end{array}$ \\
\hline & 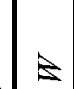 & $\begin{array}{c}m \\
\stackrel{m}{\infty}\end{array}$ & $\underset{\stackrel{+}{+}}{\stackrel{+}{+}}$ & $\bar{n}$ & $\begin{array}{l}\infty \\
\stackrel{a}{0}\end{array}$ & $\begin{array}{l}0 \\
\stackrel{i}{\infty}\end{array}$ & $\begin{array}{l}\ddot{0} \\
\ddot{b}\end{array}$ & $\begin{array}{l}\infty \\
\infty \\
\sim\end{array}$ & $\begin{array}{l}\overline{0} \\
\mathbb{G}\end{array}$ \\
\hline & $\therefore$ & $\hat{\mathrm{n}}$ & $\begin{array}{l}3 \\
0 \\
0\end{array}$ & $\stackrel{\infty}{\stackrel{\infty}{j}}$ & $\dot{m}$ & $\begin{array}{l}\infty \\
\stackrel{\infty}{\infty}\end{array}$ & $\begin{array}{l}\vec{j} \\
\vec{j}\end{array}$ & $\stackrel{n}{m}$ & $\stackrel{\infty}{m}$ \\
\hline & $\begin{array}{l}\overline{\bar{z}} \\
\hat{D}_{2}\end{array}$ & $\begin{array}{l}\infty \\
\stackrel{8}{8} \\
\stackrel{0}{0}\end{array}$ & $\dot{8}$ & $\begin{array}{l}\hat{\tilde{J}} \\
\text { dू }\end{array}$ & $\stackrel{\overrightarrow{-}}{\vec{\infty}}$ & $\frac{\tilde{n}}{\sigma}$ & \begin{tabular}{l}
$\infty$ \\
\multirow{1}{+}{} \\
$\infty$ \\
$\infty$
\end{tabular} & $\begin{array}{l}0 \\
\infty \\
\infty\end{array}$ & $\begin{array}{l}m \\
2 \\
a\end{array}$ \\
\hline \multirow{4}{*}{ 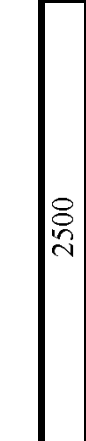 } & $\approx$ & $\overline{\mathrm{g}}$ & $\begin{array}{l}\text { to } \\
\text { o. }\end{array}$ & $\underset{\sim}{\sim}$ & $\begin{array}{l}n \\
\stackrel{m}{\infty}\end{array}$ & $\begin{array}{l}m \\
\text { हैं } \\
0\end{array}$ & $\begin{array}{l}\vec{m} \\
\overrightarrow{0}\end{array}$ & 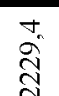 & $\begin{array}{l}0 \\
\frac{0}{\infty}\end{array}$ \\
\hline & $\hat{B}$ & $\begin{array}{l}0 \\
\ddot{\infty} \\
=\end{array}$ & 莺 & $\begin{array}{l}\stackrel{0}{0} \\
\text { do }\end{array}$ & $\stackrel{\overrightarrow{0}}{\vec{a}}$ & $\frac{n}{6}$ & $\begin{array}{l}\stackrel{.}{i} \\
\infty \\
ٍ \\
=\end{array}$ & $\begin{array}{l}0 \\
\infty \\
\cong \\
\cong\end{array}$ & $\stackrel{\stackrel{\sim}{\infty}}{\frac{1}{\infty}}$ \\
\hline & . & $\stackrel{2}{2}$ & O. & $\vec{m}$ & $\vec{\Leftrightarrow}$ & $\begin{array}{l}n \\
0 \\
0\end{array}$ & $\approx$ & $\vec{m}$ & $\stackrel{\Rightarrow}{m}$ \\
\hline & $\stackrel{\Xi}{2}$ & $\begin{array}{l}m \\
\stackrel{3}{3} \\
\stackrel{3}{n}\end{array}$ & $\begin{array}{l}\vec{n} \\
\stackrel{n}{\approx}\end{array}$ & 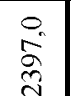 & $\begin{array}{l}1 \\
\stackrel{8}{8} \\
n \\
n\end{array}$ & $\begin{array}{l}m \\
\text { m } \\
0\end{array}$ & $\begin{array}{l}\vec{w} \\
\infty \\
\infty\end{array}$ & $\begin{array}{l}\infty \\
-\overrightarrow{3}\end{array}$ & $\stackrel{\infty}{\underline{\omega}}$ \\
\hline \multirow{4}{*}{8} & $\approx$ & 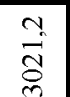 & $\begin{array}{l}\text { o } \\
\text { ij } \\
\vec{~}\end{array}$ & $\begin{array}{l}\stackrel{y}{3} \\
\underset{\pi}{\tilde{J}}\end{array}$ & $\begin{array}{l}\infty \\
\approx \\
\propto \\
\propto\end{array}$ & 苞 & 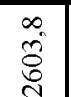 & 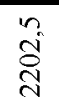 & $\begin{array}{l}0 \\
\mathscr{0} \\
\propto \\
\propto\end{array}$ \\
\hline & $\Leftrightarrow$ & $\begin{array}{l}\hat{\sigma} \\
\text { I }\end{array}$ & 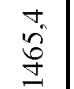 & $\begin{array}{l}\ddot{0} \\
\grave{\Xi}\end{array}$ & $\begin{array}{l}\stackrel{N}{0} \\
\stackrel{\varrho}{=}\end{array}$ & $\begin{array}{l}\ddot{0} \\
\stackrel{0}{0} \\
0\end{array}$ & 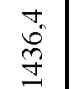 & $\begin{array}{l}n \\
\vdots \\
\Leftrightarrow \\
\Leftrightarrow\end{array}$ & $\begin{array}{l}0 \\
\infty \\
0 \\
0\end{array}$ \\
\hline & & $\begin{array}{l}\infty \\
\text { s. }\end{array}$ & $\stackrel{ }{m}$ & ț & $\begin{array}{l}\infty \\
\text { J }\end{array}$ & oे & $\ddot{n}$ & $\stackrel{m}{m}$ & $\vec{m}$ \\
\hline & 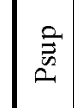 & $\overrightarrow{\stackrel{8}{8}}$ & $\frac{\vec{v}}{\frac{\partial}{m}}$ & $\frac{\vec{n}}{\stackrel{m}{m}}$ & $\begin{array}{l}\stackrel{a}{\circ} \\
\stackrel{्}{\circ}\end{array}$ & 穴 & $\begin{array}{l}\stackrel{a}{\check{~}} \\
\stackrel{\sim}{\Omega}\end{array}$ & $\stackrel{m}{\stackrel{\infty}{m}}$ & $\stackrel{\circ}{\stackrel{0}{0}}$ \\
\hline & & 至 & & $\mathrm{i}$ & $\frac{1}{b}$ & $\begin{array}{l}\underline{\bar{z}} \\
\text { 㤩 }\end{array}$ & 咅 & & $\begin{array}{l}\text { 言 } \\
8 \\
\stackrel{8}{8}\end{array}$ \\
\hline
\end{tabular}

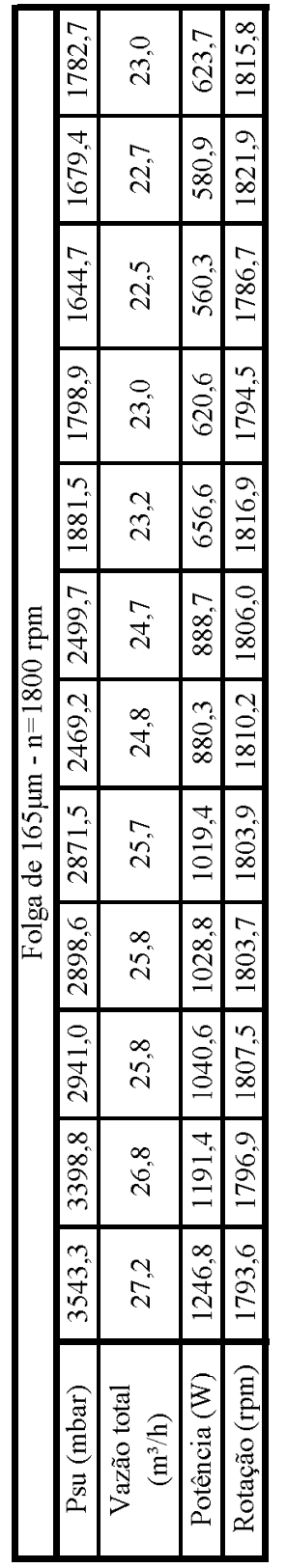

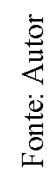




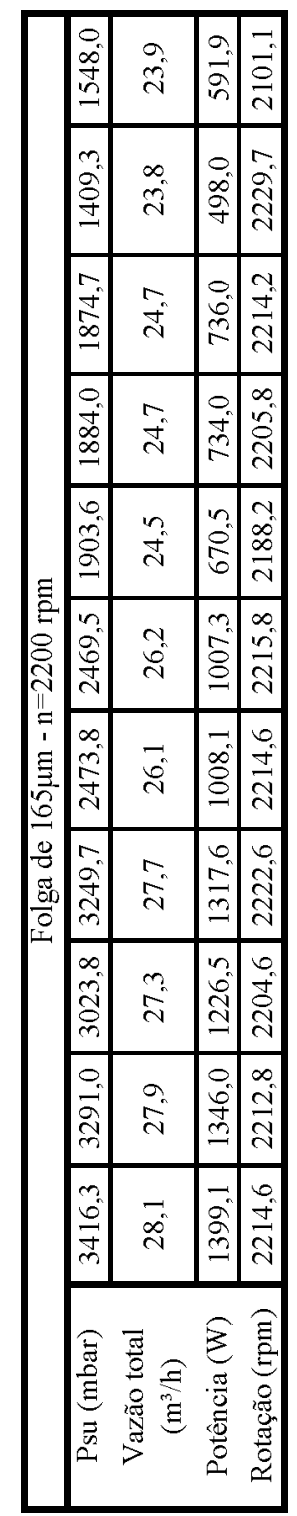

\begin{tabular}{|c|c|c|}
\hline $\overrightarrow{9}$ & 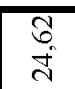 & 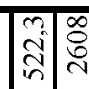 \\
\hline \begin{tabular}{l|} 
\\
0 \\
0 \\
0
\end{tabular} & \begin{tabular}{|l|}
$\frac{\infty}{a}$ \\
$\stackrel{j}{d}$
\end{tabular} & 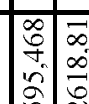 \\
\hline $\begin{array}{l}\infty \\
\infty \\
\infty \\
\infty\end{array}$ & 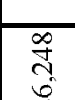 & 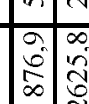 \\
\hline \begin{tabular}{|c|} 
\\
0 \\
$\vdots$ \\
$\vdots$ \\
$\vdots$ \\
\end{tabular} & 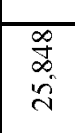 & 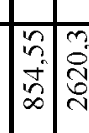 \\
\hline 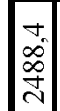 & ڤ્ळे & 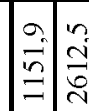 \\
\hline 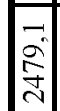 & $\bar{s}$ & 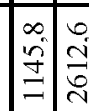 \\
\hline 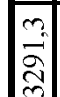 & $\vec{\alpha}$ & \\
\hline $\begin{array}{l}\vec{a} \\
m \\
m \\
m\end{array}$ & $\begin{array}{l}\infty \\
\underset{\sim}{\infty}\end{array}$ & 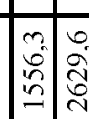 \\
\hline $\begin{array}{l}0 \\
0 \\
0 \\
0 \\
0 \\
0\end{array}$ & $\overbrace{\substack{\infty \\
\infty}}$ & 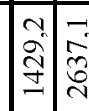 \\
\hline $\begin{array}{l}0 \\
\vdots \\
\vdots \\
\vdots \\
\end{array}$ & مे & 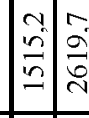 \\
\hline $\begin{array}{c}0 \\
0 \\
0 \\
0 \\
m\end{array}$ & $\stackrel{\vec{\infty}}{\stackrel{\sim}{\sim}}$ & 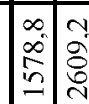 \\
\hline ज्ञ & $\stackrel{1}{\check{2}}$ & $\mid$\begin{tabular}{l|l}
0 \\
$\hat{i}$ \\
0 \\
0 \\
0
\end{tabular} \\
\hline 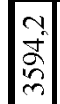 & $\begin{array}{l}0 \\
\stackrel{2}{\sim}\end{array}$ & 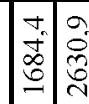 \\
\hline $\begin{array}{l}\text { | } \\
\text { के } \\
\text { mे }\end{array}$ & $\underset{\infty}{\stackrel{a}{c}}$ & $\mid \begin{array}{l}0 \\
\dot{0} \\
0 \\
2\end{array}$ \\
\hline $\begin{array}{l}\text { y } \\
\infty \\
\infty \\
\approx \\
\cdots\end{array}$ & $\stackrel{\circ}{\stackrel{i}{c}}$ & 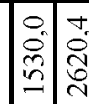 \\
\hline 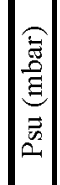 & 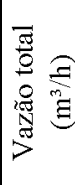 & 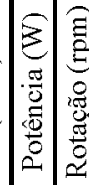 \\
\hline
\end{tabular}

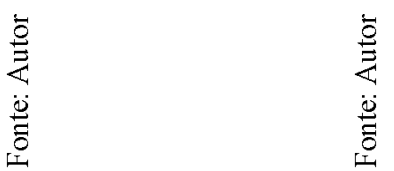


APÊNDICE B - Comparação de desempenho do expansor para uma rotação de 3000rpm, mas com folgas tangenciais distintas.
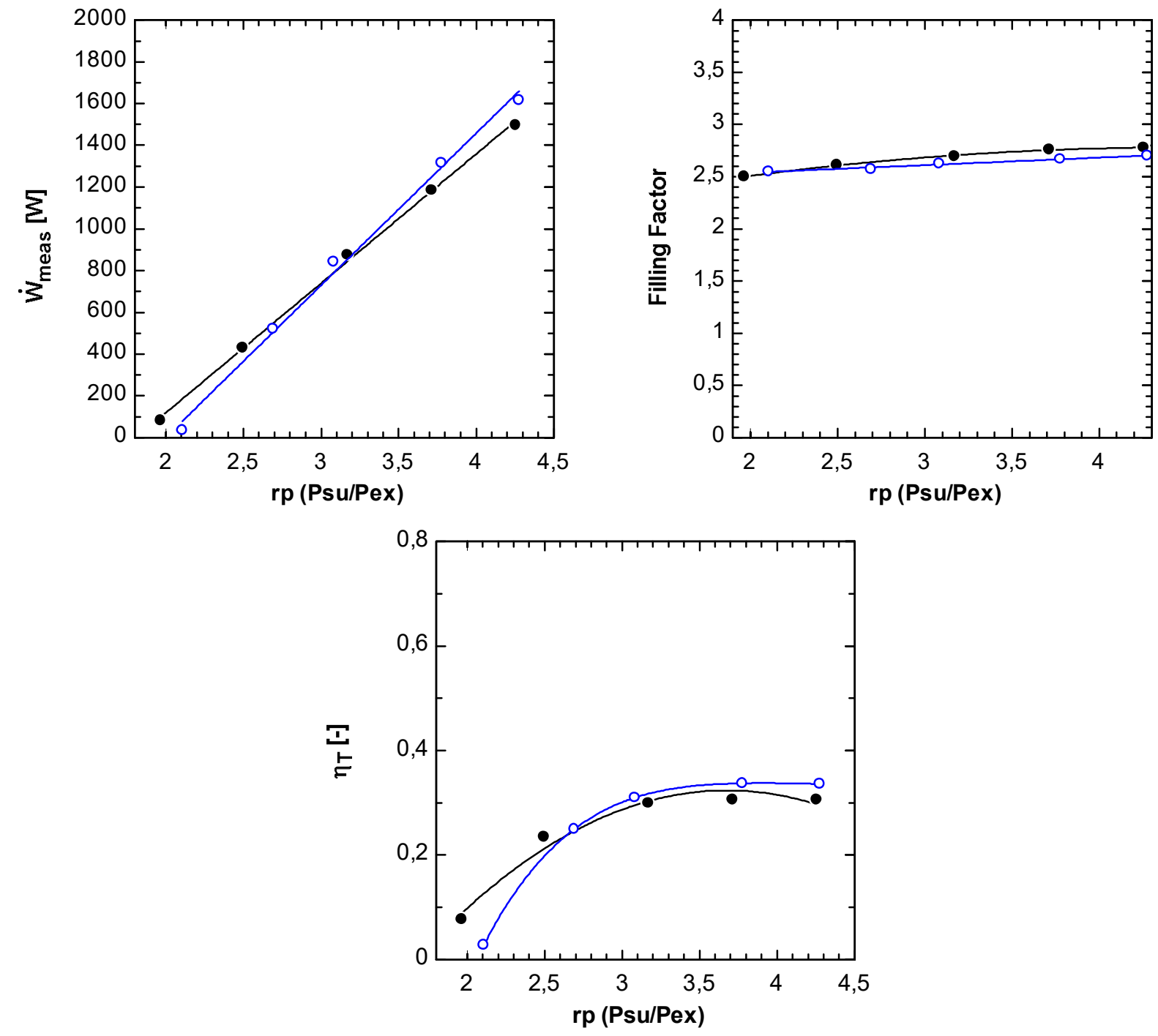

Fonte: Autor 
APÊNDICE C - Algoritmo utilizado no software EES para a comparação entre o modelo analítico e dados levantados experimentalmente

"Objetivo: Comparação entre experimental e modelo analitico"

"1 - Modelo Análitico"

"Pressão atmosférica"

P_atm=691,4*convert(mmHg;bar)

"K ar"

$\mathrm{cp}=\mathbf{c p}\left(\boldsymbol{A i r} ; \boldsymbol{T}=\mathrm{T} \_\right.$su $)$

$\mathrm{cv}=\mathbf{c v}\left(\right.$ Air $\left.; \boldsymbol{T}=\mathrm{T} \_\mathrm{su}\right)$

$\mathrm{K}=(\mathrm{cp} / \mathrm{cv})$

"Sucção"

P_su=P_atm+P_su_med

//P_su_med $=3[\mathrm{bar}]$

//T_ambiente $=18$

T_su=T_ambiente $+273[\mathrm{~K}]$

v_su=volume $\left(\right.$ Air $; \boldsymbol{T}=\mathrm{T} \_$su; $\boldsymbol{P}=\mathrm{P} \_$su $)$

$\mathrm{h} \_\mathrm{su}=$ enthalpy $\left(\boldsymbol{A i r} ; \boldsymbol{T}=\mathrm{T} \_\mathrm{su}\right)$

s_su $=\operatorname{entropy}\left(\boldsymbol{A i r} ; \boldsymbol{T}=\mathrm{T} \_\mathrm{su} ; \boldsymbol{P}=\mathrm{P} \_\right.$su $)$

rho_su $=\operatorname{density}\left(\boldsymbol{A i r} ; \boldsymbol{T}=\mathrm{T} \_\mathrm{su} ; \boldsymbol{P}=\mathrm{P} \_\right.$su $)$

V_ch_su $=75,12^{*}$ convert $\left(\mathrm{cm}^{\wedge} 3 ; \mathrm{m}^{\wedge} 3\right)$

"Relação volumétrica"

$\mathrm{rv}=1 / 3$

$\mathrm{rv}=\mathrm{v} \_\mathrm{su} / \mathrm{v} \_$int

$\mathrm{rv}=\left(\mathrm{P} \_ \text {int } / \mathrm{P} \_\mathrm{su}\right)^{\wedge}(1 / \mathrm{K})$

"Expansão isentrópica - Int"

$\mathrm{T} \_$int $=$temperature $\left(\boldsymbol{A i r} ; \boldsymbol{P}=\mathrm{P} \_\right.$int; $\boldsymbol{\nu}=\mathrm{v}_{-}$int $)$

$\mathrm{h}$ _int $=$ enthalpy $(\boldsymbol{A i r} ; \boldsymbol{T}=\mathrm{T}$ _int $)$

s_int $=$ entropy $\left(\boldsymbol{A}\right.$ ir $; \boldsymbol{T}=\mathrm{T} \_$int; $\boldsymbol{P}=\mathrm{P} \_$int $)$

"Expansão isocórica - Ex2"

v_ex $2=$ v_int

P_ex2=P_atm

T_ex2=temperature $\left(\right.$ Air $; \boldsymbol{P}=\mathrm{P} \_$ex $2 ; \boldsymbol{v}=$ v_ex 2$)$

h_ex $2=$ enthalpy $\left(\boldsymbol{A i r} ; \boldsymbol{T}=\mathrm{T} \_\mathrm{ex} 2\right)$ 
s_ex $2=\operatorname{entropy}\left(\boldsymbol{A i r} ; \boldsymbol{T}=\mathrm{T} \_\right.$ex $2 ; \boldsymbol{P}=\mathrm{P} \_$ex 2$)$

"Expansão para atm"

P_ex=P_atm

h_ex=h_ex1

T_ex $=$ temperature $\left(\boldsymbol{A i r} ; \boldsymbol{h}=\mathrm{h} \_\mathrm{ex}\right)$

S_ex $=\operatorname{entropy}\left(\boldsymbol{A i r} ; \boldsymbol{T}=\mathrm{T} \_\mathrm{ex} ; \boldsymbol{P}=\mathrm{P} \_\mathrm{ex}\right)$

v_ex $=\operatorname{volume}\left(\boldsymbol{A i r} ; \boldsymbol{T}=\mathrm{T} \_\mathrm{ex} ; \boldsymbol{P}=\mathrm{P} \_\mathrm{ex}\right)$

s_ex_iso $=$ s_su

$\mathrm{h} \_$ex_iso $=$enthalpy $\left(\boldsymbol{A i r} ; \boldsymbol{P}=\mathrm{P} \_\right.$ex; $\boldsymbol{s}=\mathrm{s} \_$ex $\_$iso $)$

"Mistura adiabática para Ex1"

m_dot_in*h_ex $2+\mathrm{m} \_$dot_leak $* \mathrm{~h} \_\mathrm{su}=\mathrm{m}$ _dot_su*h_ex 1

T_ex $1=$ temperature $\left(\boldsymbol{A i r} ; \boldsymbol{h}=\mathrm{h} \_\right.$ex 1$)$

"Vazões"

"Sucção medida"

//V_dot_su=36,79 $\left[\mathrm{m}^{\wedge} 3 / \mathrm{h}\right]$

$\mathrm{m} \_$dot_su $=\mathrm{V} \_$dot_su* convert $\left(\mathrm{m}^{\wedge} 3 / \mathrm{h} ; \mathrm{m}^{\wedge} 3 / \mathrm{s}\right) *$ rho_su

"In"

$/ / \mathrm{n}=3000[\mathrm{rpm}]$

$\mathrm{n} \_\mathrm{hz}=\mathrm{n} / 60$

m_dot_in $=\left(\mathrm{n} \_\mathrm{hz} * \mathrm{~V} \_\mathrm{ch} \_\mathrm{su}\right) / \mathrm{v} \_\mathrm{su}$

"Leak"

//Folga_eixos $=0,468$

A_leak $=2 *(3+40 *$ Folga_eixos $) * \operatorname{convert}\left(\mathrm{mm}^{\wedge} 2 ; \mathrm{m}^{\wedge} 2\right)$

$\mathrm{x}=2 /(\mathrm{K}+1)$

$\mathrm{y}=\mathrm{K} /(\mathrm{K}-1)$

$\mathrm{z}=\mathrm{x}^{\wedge} \mathrm{y}$

$\mathrm{P} \_$crit $=\mathrm{P} \_$su* $\mathrm{z}$

"P_crit>P_ex, portanto há escoamento sônico no bocal"

$\mathrm{P} \_$thr $=\mathrm{P}_{-}$crit

s_thr=s_su

h_thr $=$ enthalpy $\left(\boldsymbol{A i r} ; \boldsymbol{s}=\mathrm{S} \_\right.$thr $; \boldsymbol{P}=\mathrm{P} \_$thr $)$

v_thr=volume $\left(\right.$ Air $; \boldsymbol{P}=\mathrm{P} \_$thr; $\boldsymbol{s}=\mathrm{S}_{-}$thr $)$

c_thr=sqrt $\left(2 *\left(h \_s u-h \_t h r\right)\right)$

m_dot_leak $=$ A_leak $*$ c thr $/ \mathrm{v}$ thr

$\mathrm{m} \_$dot_suteorica $=\mathrm{m} \_$dot_in $+\mathrm{m} \_$dot_leak 
"Sucção teórica"

F_f_analitico $=\left(m \_d o t \_s u t e o r i c a\right) / m \_d o t \_i n$

"Potências"

"W_dot_pred=m_dot_in* ((h_su-h_int $)+\mathrm{v}$ int* $(\mathrm{P}$ _int-P_ex $))$ "

W_dot_pred $1=\mathrm{m} \_$dot_in*(h_su-h_int $)$

W_dot_pred $2=\mathrm{m} \_$dot_in*v_int* ${ }^{*}$ convert $($ bar; $P a) *\left(P \_\right.$int-P_ex $)$

W_dot_pred=W_dot_pred1+W_dot_pred2

W_dot_analitico $=\mathrm{W} \_$dot_pred

"Eficiência isentrópica"

ETA_T_analitico=W_dot_analitico/(m_dot_suteorica*(h_su-h_ex_iso))

"2 - Ensaios"

//W_dot_experimental=1200 [W]

"Outras medidas: braço do freio Foucault"

$\mathrm{Tau}=\mathrm{W} \_$dot_experimental/(2*pi*(n/60[s]))

"Eficiência isentrópica"

ETA_T_experimental $=\mathrm{W} \_$dot_experimental $/ \mathrm{W}$ _dot_iso

$\mathrm{W} \_$dot_iso $=\mathrm{m} \_$dot_su*(h_su-h_ex_iso)

"Relação de pressão"

$\mathrm{rp}=\mathrm{P}_{-} \mathrm{su} / \mathrm{P}_{-} \mathrm{atm}$

"Favrat (1994): filling factor"

F_f_experimental $=\mathrm{m} \_$dot_su/(V_dot_sup $\left./ \mathrm{v} \_s u\right)$

"Swept volume/rev $\left(\mathrm{m}^{3}\right) "$

V_s $=75,12 *$ convert $\left(\mathrm{cm}^{\wedge} 3 ; \mathrm{m}^{\wedge} 3\right)$

"Swept volume $\left(\mathrm{m}^{3} / \mathrm{s}\right)$ "

V_dot_sup $=$ V_s*n_hz

"3 - Comparação entre modelo analitico e experimental - Desvios"

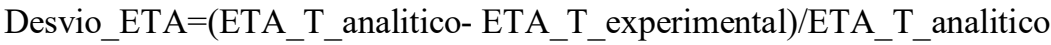

Desvio_F_f=(F_f_analitico-F_f_experimental $) /$ F_f_analitico

Desvio_W_dot=(W_dot_analitico-W_dot_experimental $) / W$ dot_analitico 
APÊNDICE D - Comparação modelo Analítico x Experimental - Folgas de $468 \mu \mathrm{m}$ e 489 $\mu \mathrm{m}$

D-1) Comparação modelo analítico x experimental para folgas de $468 \mu \mathrm{m} 3000 \mathrm{rpm}$
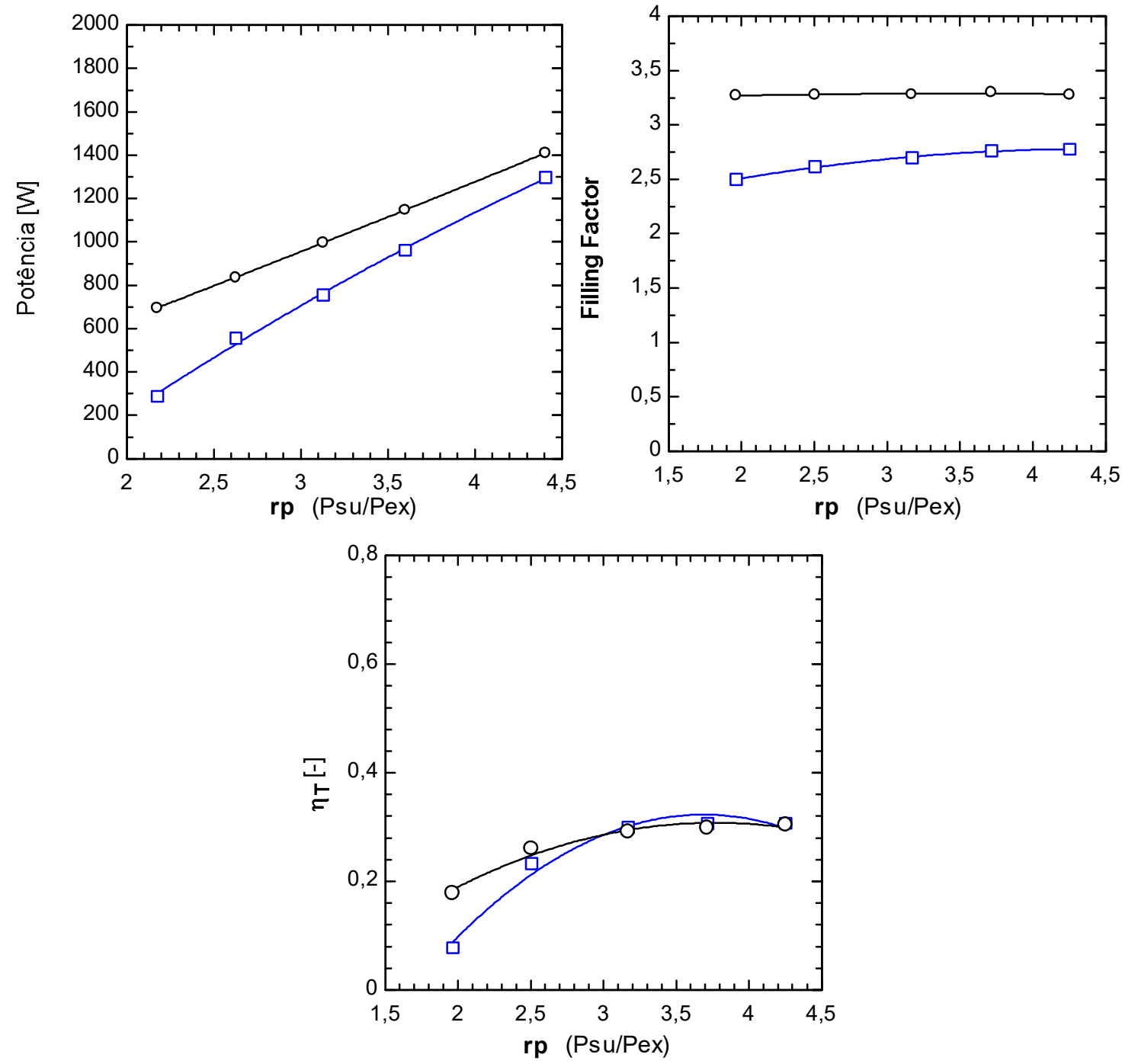

$\longrightarrow$ Analítico

$\longrightarrow$ —Experimental

Fonte: Autor 
D-2) Comparação modelo analítico x experimental para folgas de $468 \mu \mathrm{m} 2600 \mathrm{rpm}$
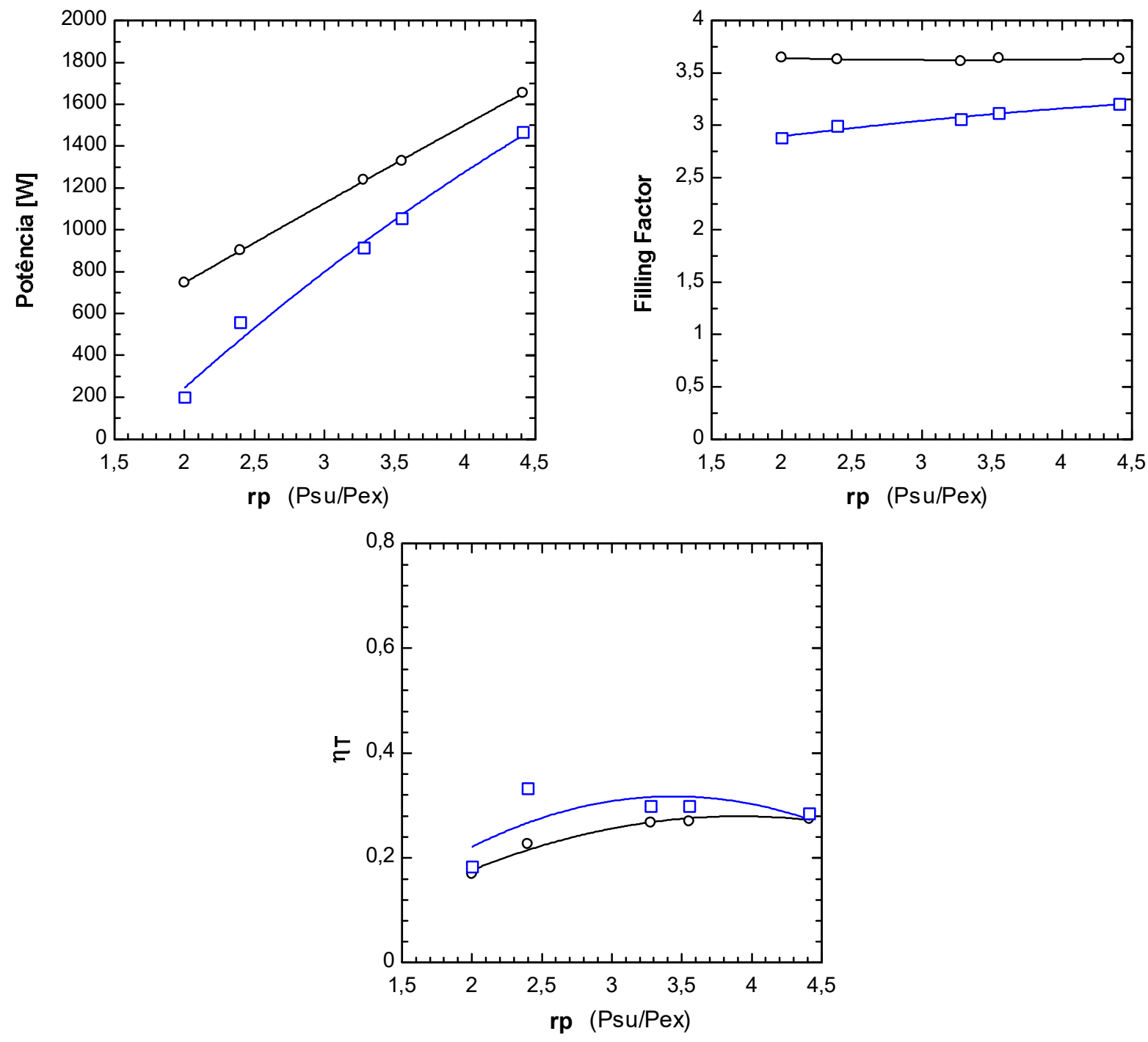

$\longrightarrow$ Analítico

$\longrightarrow$ - Experimental

Fonte: Autor 
D-3) Comparação modelo analítico x experimental para folgas de $468 \mu \mathrm{m} 2200 \mathrm{rpm}$
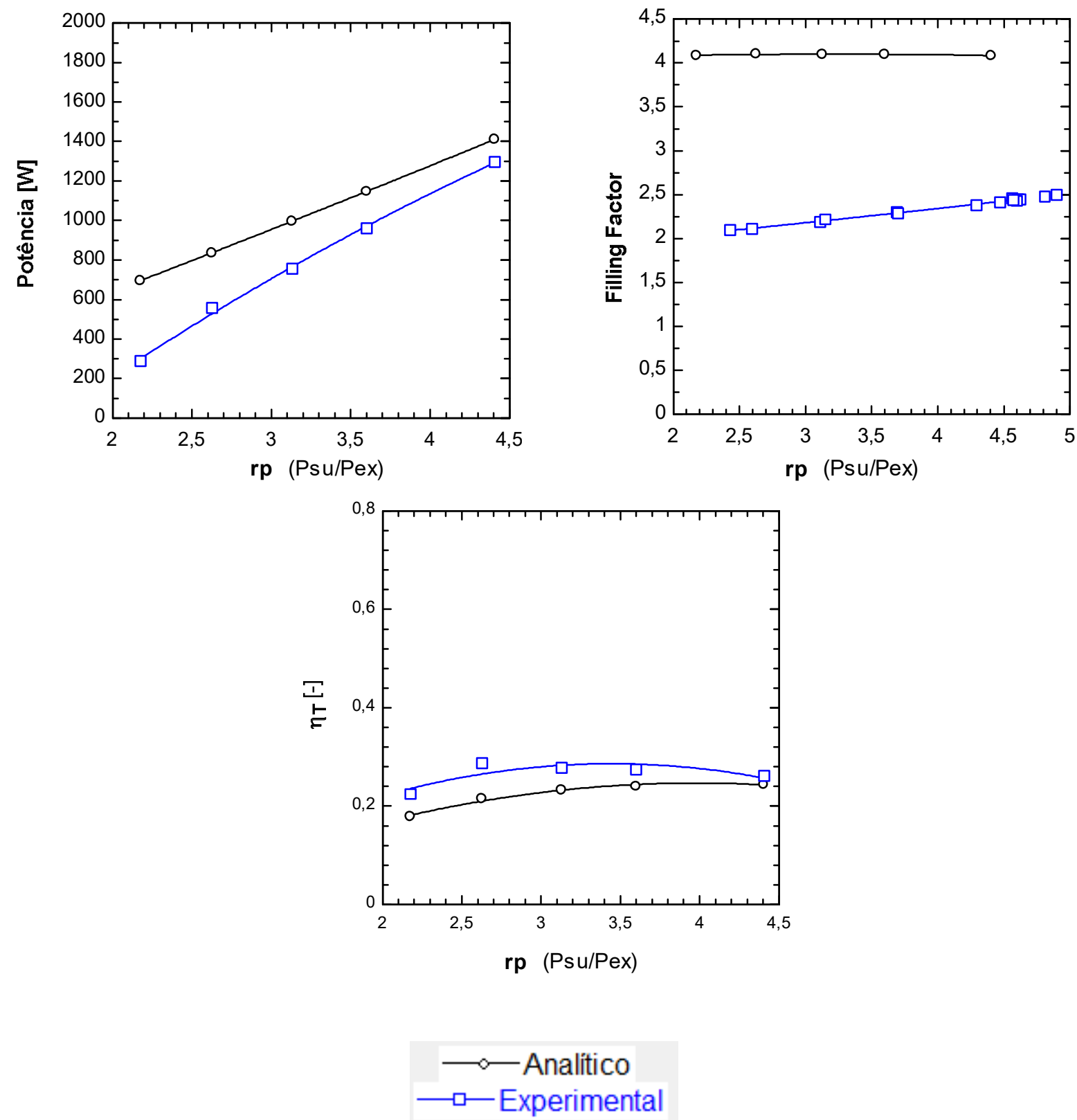

Fonte: Autor 
D-4) Comparação modelo analítico x experimental para folgas de $468 \mu \mathrm{m} 1800 \mathrm{rpm}$
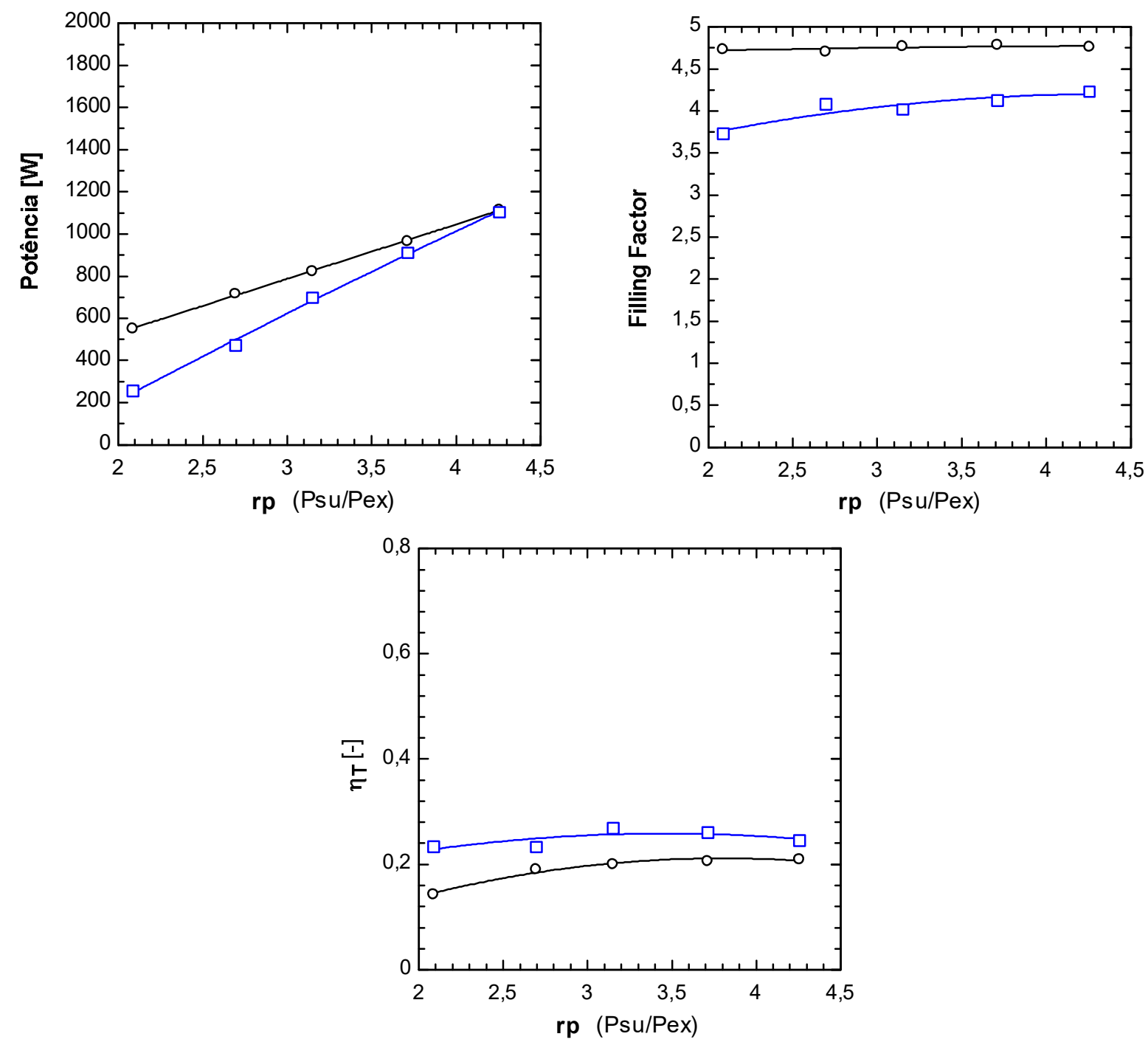

$\multimap$ Analítico

$\longrightarrow$ —-Experimental

Fonte: Autor 
D-5) Comparação modelo analítico x experimental para folgas de $489 \mu \mathrm{m} 3000 \mathrm{rpm}$
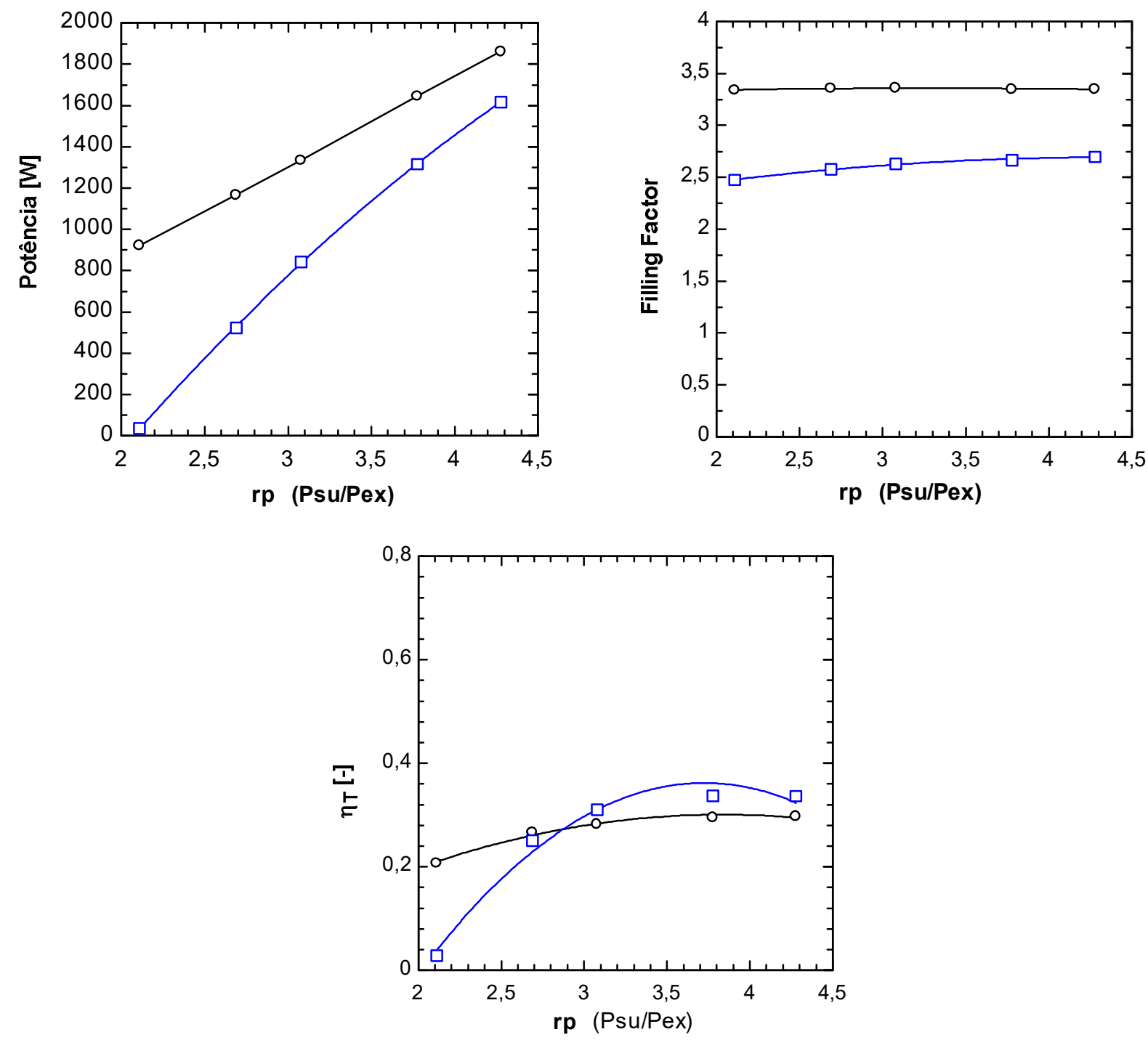

$\longrightarrow$ Analitico

$\longrightarrow$ —Experimental

Fonte: Autor 
D-6) Comparação modelo analítico x experimental para folgas de $489 \mu \mathrm{m} 2600 \mathrm{rpm}$
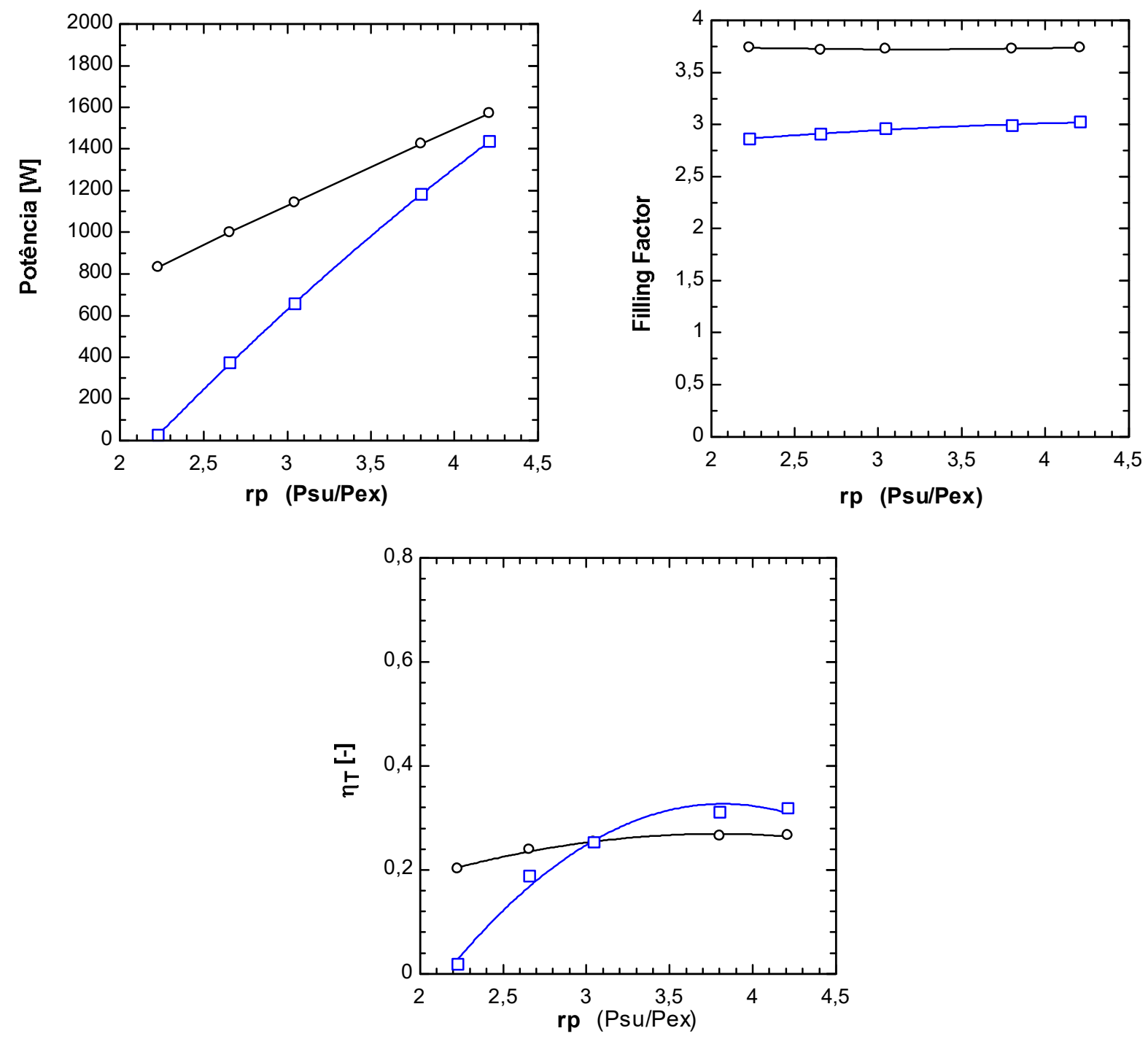

Fonte: Autor

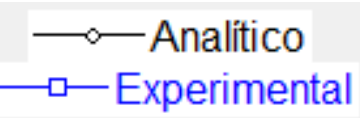


D-7) Comparação modelo analítico x experimental para folgas de $489 \mu \mathrm{m} 2200 \mathrm{rpm}$
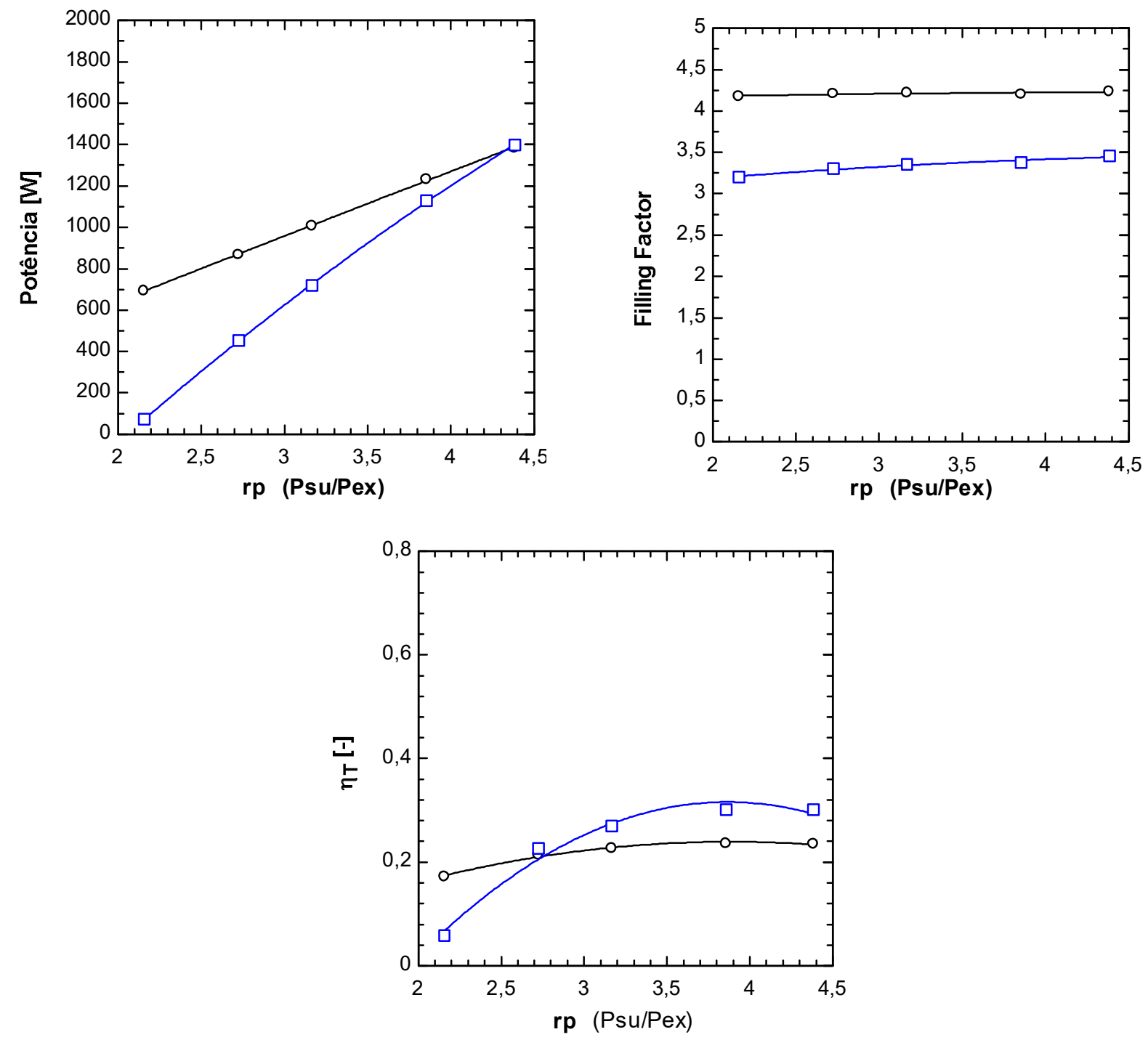

$\longrightarrow$ Analítico

$\longrightarrow$ —-Experimental

Fonte: Autor 
D-8) Comparação modelo analítico x experimental para folgas de $489 \mu \mathrm{m} 1800 \mathrm{rpm}$
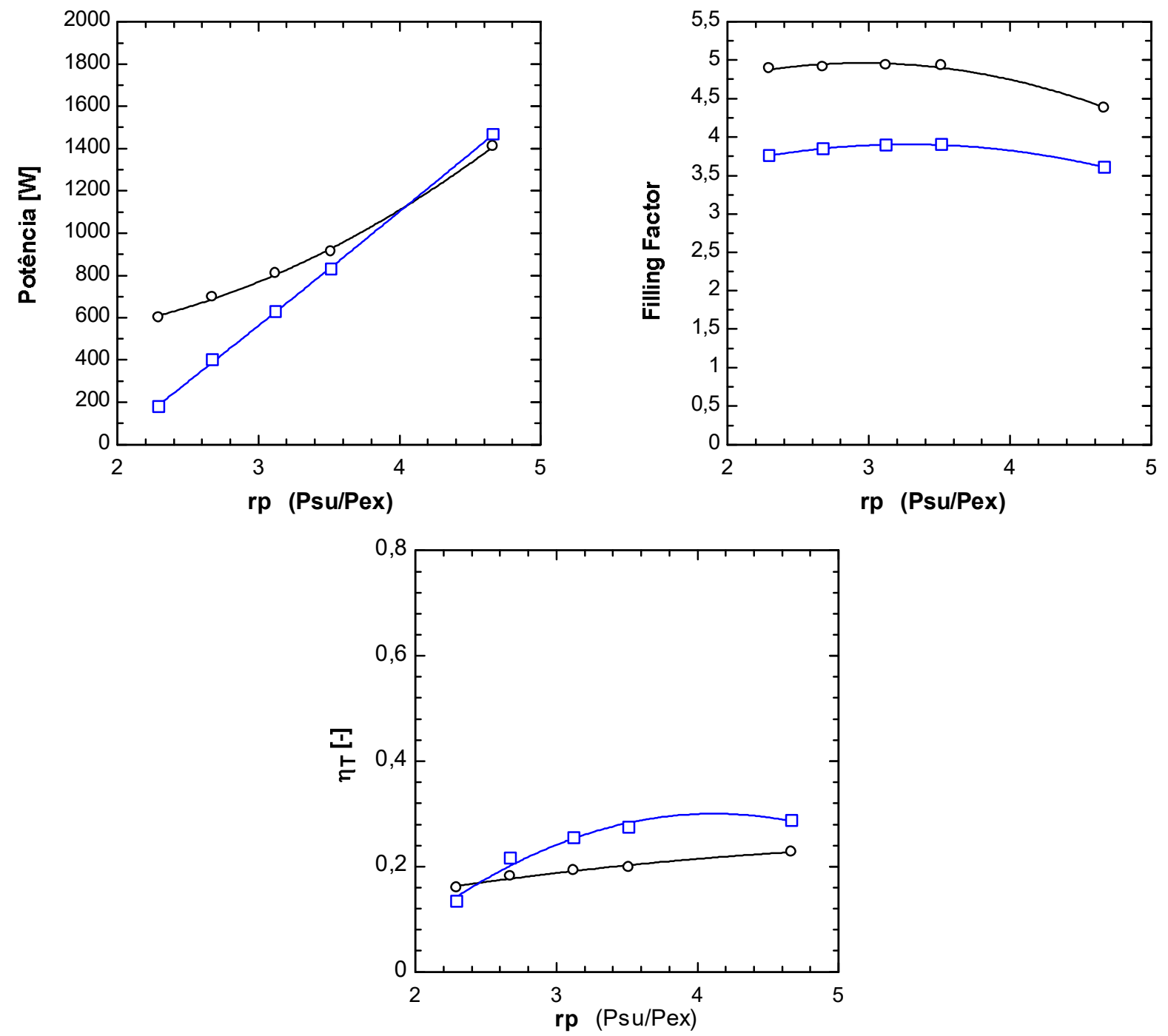

$\longrightarrow$ Analítico

$\longrightarrow$ - Experimental

Fonte: Autor 